\title{
Jóvenes y política: \\ una mirada desde la comunicación
}

Una epistemología de la reconstrucción 


\section{Jóvenes y política: \\ una mirada desde la comunicación}

Una epistemología de la reconstrucción

Autora: Andrea Varela

Directora : Florencia Saintout 


\section{Indice}

Introducción

Antecedentes de la investigación y perspectivas epistemológicas

Los medios de comunicación: aproximaciones teóricas a su definición

Relatos y discursos mediáticos sobre juventudes Antecedentes sociológicos y antropológicos en el estudio de las juventudes:

la Escuela de Chicago, el estructural funcionalismo y la Escuela de Birmingham

Posiciones epistemológico-políticas en torno a la relación entre jóvenes y política

La generación política

Presentación del problema: Juventudes contemporáneas; decisión y acción para la transformación social

Metodología 
Informe sobre los jóvenes en los medios de comunicación:

Representaciones mediáticas en los diarios nacionales

Jóvenes y participación política

Jóvenes y políticas públicas

De la desesperanza a la reconstrucción: al 70 \% de los jóvenes les interesa la política

Sondeo de opinión Octubre 2012

Sondeo de opinión Junio 2013

Bibliografía

Anexos

Informe cuantitativo: los jóvenes en los medios de comunicación

Sondeo de opinión. Cruces y tablas por nivel

socioeconómico

Fichas de lectura 


\section{Introducción}

El estatuto de las juventudes durante las largas décadas neoliberales ha sido abordada desde las ciencias sociales, pero también desde las agendas mediáticas y políticas, desde unas perspectivas del deterioro. Esto es, focalizando la mirada en los procesos de exclusión y fragmentación social y el modo en que estaban incidiendo particularmente entre los jóvenes. ${ }^{1}$

Las agendas del deterioro sólo podían reconocer jóvenes sin agencia, sin capacidad de intervención en el mundo, de ejercer poder (Saintout 2012). A medida que se avanzaba en un contexto regional de afirmación de derechos y de luchas populares, a través de gobiernos que fueron implementando una agenda política emancipadora, que además tuvo en el centro de su protagonismo a los jóvenes, las miradas académicas sobre Juventudes se fueron desplazando desde una epistemología de la devastación, hacia una epistemología de la esperanza.

El actual momento histórico latinoamericano, pone en escena la pregunta por dos cuestiones que serán abordadas en

\footnotetext{
${ }^{1}$ Hablaremos de los jóvenes a lo largo de trabajo para facilitar la lectura del mismo, aunque incluimos en ese nombramiento a las diferentes juventudes que habitan el concepto; a los y las jóvenes, a las identidades disidentes que en el mismo se enmarcan y sus procesos de participación política y tratamiento mediático.
} 
este trabajo de investigación: los modos de ejercicio de la ciudadanía juvenil en sociedades que, en algunos casos, parecen ampliar cada vez mas los límites y la diversidad de derechos que consagran; y la comunicación como campo para pensar los modos en que se configura la experiencia juvenil contemporánea, en dinámicas de autopercepción y heteroreconocimiento, atravesando las múltiples tensiones que caracterizan a la juventud como categoría.

Las políticas públicas implementadas desde los Estados latinoamericanos; constituyen nuevas experiencias de participación juvenil (política, ciudadana, social, estudiantil) que fueron tomando protagonismo en la escena pública. En este sentido, resulta clave, el análisis acerca de los procesos políticos y culturales juveniles.

Abordaremos en este trabajo de investigación reflexionando sobre los discursos de los medios masivos y al modo en $\mathrm{q}$ desde allí se narra el estatuto de lo juvenil. El neoliberalismo dejó huellas en su paso por las universidades, y luego de años de discutir la capilaridad del poder y la resistencia cultural, hasta el punto de que a veces esa indagación se consagró a describir los modos en que dicha impugnación se volvía estilo, finalmente la pregunta por la transformación real y efectiva pareció quedar de lado las agendas de la devastación y posicionarnos desde la epistemología de la esperanza, lo que no significa adoptar un optimismo absurdo, sino estar atentos a las posibilidades de un mundo más justo y a la capacidad de imaginar lo nuevo que tienen todas las culturas, aún en los momentos de mayor reproducción. Las nuevas leyes que regulan los medios de comunicación masivos (sancionadas 
en 2004 en Venezuela, en 2009 en Argentina, en 2013 en Ecuador, entre otras) y las múltiples iniciativas de la sociedad civil que promueven transformaciones en el mismo sentido en toda la región han supuesto un marco de intervención fértil para la producción de unos discursos otros, ya no adultocéntricos sino respetuosos de las experiencias juveniles y atendiendo a una perspectiva de derechos, y por otro lado ha iniciado la desconcentración mediática, medida imprescindible para la construcción de unas agendas descolonizadas y populares.

\section{Epistemología de la reconstrucción: los y las jóvenes en la política}

En esta investigación abordaremos el lazo entre juventud, política y medios de comunicación. Mencionamos anteriormente, como durante mucho tiempo, el relato de los medios de comunicación fue generando agendas del deterioro sobre la política y los jóvenes ${ }^{2}$ que participan de ella. La politica como podredumbre, la estigmatizatización, el marcaje, es un mecanismo repetitivo e intencionado que se reproduce incansablemente desde los medios hegemónicos de comunicación, de manera tal que se va construyendo esa relación de un modo ahistórico y descontextualizado. Veremos como esa relación, en el marco de una epistemología de la devastación (Saintout 2013) no corresponden solamente a la agenda mediática y sus discursos, sino al campo de la sociología sobre juventudes y las producciones académicas que han abordado esta relación. 
Haremos un recorrido por el abordaje mediático de los medios de comunicación hegemónicos y el periodismo en la Argentina de hoy y sus relatos sobre los jóvenes en la vida pública y política, en el contexto de discusión sobre la ampliación de derechos y el llamado voto Joven en la Argentina contemporánea.

Actualmente asistimos a una convocatoria y un llamado de la política que compromete a los jóvenes desde un Estado que se enmarca en una política de ampliación de derechos hacia los sectores juveniles, quienes ingresan a la política en un tiempo histórico iniciado en 2003, que los convoca a ser protagonistas. Veremos entonces, como es que esos jóvenes responden y que dicen respecto a esos relatos mediáticos.

Entendiendo que los medios de comunicación no crean la realidad ni la representan, modelan sentidos preexistentes, con mayor o menor influencia, al mismo tiempo que se disputan la capacidad legítima de nombrar verdaderamente al mundo, vemos que nombrar a los jóvenes de un modo estigmatizador suele ser una de las formas en que la violencia se manifiesta sobre ellos. Por ello, la intervención comienza con la deconstrucción de ese ejercicio de violencia, pero no puede detenerse allí: la vulneración de derechos nos demanda acciones que no se agoten en la denuncia y desde una epistemología de las esperanza es donde podemos empezar a desarrollar esas acciones.

Es así, que en este trabajo, nos abocamos a pensar el vinculo entre los jóvenes y la política en el mundo contemporáneo, haciendo especial hincapié en los procesos políticos que en nuestro país tienen como protagonistas a los jóvenes. Pensamos a los jóvenes como sujetos de derechos, enmarcados en 
un Estado que los interpela a la participación, q los invita a ocupar el espacio público y que los convoca como sujetos capaces, valiosos, no solo para el futuro, sino para el presente del país.

Para esto, se busca analizar como viven, sienten y valoran su militancia política estos jóvenes; y por otro lado, se realiza un relevamiento del sistema de medios hegemónicos, en el marco del monitoreo, en el que buscamos rastrear cuáles son los modos en que los discursos mediáticos abordan el vínculo entre los jóvenes y la política. Además se busca producir conocimiento a contrapelo de estos discursos que estigmatizan a los jóvenes, e insisten en nombrarlos como desinteresados y apáticos.

Desde una mirada adultocéntrica, se ha pensado sin ataduras a la juventud y la política; siendo los medios de comunicación hegemónicos quienes han dotado de categorías que los ubican como sujetos inadecuados, incapaces, sin nombre y mayormente asociado al miedo que representan para la sociedad en la que están insertos.

\section{Jóvenesenlosmedios:estigmaydesciudadanización}

Para reflexionar sobre la relación juventudes-comunicación-política es ineludible una mirada atenta a esos pilares sobre los que se sostiene el poder mediático. Florencia Saintout (2012) sostiene que son al menos tres cuestiones las que sostienen dicho poder: la primera de ellas tiene que ver con que los medios se basan en su alcance masivo y en un sistema comunicacional que "permite el infinito juego de espejos, 
de reproducción de las imágenes y relatos moldeados por los medios aun en la fragmentación de propuestas"; en segundo término, éstos son actores empresariales que en función de las políticas neoliberales adquieren una acumulación de capital inconmensurable que los privilegia; $\mathrm{y}$, además, su materia especifica es la producción de sentido.

Así, los medios de comunicación no crean la realidad ni la representan, modelan sentidos preexistentes, con mayor o menos influencia, al mismo tiempo que se disputan la capacidad legitima de nombrar al mundo. Nombrar a los jóvenes de un modo estigmatizador suele ser una de las formas en que la violencia se manifiesta sobre ellos. Especialmente si se trata de los jóvenes de sectores populares, sus modos de vestir, de hacer música, de escucharla, los territorios, sus prácticas, en fin, sus estilos son puestos en escenarios de violencia. Y estas operaciones también son habituales a la hora de narrarla relación entre los jóvenes y la política.

\section{El voto joven: el derecho votar a los 16 años}

Abordaremos las percepciones de los y las jóvenes platenses de 16 y 17 años de edad, que están en condiciones de votar y ejercer su ciudadanía política por primera vez.

Iremos desentrañando aquí la compleja relación entre los discursos mediáticos y los discursos de los propios jóvenes, pudiendo observar en algunos casos la reproducción de los discursos hegemónicos que circulan a través de los medios masivos y en otros la negociación con esos sentidos. Final- 
mente podemos dar cuenta en este trabajo como los jóvenes le dicen "sí" a la política y se sienten convocados por esta marca epocal, donde los proyectos colectivos vuelven a tener sentido para ellos y para la sociedad toda.

Asimismo trabajaremos como es que aparece dicha relación en la opinión pública y en los grandes medios masivos y corporativos (y también en algunas sociologías académicas) siendo presentada como deslegitimada y/o invisibilizada, donde los jóvenes aparecen nombrados una y otra vez como sujetos carentes y / o manipulados, pero siempre sin capacidad de agencia, creativa o de participación social y política. Son el resultado de una profunda maniobra de invisibilización -el no lugar de las juventudes en los medios hegemónicos-. O de visibilización interesada y maliciosa.

Se presentarán dos materiales que serán analizados en esta investigación: el primero de ellos es una encuesta ${ }^{3}$ realizada en la ciudad de La Plata, en el contexto de discusión de la sanción de la ley que habilita a votar a los jóvenes, cuyo resultado arroja que al $70 \%$ de los jóvenes, les interesa la política y apoyan diferentes medidas de ampliación de derechos del actual gobierno.

En segundo lugar, analizaremos también en esta tesis informes y seguimientos mediáticos ${ }^{4}$ sobre la cobertura mediática de la participación política juvenil, donde veremos que el $70 \%$ de las informaciones relevadas producidas sobre jóvenes aparecen en las secciones policiales, donde los jóvenes son

\footnotetext{
${ }^{3}$ La encuesta fue realizada en la ciudad de La Plata, por el Observatorio de Investigación en Opinión Pública de la FPyCS de la UNLP.

4 Informes producidos por Observatorio de Jóvenes, Comunicación y Medios de la FPyCS de la UNLP.
} 
"victimas" o "productores" de esas violencias, siendo muy escasa (13\%) la producción informativa que los referencia como actores que realizan algún tipo de practica institucionalizada como trabajar o participar políticamente.

Trabajaremos específicamente en el marco de aprobación de la Ley 26.774, también llamada Ley del Voto Jóven. ${ }^{5}$

${ }^{5}$ A partir de esta Ley N 26.774, aprobada en el año 2012, las personas de entre 16 y 18 años están habilitados (de manera optativa) para votar. 


\section{Juventudes contemporáneas: decisión y acción para la transformación social}

El camino único para describir e interpretar a las juventudes durante el neoliberalismo fue la denuncia del desencanto. Jóvenes a los que no le interesaba la política como vía de transformación del mundo y que a lo sumo podían marcar el descontento en el plano de la cultura( Auyero, 1993; Balardini, 2000; García Canclini, 2003). Esta dimensión estética de la política está especialmente presente en un campo de estudios como el nuestro, con fuerte influencia de los llamados cultural studies o estudios culturales de Birmingham. La idea de la resistencia a la cultura hegemónica desde las subcuturas (Hebdige 1974 2004, Beck, 1999 Hall y Jefferson, 2000; Feixa, 1998; Mafessoli, 1990) encontró a los jóvenes como sujetos provilegiadios de análisis e ilustración de la perspectiva en la América Latina neoliberal. Jóvenes que solo pueden tener movimientos tácticos (Michel de Certeau, 1997), casi clandestinos, en la cuadricula de un poder diseñado por Otro.

Por eso, en el cruce de siglos, y con la emergencia de gobiernos populares en toda la región que convocaron a los jóvenes a la política, se da una ruptura muy fuerte en los modos de verlos. Florencia Saintout en Los jóvenes en la Argentina (2013) 
trabaja especialmente la necesidad del cambio de punto de vista teórico sobre los jóvenes, porque los jóvenes mismos están mutando y no alcanza con verlos solo a partir del desencanto o de sus capacidad de resistencia. Escribe: "Hay algo que nadie pude dejar de ver: que la relación entre juventud y política está viva. Se podrá decir que no todos los jóvenes militan o que la militancia no significa lo mismo para todos. En fin, se puede dar vuelta sobre esta afirmación de mil maneras y seguramente cada una de ellas tiene algo interesante para pensar complejamente el tema. Pero lo que no se puede negar es la existencia de esa relación, que ha transformado a los jóvenes pero que también ha transformado a la política. Hoy la política está viva y muchos hijos o hermanos de una generación que dijo que se vayan todos, se vuelcan hacia ella" (Saintout, 2013, p. 115).

Por otro lado, Melina Vázquez para estos años piensa que "la consagración de la juventud como valor o capital político tiene menos que ver con la propia intervención de la juventud en el campo político que con la consagración de los adultos de la condición juvenil. En otras palabras, lejos de ser resultado de disputas generacionales por el ingreso y la participación en un mismo campo, es reivindicada por dirigentes adultos" (Vázquez, 2013:5). Para sostener esta afirmación estudia los discursos que proponen "dar lugar a la juventud" o hablan de un "trasvasamiento generacional", que suponen que en la juventud están los futuros cuadros, los hijos o los herederos de las generaciones adultas. Su conclusión es que el estatuto de juventud militante, política o dirigencial depende de la generación adulta que "forman", "dan espacio" o "pasan la posta" a los recién llegados. Pero ella misma revisa su propio recorrido, 
y reconoce que está sucediendo algo en otro sentido cuando la juventud construye su propio mito, refiriéndose al "Nestornauta" o "Eternéstor" (en referencia a la historieta El Eternauta de Héctor Oesterheld): "la consagración de la juventud pone en juego, también, la construcción de los adultos a través de símbolos por medio de los cuales la juventud se representa" (Vázquez, 2013:12).

Una cuestión que nos parece relevante para esta investigación y que trabaja Melina Velazquez es el cambio de percepción de los jóvenes con respecto al Estado y las políticas públicas. El Estado como causa pública y ellos formando parte de la gestión del mismo, como "gestión militante". Los jóvenes ya no piensan en el Estado como maquinaria demoledora que hay que destruir o como elefante inservible que hay que ignorar (ambas cuestiones ligadas a la experiencia de otras generaciones con la dictadura o con el trabajo fino llevado adelante por el neoliberalismo que tuvo como objetivo achicar y denostar al Estado). El Estado les es palpable y cotidiano, ya que han sido convocados a la gestión de políticas públicas. Y además han sido interpelados por ellas, como sujetos específicos. Dice Vázquez: "esto permite matizar las lecturas sostenidas desde posiciones acusatorias que explican la centralidad de la juventud en la agenda pública y política como mero efecto de su construcción o legitimación 'desde arriba', mostrando que el Estado construye y es construido como causa pública" (2013:17).

Estas mutaciones, trabaja Vázquez, implican también mutaciones en las posiciones militantes. Si desde la dirigencia adulta se reclama a los jóvenes que comprendan 
la oportunidad histórica, casi al modo de "aprovechar", o agradecer, o celebrar un tiempo para el cual nadie estaba preparado, también la militancia juvenil tiene reclamos. Como el de que se reconozca mejor el poder de sus militancias o que se confronte a lo que se llama la vieja política

Podríamos decir, leyendo a Vazquez y Vommaro, que luego del cruce de siglos el estatuto de lo juvenil en la política argentina no solo se transforma sino que adquiere un gran valor luego de décadas de estigmatización. Recordemos siempre que la política argentina está marcada por la desaparición y exterminio de una generación de jóvenes por razones políticas. Pero décadas después y con los gobiernos populares, ser jóven y hacer política es visto positivamente, "incluso puede llegar a desplazar a la experiencia o a la trayectoria como capital político. Es importante 'parecer' joven o 'aparecer' como joven, y no sólo 'ser' joven, puesto que los atributos juveniles aparecen como valores que facilitan la apertura de espacios políticos antes reservados a los adultos" (Vázquez y Vommaro, 2012:173). El cambio de valoración es de 180 grados para una parte de la sociedad.

Hacemos la salvedad de que no es toda la sociedad la que cambia de posición con respecto al valor de la ligazón entre juventud y política. Los medios hiperconcentrados de comunicación dan cuenta de la voz de los sectores más conservadores y retrógrados que van a seguir estigmatizando la participación política de los jóvenes. Así, clasifican a los jóvenes de "interesados en puestos", "manejados desde arriba", "soberbios" o "irracionales y peligrosos" (Saintout, 2013).

De manera sintética podemos decir que en pocas décadas se pasa de la proscripción a la relación de los jóvenes con la 
política en la dictadura (construida de hecho y dramáticamente) hacia la afirmación en la larga década neoliberal de que a los jóvenes no les interesa la política -o solo son capaces de micro resistencias en las arenas culturales-, a imaginar que es esa una relación potente y transformadora. El campo de estudio de la comunicación, inscripto en las ciencias sociales, ha ido dando cuenta de estos desplazamientos.

Para Melina Vazquez, hoy "la juventud se convierte en una causa militante que promueve identificaciones, reconocimiento y adhesión, a la vez que consagra la juventud como un valor por el que vale la pena luchar" (Vázquez, 2013:25).

juveniles aparecen como valores que facilitan la apertura de espacios políticos antes reservados a los adultos" (Vázquez y Vommaro, 2012:173). El cambio

Sentidos de lo público, la política y el Estado

Valorización de política como herramienta de transformación. Jóvenes militantes. Discursos mediáticos y respuestas. (Saintout)

Gramáticas de movilización en espacio público (Vommaro, Alvarado, Bonvillani)

Identidades colectivas. Organización y organicidad (Pérez y Natalucci)

Valorización de instituciones formales (dossier Obsevatorio voto joven)

Transformación desde el Estado: gestión militante (Sandra Russo)

Juventud como causa pública (Vazquez)

La política en las instituciones

La política en la escuela y la universidad (Nuñez, Kriger, 
Mayer, Manzano, Pechín)

Política, trabajo, sindicalismo (Abal Medina)

Justicia, seguridad y conflictividad penal (dossier Observatorio conflictividad penal, Guemureman, Oyhandy, Tonkonoff, Rodriguez Alzueta)

Políticas públicas (Laura Braiza, informes del Observatorio de PCI, RCE, AUH, Progresar, Sumar)

Memoria, historia (Jelin, Lorenz, Raggio, Bonaldi, Ruiz Silva, Carretero)

Identidades políticas: cruces entre edad, género, etnia y clase

Género, juventud y política (Elizalde, Jones, Palermo, Bonvillani)

Política y jóvenes de sectores populares (Corsiglia Mura, Esteche, Fernandez y Lopez)

Aboriginalidad y movimientos políticos (Kropff, Botero) 


\section{Jóvenes, comunicación y política: antecedentes de la investigación y perspectivas epistemológicas}

La irrupción de la juventud argentina como actor social en el espacio público podría situarse en la década de los sesenta y setenta. Emergen, en aquellos años, un conjunto de prácticas de participación y movilización grupales identificadas específicamente con la pertenencia al grupo etario. Podríamos decir que dicha representación se tornó hegemónica, en tanto el sentido de lo joven se articuló directamente a un compromiso con la política. Por supuesto, hablamos aquí de una concepción particular de la política, asociada a las identidades partidarias y a la lucha por la conquista del aparato estatal. La práctica política juvenil se definía, entonces, inmersa en las relaciones de poder del conjunto de la sociedad y su marco de acción alcanzaba el direccionamiento de los destinos de una nación. La referencia esta generación como "lugar originario" de la relación entre jóvenes y política no puede ser abordada sin contemplar sus riesgos, en tanto ha sido eje de comparaciones e idealizaciones, habilitando la construcción de un relato despolitizador sobre las juventudes subsiguientes.

Con lo anterior, pretendemos ilustrar que los sentidos construidos en torno a las características del vínculo entre jóvenes y política no han permanecido estables a lo largo de las décadas. Existen también claras divergencias en función de las plataformas enunciativas abordadas, especialmente entre el discurso mediático o del sentido común y la discursividad científica, entre las que se destacan los acercamientos realiza- 
dos por la sociología, la antropología y los estudios culturales. En América Latina es meritorio subrayar los trabajos de Rossana Reguillo, José Manuel Valenzuela Arce, en México; Mario Margulis, Marcelo Urresti, Sergio Balardini, en Argentina; Alonso Salazar y Jesús Martín Barbero en Colombia. Se trata de perspectivas de carácter constructivista y relacional, que se interrogan sobre las prácticas y percepciones de los jóvenes problematizando tanto lo simbólico como las condiciones materiales de existencia, es decir, la relación entre la dimensión subjetiva y la objetiva de la acción social, entre la agencia y la estructura. En el primer apartado de este estado de la cuestión, recuperaremos brevemente los aportes diferentes autores que nos permiten hacer un recorrido teórico sobre los medios de comunicación, así como aquellas perspectivas que han pensado a las categorías juveniles desde la sociología y/o la antropología que han resultado fundantes para el campo de estudios socioculturales donde ubicaremos a este trabajo de investigación.

En el segundo apartado se trabajaran diferentes perspectivas en torno a la categoría de juventud, específicamente, las conceptualizaciones que nos permiten pensar su relación con una generación política.

En el tercer apartado, diferenciaremos las posiciones epistemológicas para pensar la relación entre los jóvenes y la política, en función de su concepción sobre lo político. Sin recurrir a generalizaciones, en la década del noventa y principios del nuevo siglo, podemos distinguir tres grandes tradiciones académicas. La primera, enfatizó en las representaciones de los jóvenes en torno a lo político, los políticos y el Estado. Gran parte de los trabajos inscriptos aquí han distinguido un proceso de desafiliación y apatía hacia las hacia las instancias de participación formales, enunciando un contexto de crisis institucional desde una visión moderna 
de la política. La segunda, destacó la politicidad de una gran variedad de prácticas juveniles, no necesariamente relacionadas a los espacios políticos tradicionales, visualizando la dimensión política en el terreno de la cultura. La tercera, desde un enfoque de derechos y de construcción de ciudadanía, ha indagado en la participación de la juventud en la toma de decisiones en la vida cotidiana, su empoderamiento e iniciativa en la acción. La presente investigación se inscribe en una cuarta perspectiva, que ha vigorizado en el último decenio, que supone la compresión de los jóvenes como sujetos políticos inmersos en las relaciones de poder y de sentido del campo social, cuyas identidades políticas colectivas suponen la identificación de antagonismos y la irrupción en el espacio público a través de la enunciación de demandas y proyectos particulares.

A esta altura, resulta evidente que comprendemos que las diferencias entre las generaciones políticas no son excluyentemente juveniles, sino que se trata de marcas históricas comunes que transforman no sólo los marcos de interpretación y acción de los jóvenes en su contexto socio-político, sino su relación con las otras generaciones. En el tercer apartado, enunciaremos ciertas condensaciones de sentido en torno a las generaciones políticas de las juventudes argentinas. Luego de los movimientos políticos confrontativos de los sesenta ya mencionados, podemos situar una generación joven que se manifestó a través de la resistencia, ante la clausura de los canales institucionales de participación en la última dictadura cívico-militar (19761983). El tercer momento, coincidente con los estudios pioneros sobre juventud en la Argentina (Braslavsky, 1986) está dado por el retorno de la democracia, donde el ejercicio de la política se asocia a las vías institucionales tradicionales de participación y la actividad política juvenil se restringe al ejercicio de la ciudadanía. El cuarto período corresponde a la larga década neo- 
liberal y a un crecimiento exponencial de las investigaciones sobre jóvenes, que predominantemente versaron sobre unos jóvenes descreídos hacia la política y desinteresados hacia las formas tradicionales de organicidad y militancia (Auyero, 1993; Balardini, 2000; García Canclini, 2003; Martín-Barbero, 1998). Luego de la crisis del 2001 comienza la etapa en la que focalizaremos la presente investigación, caracterizada por una gradual legitimación de la política como herramienta de transformación, una vigorización de la movilización en el espacio público con identificaciones políticas juveniles y la revalorización de las prácticas y discursos institucionales y estatales (se destacan las investigaciones de Saintout, 2012; Nuñez, 2008; Kriger, 2010; Alvarado y Vommaro, 2010; entre otros).

Las generaciones de jóvenes contemporáneos configuran sus prácticas políticas en un escenario que se trastocado sustancialmente respecto al pasado reciente. En principio, se ha propuesto un discurso de abierta confrontación con las políticas neoliberales, aquellas que provocaron un crecimiento exponencial de las diferencias sociales y redujeron el aparato estatal frente al empoderamiento creciente de las corporaciones económicas trasnacionales y locales. Por otro lado, los procesos políticos encabezados por los gobiernos de Néstor Kirchner y Cristina Fernández, del 2003 a la actualidad, han sostenido una transformación anclada en la necesidad de recuperar la política y el Estado en el marco de un proyecto de inclusión y soberanía nacional, con el reconocimiento de la diversidad y la búsqueda de una unidad regional, reafirmando la lucha por la memoria, la verdad y la justicia. Por último, es menester señalar una interpelación a la juventud como actor protagónico para el cambio social y su empoderamiento para la acción e inserción en lugares de decisión política. Asimismo, abordaremos en el apartado 5 y 6 de este trabajo los discursos mediáticos. 


\section{Los medios de comunicación: aproximaciones teóricas a su definición}

La comunicación no es todo, pero debe ser hablada desde todas partes

En primer lugar diremos que los medios de comunicación no pueden ser concebidos solo como transmisores de información, sino que es necesario comprenderlos en su carácter de agentes sociales que disputan entre otros agentes, poder y legitimación dentro del espacio social. Los medios no son solo técnicas, neutrales, sino que adquieren sentido desde un espesor sociocultural e histórico. No reflejan la realidad, sino que la construyen, disputándose ese poder junto a otros actores.

Dice Hector Schmucler (1997: p 141) que hay dos perspectivas frecuentes para investigar sobre los medios de comunicación -a las cuales no va a adscribir- : la primera es la que se ofrece a los medios como legitimadores de la actual estructura social y la segunda mirada, se postula como "develadora" de la ideología de los mensajes pero prescinde de la circunstancia político social en la que ese mensaje se inscribe. En este sentido propone dos cuestiones:

En primer lugar, un mensaje adquiere significación en la experiencia socio-cultural de los receptores. Los mensajes solo se van a interpretar en el encuentro con el receptor. Por ende lo que hay que indagar es ¿desde que ideología, desde que relación con el mundo se ejerce esa recepción?

En segundo aspecto a destacar es aquel que tiene que ver con el momento de la decodificación, que es cuando surge esa significación, que puede tener diferentes aspectos: coincidiendo o entrando en contradicción ambas lógicas del emisor y del receptor. "El 'poder' de los medios puede ser nulo e incluso revertirse en la medida que el mensaje es 'recodificado' y sirve de confirmación del propio código de lectura”. 
En un texto clásico, publicado hacia 1973, "Codificar/decodificar", Stuart Hall (1980) criticando la linealidad del proceso comunicativo menciona que hay tres tipos de lecturas que ejercen los receptores al exponerse a los medios de comunicación: lectura preferencial, lectura negociada y en tercer lugar lectura oposicional. El autor al estudiar la función ideológica de los medios, caracteriza cuatro momentos en el proceso comunicacional: producción, circulación, distribución/consumo y distribución, que se van relacionando, que coexisten pero que son diferentes entre si. De este modo cada momento tiene formas y condiciones de existencia propias e interactúan. Aparecen claras aquí varias premisas: el proceso comunicativo se puede codificar de mas de una manera; el mensaje siempre contiene mas de una lectura y por último comprender el mensaje es una práctica compleja.

Hall, desde el Centro de Estudios Culturales de Birmingham, se caracteriza por anclar la problemática de la comunicación en: la recepción de los programas de televisión o radiofónicos, la vuelta a la investigación y la pregunta por los sujetos, la subjetividad y la intersubjetividad y la integración en la problemática de la dominación las nuevas modalidades de las relaciones de poder (género, raza, etnia).

Nada de lo que digan los medios, entonces puede ser dicho por fuera del espacio social en el que se insertan. Son actores, que junto a otros se disputan el sentido legitimo de nombramiento de mundo. Pero no lo hacen desde cualquier posición, sino desde un lugar privilegiado. Principalmente en nuestras sociedades mediatizadas donde las practicas sociales esta en mayor o menor medida atravesadas por los medios de comunicación. Como ya fue enunciado en este trabajo, Florencia Saintout (2013) enumera en poder de los medios en tres cuestiones: en primer lugar Su alcance masivo, que se sostiene en el gran público y la reproducción 
infinita de imágenes y relatos, donde fragmentación y homogeneización no necesariamente son opuestos. Luego sostiene que los medios son actores empresariales que en las ultimas décadas han acumulado capital tanto material como simbólico escandalosamente desigual en relación a otros actores. Lo han concentrado creando monopolios, oligopolios, atentando contra los derechos de la libertad de información y la libertad de comunicación de los pueblos. ${ }^{1}$ y por último, a través de los mecanismos de focalización, deshistorización y rehistorización van construyendo el sentido de la realidad, presentando la información muchas veces con la forma de los intereses que sostienen y bajo la lógica de la mercancía, atacando a la política y al Estado como asuntos sucios de los cuales hay que huir. "Clasifican la realidad de un modo que oprime, menos por lo que no se permite decir de ella que por lo que obliga a decir de ella "

Asi como nada que digan los medios de comunicación, se da por fuera del espacio social, hay una mirada rapiñadora que enseña desde los medios masivos y hegemónicos de comunicación, a trabajar desde la crueldad. Esa pedagogía de la cruedad, hace creer y pensar al público que está del lado de la lente, de lado de quien ejerce es acción rapiñadora (Segato 2014) Y esa pedagogía es la que opera sobre las juventudes en nuestras sociedades a través de sus dispositivos mediáticos. En este sentido, Rita Segato sostiene que el mercado global necesita de personas con un bajo umbral de sensibilidad ante el sufrimiento humano, especialmente en momentos donde el capital, el sistema neoliberal debe arraigarse con fuerza cada vez que es puesto en jaque ante las luchas populares que a lo largo y ancho de nuestro continente avanzan dando cuenta de

\footnotetext{
${ }^{1}$ Saintout describe aquí el proceso de concentración mediática que se va constituyendo, aún por fuera de la ley, comprometidos en ocasiones con crímenes de lesa humanidad. Op cit, p 50.
} 
sus grietas, des-cubriendo sus falacias. En este sentido, desde los medios de comunicación concentrados, hegemónicos -máximos aliados del capitalismo- se modela un cierto tipo de sensibilidad o bien, de insensibilidad que entrena a los sujetos pata la crueldad.

Esto es, una pedagogía de la crueldad se gestione desde estos medios atendiendo a la configuración de unas subjetividades entrenadas para la falta de empatía con el otro, con lo otro; para la falta de identificación con la posición del otro. Y esta crueldad, dice Segato, se ejerce fundamentalmente en el cuerpo de las mujeres, de los niños, de los jóvenes, en lo medida en que se narran a diario y de modo naturalmente espectacularizado las violencias, los abusos, los asesinatos y el acallamiento o la negación de la voz que recaen sobre estos sectores de la población.

\section{Relatos y discursos mediáticos sobre juventudes}

No podemos dejar de mencionar en este apartado, una clásica teoría sobre la estrecha relación medios de comunicación y la cultura de control, que opera fundamentalmente sobre las culturas juveniles, que desarrollan Hall y Jefferson en "Resistencia a través de rituales"(2010). Los autores describen como las noticias están basadas en la reproducción de las definiciones que provienen de lo que llaman Cultura de Control (la policía, los jueces). Plantean una serie de elementos que denominan espiral significante que contiene los siguientes elementos: a) la identificación de un acontecimiento, b) la identificación de una "minoría subversiva", c) vinculación de ese acontecimiento con otros problemas, también llamado convergencia d) utilización de la noción de "umbral", que una vez que se cruza, puede llevar a una 
escalada del problema que "amenaza" a la sociedad, e) y por último deviene el pedido de acciones firmes.

Los autores describen como desde 1968 en adelante, este se volvió el paradigma para tratar los temas amenazantes ( vinculados a jóvenes ) en los medios de comunicación.

Los múltiples relatos construidos sobre los jóvenes de hoy, construyen unos modos de concebir las juventudes, en una disputa por nombrar y definir el estatuto de lo juvenil en nuestras sociedades.

Florencia Saintout sostiene que el discurso de jóvenes desinteresados, peligrosos, apolíticos se reproduce sin discusión por los medios hegemónicos, bajo la consigna de que solo les interesa el presente. Las referencias a sus compromisos si se expresan, se manifiestan en torno a la individualidad y la falta de compromiso social. Cuando se establecen referencias en torno a acciones relacionadas con procesos políticos se los ubica desde una mirada que los clasifica de la siguiente manera: (Saintout, 2013):

- aquellos que no pueden, estableciendo un parangón con los jóvenes de los setenta (los del pasado) como idealistas y los de hoy como carentes;

- como aquellos que son interesados y calculadores, escondiendo intereses por sobre sus acciones sin hacerlos visibles y que, si los trasparentaran, también serian ilegítimos; - los inocentes, quienes se interesan por la política y que son presentados por los medios de manera positiva, despolitizándolos, militando por un bien común por fuera de la historia siendo, mayormente, las víctimas de determinadas situaciones sociales

- por último, los que integran movimientos políticos antisistema, referenciados como los irracionales. Provenientes, en su mayoría, de sectores excluidos o marginalizados y clasificados como peligrosos. 
Esta mirada, que sitúa a los jóvenes en ese lugar de la carencia, la incapacidad y los invisibiliza, tiene su relato en "el gran NO" que desde las miradas hegemónicas se realizan sobre la juventud. Mariana Chaves (2010) en un análisis que realiza sobre las representaciones y discusos vigentes, sostiene que "la juventud es negada (discurso jurídico) o negativizada (modelo represivo). Se le niega existencia como sujeto total (en transición, incompleto ) o se negativizan sus practicas (juventud problema, juventud gris, rebelde, delincuente )"

\section{Antecedentes sociológicos y antropológicos en el estudio de las juventudes: la Escuela de Chicago, el estructural funcionalismo y la Escuela de Birmingham}

\section{La Escuela de Chicago}

Nos detendremos en los aportes hechos desde esta corriente a los estudios sobre comunicación y juventudes. ${ }^{2}$ Dentro de sus exponentes quizás el más destacado sea Robert Park. Antes de ser sociólogo, este investigador trabajó muchos años como periodista. Esa experiencia quizás haya marcado su fuerte rechazo hacia las producciones sociológicas más estructuralistas o positivistas, así como su interés por fenómenos que hasta entonces no habían sido objeto de interés científico. A Park le interesa comprender las transformaciones que durante el primer cuarto del siglo XX aparecen en los barrios estadounidenses repletos de inmigrantes, con tradiciones y formas de vida que se mezclan en medio de la vulnerabilidad social. Con metodologías como la observación participante y las entrevistas cualitativas, Park y otros investigadores se lanzan a conocer las conductas

\footnotetext{
${ }^{2}$ Se retoma aquí la descripción que realiza Carles Feixa en “De jóvenes, bandas y tribus .. Feixa Carles (2006) Editorial Ariel, Barcelona.
} 
específicas de los actores que comparten los barrios, y allí encuentran a los jóvenes que frecuentan las esquinas de las calles y comparten tiempo entre ellos. Estas "bandas" solían concitar el temor de las instituciones tradicionales por su aspecto extraño, conductas agresivas. Si bien esta clase de conductas ya habían sido explicadas, esos argumentos eran predominantemente moralizantes o psicomédicos: había algo en esas personas que las hacía desviadas. Pero Park propone otra manera de describir el fenómeno: él dice que lo que hay es una sociedad fragmentada, con instituciones desgastadas; en resumen, en un ambiente de libertad y soledad, las conductas por fuera de las normas encontraban un ámbito favorable a su reproducción, mediante un fenómeno de "contagio social", que habilitaba la aparición de "regiones morales" en las cuales los valores y las pautas de comportamiento eran sensiblemente diferentes a los del resto de la sociedad. Es decir, lo que aparecía en esa explicación era la tesis de la anomia, de la falta de controles informales producto de determinados procesos sociales.

"La banda es un grupo intersticial que en origen se ha formado espontáneamente y después se ha integrado a través del conflicto", afirma un estudio de 1926 de Frederick Thrasher, también de la Escuela de Chicago. Es decir, son grupos de jóvenes que se conforman del espacio entre zonas (urbanas y sociales) sin controles firmes, y en los que surgen lo que hoy denominaríamos elementos identitarios.

Pero es con "La sociedad de la esquina" que llega el trabajo definitivo sobre juventudes y delito por parte de esta corriente. De 1943, este trabajo de William Foote Whyte tiene también elementos de ruptura dentro de la Escuela: los estudios ya no se delimitan por zona geográfica, sino por organizaciones. También es cierto que en el transcurso de esos veinticinco años, "las bandas" cambian, crecen en número de integrantes y complejidad. Con sus diferencias históricas y de perspectivas, 
lo que estos diferentes autores de espíritu reformista aportarán será clave: en su cuestionamiento a la explicación de conductas delictivas mediante argumentos macroestructurales, en la búsqueda de los significados que tienen para los actores esos comportamientos, hicieron aportes sustanciales para empezar a estudiar las culturas juveniles.

\section{El estructural funcionalismo}

En la Norteamérica de posguerra, comienza a desarrollarse un tipo de estudios que van a describir a las culturas juveniles que estaban emergiendo en el espacio público. Comienzan a surgir "productos" para consumo de los jóvenes -música, vestimenta, cine - al mismo tiempo que se alarga su paso por las instituciones educativas. Describen desde esta corriente el surgimiento de patrones culturales exclusivos para los jóvenes estadounidenses, diferentes a los de los adultos. La institución escolar y el tiempo de ocio profundizaban la brecha generacional entre jóvenes y adultos.

La escuela se convierte en el centro de vida de los jóvenes, una ciudad dentro de otra ciudad van a decir desde esta corriente . "La high school se había convertido en el centro de la vida de los muchachos: la escuela no sólo ofrecía una cultura académica sino también un espacio de sociabilidad" (Feixa , 2006) donde los deportes, las fiestas, los bailes, también tenían lugar y eran exclusivos de las jóvenes generaciones .

Talcott Parsons, quien fue el exponente mas destacado de esta corriente, en los años cincuenta y sesenta, centraba su mirada en la juventud de clase media, que concurría a escuela secundarias, los llamados college boys. Indagaba en la constitución de una identidad que se construía en la escuela $y$ donde la edad funcionaba como un clivaje mas determinante que la clase. 


\section{La Escuela de Birmingham}

Esta corriente nace a fines de la década del cincuenta en Birmingham, Inglaterra. Los estudios culturales son una corriente que, como la Escuela de Chicago, no se dedica exclusivamente al estudio de juventudes, pero sí es uno de sus temas recurrentes. Lo primero que podemos decir para diferenciarla de otras experiencias, es que aquí los autores vienen de una clara tradición marxista. Pero con reservas: son fuertemente críticos con el determinismo económico de los pensadores más ortodoxos dentro de esa línea, e intentan dar autonomía a lo cultural.

En la Gran Bretaña de posguerra, y ante el progresivo declive del Estado de Bienestar, la aparición de grupos de jóvenes que se diferencian fuertemente de las generaciones previas llama la atención de estos investigadores: los punks, los mods, los teddies y muchos otras grupalidades son tomadas como objeto de estudios en "Resistencia a través de rituales" (Hall y Jeffesron, 2010) Explican Stuart Hall y Tony Jefferson, que "mucho de la teorización que se daba en el libro surgió como el resultado de un esfuerzo sostenido por pensar y encontrar conexiones entre subculturas y clase sin reducir simplemente una a la otra". Tenemos en esta cita no el carácter marxista y a la vez interpretativo de esta corriente, sino uno de sus principales aportes conceptuales: la noción de subcultura. Los autores aclaran que no se trata de sujetos aislados: "una subcultura, a pesa de diferir en importantes modos -en sus 'asuntos centrales', sus formas y actividades peculiares- de la cultura de la cual deriva, también compartirá algunas cosas en común con esa cultura 'parental'”. Así y todo, muchas veces se criticó a este tipo de trabajos por exotizar a los sujetos que describían en sus investigaciones. Los investigadores también distinguen entre subculturas por su grado de definición, por la permeabilidad que exhiben respecto de la cultura parental: 
"algunas son simplemente filamentos vagamente definidos dentro de la cultura parental; otras desarrollan una identidad y estructura clara y coherente".

La lista de trabajos de la Escuela de Birmingham sobre culturas juveniles es realmente larga, y destaca la inventiva de los autores por producir investigaciones novedosas, por la riqueza de los mestizajes teóricos a que echaron mano ante la emergencia de fenómenos novedosos. Y también, nuevamente, encontramos muchos argumentos que nos permiten decir que estos trabajos elaboran una mirada comunicacional. Hay dos trabajos puntuales que vamos a citar aquí:

En primer lugar, el libro de Dick Hebdige "Subcultura. El significado del estilo". (Hebdige, 2004) Publicado en 1979, describe las subculturas que aparecen en el marco de la música popular que escuchan sectores obreros blancos, más precisamente el punk. Y un fuerte énfasis en la interpretación se encuentra en el modo en que esa diferencia cultural se hace comunicacable, inteligible hacia afuera tanto como para los integrantes del grupo. Dice nuestro autor que estas subculturas lo que hacen es resituar y recontextualizar las mercancías, subvertir sus usos convencionales y darles unos nuevos. Explícitamente, dice que el carácter divergente del estilo es "el término superordinario bajo el cual se agrupan todas las demás significaciones, el mensaje a través del cual hablan todos los demás mensajes". Justamente entre los jóvenes punks, que parecen tener en el desorden y la revoltura su modo de expresión, Hebdige se preocupa por reponer las condiciones de comprensión por las cuales las prácticas de las subculturas tienen un preciso sentido.

Paul Willis, por su parte, publica dos años antes una detallada etnografía sobre los jóvenes británicos en las escuelas, "Aprendiendo a trabajar". Willis retoma la idea de aparatos ideológicos del Estado, formulada por el marxista francés 
Loius Althusser pero no lo da por sentado: justamente se propone, y este es el subtítulo del libro, reconocer "Cómo los jóvenes de clase obrera consiguen trabajos de clase obrera". $\mathrm{Y}$ aquí aparece la mirada comunicacional: su constitución como sujetos pertenecientes a una clase particular está condicionada por la pertenencia a esa clase, pero se produce en el marco de intercambios cotidianos, por ejemplo, en la escuela. La mirada de Willis describe, de este modo, como es que expresando en dicha institución un estilo indisciplinado y una masculinidad belicosa, y al mismo tiempo, rehuyendo de los valores intelectuales y de la docilidad que las rutinas escolares exigen, estos jóvenes resisten al ímpetu socializador de la escuela y reivindican valores de la clase trabajadora.

\section{Posiciones epistemológico-políticas en torno a la relación entre jóvenes y política}

El principal desafío que nos convoca es conceptualizar la noción de juventud. Definir esta noción es, sin dudas, ineludible para avanzar en la problematización de la relación de los jóvenes y la política. Se trata de un significante por demás complejo, por lo que será necesario reconocer sus heterogeneidades y diversidades; será prioritario desentrañar un concepto que pareciera ser autoevidente en un primer acercamiento, restringiéndolo en general a cualidades biológicas. Específicamente, si la tarea que nos convoca es analizar sus prácticas y discursos sociales, será primordial comenzar por comprender de quiénes hablamos cuando hacemos referencia a los jóvenes, en tanto reconocerlos como actores, agentes, sujetos o identidades no posee las mismas connotaciones y corresponde a posiciones epistemológico-políticas diversas.

Dentro del campo de la comunicación/cultura, se ha hecho referencia a la juventud como una categoría construida social y culturalmente, como resultado de las capas de significaciones y 
las condiciones históricas de una sociedad, lo que permite pensar la existencia de diferentes tipos de jóvenes. La condición de juventud no se ofrece de igual forma al conjunto de los integrantes de la categoría estadística joven. En este sentido es que, Mario Margulis (1996) propone que "La juventud es más que una palabra”, reflexionando que ser joven es una condición que se articula social y culturalmente en función de la edad, la generación, el crédito vital, la clase social, la memoria incorporada, el marco institucional, el género y la etnia: la juventud es hablada y habla de la vida en sociedad.

En otras palabras, la juventud debe ser pensada en plural, como diferentes modos de asumir la condición de joven y por lo tanto, distintas formas de percibir y dar sentido al mundo. Estas diversas materialidades articuladas bajo la condición de juventud según la diferenciación social, las distintas clases y segmentos sociales, configuran diversas juventudes. La investigadora Rossana Reguillo (2000), sostiene al no compartir todos los jóvenes los modos de inserción en la estructura social, sus esquemas de representaciones configuran campos de acción diferenciales y desiguales.

Acordando con esta advertencia, el antropólogo mexicano José Manuel Valenzuela Arce (1997), señala que la juventud es un concepto vacío de contenido fuera de su contexto sociohistórico y cultural. En consecuencia, existe una amplia variedad de acotaciones y rangos temporales a partir de la cual se destaca la condición juvenil en diferentes países, dependiendo de su avance social, económico y cultural. El investigador enfatiza en el clivaje de clase para pensar la categoría juvenil. "El concepto de juventud se inscribe en las características fundamentales de la clase social de pertenencia. Esta afirmación puede parecer anacrónica para quienes se adscriben a algunas de las vertientes que han enterrado las condiciones estructurales como condicionantes centrales de conductas 
sociales. No obstante, la realidad de nuestros países muestra grandes diferencias en los procesos de envejecimiento a partir de la adscripción de clase" (Valenzuela Arce, 1997).

Desde la sociología de la cultura, Margulis y Urresti (1996), sostienen que es necesario dotar de "materialidad" e "historicidad" al uso de la categoría juventud: "La juventud es una condición que se articula social y culturalmente en función de la edad, con la generación a la que se pertenece, con la clase social de origen, con el género y con la ubicación en la familia. Pero también hay que tener en cuenta la malla de las instituciones en las que se pone en juego la vida social"

Citamos la tesis de grado de Josefina Bolis": "debemos tener en cuenta la acción performativa de los discursos que nombran y han inventado la juventud: el mercado con sus productos para jóvenes; el sistema jurídico con los derechos de la juventud, y el estatal-institucional que designó espacios de juventud en relación con una necesidad de postergación de su ingreso al sistema productivo, para reducir la población económicamente activa. Estos son discursos que produjeron la juventud, que crearon una categoría de identidad que se hizo carne en los sujetos que se sienten/ven/actúan como jóvenes, y en los otros no identificados como jóvenes, que también distinguen jóvenes y se ven a sí mismos como no-jóvenes. La performatividad del discurso es visible en el desplazamiento que se produce desde el "hacer-hacer" al "hacer-ser" (Leonor Arfuch, 2008) las prácticas de ciertos sujetos (sus consumos, sus derechos, su pasaje por instituciones especializadas) los hace ser jóvenes.

3 Tesis de Grado Jóvenes y soberanía: Hegemonía, discursos y trayectorias hacia la emancipación. Dirigida por Andrea Varela y Co dirigida por Rodrigo Aramendi (2014) 


\section{La generación política}

Si bien consideramos que no se puede pensar a la juventud de modo singular, algunos autores han propuesto la existencia de un dispositivo de unificación que actúa como escenario en el que los jóvenes se socializan y que, a su vez, imprime sobre ellos modalidades de percepción, códigos, lenguajes y formas de clasificar: la generación (Ortega y Gasset (1983); Mannheim (1993) ; Baumann; Urresti; Margulis 2003). Sin homogenizar a la juventud, la generación actuaría como plataforma conformada por hechos culturales, históricos y políticos, vividos en un mismo tiempo cronológico, pero experimentados desde la diversidad y multiplicidad de los modos de estar y abrirse al mundo.

El concepto de generación hace posible retomar ciertos rasgos etarios, no ya desde la biología, sino desde la historia. Dice Margulis: "La generación, alude a la época en que cada individuo se socializa, y con ello, a los cambios culturales acelerados que caracterizan nuestro tiempo. Cada generación puede ser considerada, hasta cierto punto, como parte de una cultura diferente, en la medida en que los más jóvenes incorporan en su socialización nuevos códigos y destrezas, lenguajes y formas de percibir, de apreciar, de clasificar y distinguir. Cada época tiene su episteme, y las variaciones epistémicas son percibidas y apropiadas, durante su proceso de socialización, por los nuevos miembros que va incorporando la sociedad". (Margulis, 2003)

De este modo, más que constituir una categoría estadística relacionada con la biología, la noción de generación remite a la edad pero procesada por la cultura y la historia. De este modo si se considerara toda una población, una alineación vertical la agruparía de acuerdo a las características socioeconómicas, en tanto que una alineación horizontal la clasificaría 
considerando el plano generacional (Margulis, Urresti: 2001). Dicho de otro modo, la generación persevera y acompaña en la vida, y considerada dentro de ella la juventud es sólo uno de sus estadios. Lo que hace la generación es remitir a la historia, y dar cuenta del momento social en que una cohorte se incorpora a la sociedad; es esto lo que define características comunes en el proceso de socialización y hace que sus miembros incorporen los códigos culturales que imperan en una época dada y junto con ellos factores y elementos políticos, sociales, tecnológicos, etc.

He aquí la importancia de considerar, en un estudio sobre jóvenes, la pertenencia generacional como vía de acceso a la memoria, la historia que la atraviesa y la forma de percibir que la caracterizan. Y por qué puede afirmarse que pertenecer a una generación, y no a otra, supone poseer códigos culturales diferentes que orientan las percepciones, los gustos, los valores y los modos de apreciar, todo lo cual desemboca en mundos simbólicos heterogéneos, con distintas estructuraciones de sentido.

Ahora bien, lo que se busca sostener con esta noción es que la idea de "delimitación generacional" si no se quiere emplear el término de pertenencia generacional- lo que permite es deconstruir la sociedad en un momento dado reconociendo la importancia de la diversidad, el contexto y la historia en los procesos de "reproducción social empírica" (Giddens, 1991). Es decir, si bien estos hacen intersección entre sí de distintas maneras lo hacen en un cierto contexto espacio-temporal, frente a una cierta generación y distribución de poder y a una cierta reflexividad institucional.

Sin embargo, la contemporaneidad cronológica no agota la problematización de la categoría de generación sino que debe poner en juego unos criterios de identificación común entre sujetos que comparten un problema. De este modo, el 
vínculo generacional se constituye como un efecto de subjetivación, ligado a una vivencia común en torno a una experiencia de ruptura (Lewkowicz, 2003) que posibilita la percepción de un "nosotros".

La indagación acerca de las prácticas y representaciones políticas de jóvenes permitiría problematizar el sentido de una totalidad que destaque los rasgos comunes de las unidades que la conforman. De esta manera, nos preguntamos acerca de las particularidades y especificidades de una posible generación política que no sólo comparta percepciones y prácticas sino que además se constituya como grupo -aunque fragmentario sobre la base de un rechazo y crítica al orden establecido, que implique la búsqueda del redireccionamiento del curso de la política como expectativa o misión (Braungart y Braungart, 1986).En este sentido, la categoría de la generación se presenta como un nudo problemático a desentrañar.

Perez Islas, leyendo a Bourdieu, sostiene que "las diferencias de generación son diferencias en el 'modo de generación' -en las formas de producción- de los individuos, diferencias que se limitan a grupos y campos concretos en cada momento (...) estos cambios son los que producen diferencias de generación, es decir, es cuando los nuevos miembros (los jóvenes) son generados de manera distinta" (Pérez Islas, 2000:30). Es así que Bourdieu advierte que hay que realizar el recorrido inverso: no es buscando dentro de "una juventud" que sobrevendrán los "nuevos códigos", sino "partir de una teorización sobre la estructura social y la producción de sujetos y, a partir de aquí, plantear los conceptos de edad y generaciones" (Pérez Islas, 2000:30). 


\section{METODOLOGÍA}

La presente investigación pretende aproximarse a los modos en los que las juventudes son nombradas, representadas, en los medios gráficos de comunicación a partir de un diseño que combina perspectivas cuantitativas y cualitativas para el tratamiento de los datos.

Dado nuestro objetivo de estudio, la información relevada corresponde a cuatro diarios de interés general y de alcance nacional, en sus versiones digitales: CLARÍN, DIARIO POPULAR, LA NACIÓN y PÁGINA/12, en el período comprendido entre julio de 2012 y junio de 2013.

Se trabajó con una muestra intencional, basada, principal mente, en los niveles de venta y de circulación de los diarios, en tanto se verifica cierta correspondencia relativa a la concentración de lectores entre la prensa gráfica y la digital. Asimismo, se procuró alcanzar diversidad a partir de considerar los diferentes acentos ideológicos de los medios seleccionados.

El trabajo se organizó en dos fases: en la primera se realizó el monitoreo de medios y el tratamiento de corte cuantitativo; en la segunda, se efectuó el abordaje de las noticias de corte cualitativo. 
Asimismo esta investigación, presenta el análisis de una encuesta realizada en la ciudad de La Plata ${ }^{1}$, en el marco de la aprobación de la llamada Ley de voto joven. (Ley de Ciudadanía Argentina )

Ficha técnica de las encuestas utilizadas en la investigación: Encuesta 1:

Instrumento de recolección: cuestionario estructurado, aplicado a jóvenes de 16 años o más en condiciones de votar; en el partido de La Plata. El muestreo utilizado fue probabilístico, por conglomerados polietápicos, son selección de la unidad final según cuotas de edad y sexo según censo 2010. Tamaño de la muestra : 300 casos, error de muestra global ; +/-3,1, nivel de confianza: $95 \%$, fecha de relevamiento: 13 y 14 de octubre de 2012.

\section{Encuesta 2:}

Intrumento de recolección: cuestionario estructurado, aplicado a jóvenes de 16 años o mas en condiciones de votar, en el partido de La Plata. El muestreo fue probabilístico, polietápico, con selección de la unidad final según cuotas de edad y sexo. Tamaño de la muestra : 300 casos, error de muestra global ; $+/-3,1$, nivel de confianza: $95 \%$, fecha de relevamiento: 8 y 9 de junio de 2013 .

\footnotetext{
${ }^{1}$ La encuesta fue realizada por el Observatorio de Opinión Pública y Comunicación de la Facultad de Periodismo y Comunicación Social.
} 


\section{La triangulación en el enfoque metodológico}

Luego de una primera aproximación al seguimiento y al monitoreo de medios a través de la matriz de datos del Observatorio de Jóvenes, Comunicación y Medios, el trabajo de tipo cualitativo se orientó a analizar las representaciones mediáticas sobre las juventudes, considerando las siguientes dimensiones latentes de relevancia: Participación política y Políticas públicas (aquellas focalizadas en las juventudes y que constituyen su producción como sujetos de derecho)

Para desentramar los mecanismos de construcción de representaciones mediáticas sobre los jóvenes, se trabajó sobre tres variables: el contenido tratado (qué se representa); las fuentes de información (quién / quiénes representan); los modos o los mecanismos (cómo se representa).

La dimensión discursiva se trabajó, en primera instancia aunque no de manera estricta ni agotada en sí misma- con el análisis de contenido. En este sentido, se relevaron los textos vinculados a las dimensiones mencionadas a fin de clasificarlos en temas y luego en categorías de análisis. Tal es que el proceso se orientó a determinar el núcleo de significaciones, el sentido del discurso, utilizando para ello un criterio de clasificación semántica.

Cabe aclarar que en un análisis cualitativo partir de categorías de análisis no significa cerrarse a la posibilidad de que surjan nuevas categorías que puedan enriquecer el abordaje. En algunos casos, la clasificación o la codificación parte de, o se corresponde inicialmente con, las categorías propuestas por la matriz de datos del Observatorio; en otros se construye según 
necesidad del analista, siempre atendiendo al marco teórico al tiempo que se revisa el material.

De este modo, el procedimiento de clasificación arroja un corpus de 391 noticias para un tratamiento cualitativo. 40 noticias corresponden al eje participación política y 351 al eje políticas públicas.

Un enfoque como el que hemos elegido para analizar el contenido de las representaciones nos permite investigar no sólo cuáles son las creencias que se transmiten, sino también cuáles son los roles sociales que entran en juego y qué permite transmitir cada uno de ellos.

La mejor forma de acceder a las representaciones es mediante el análisis del lenguaje porque es a través de este que los actores sociales -como los medios- transmiten sus formas de ver el mundo. En este caso, realizaremos interpretación a partir de la puesta en relación de las noticias con las herramientas conceptuales adoptadas para este trabajo. 


\section{Informe sobre los jóvenes en los medios de comu- nicación: Representaciones mediáticas en los dia- rios nacionales}

Como dijimos en capítulos anteriores, indagar las representaciones que construyen los medios masivos de comunicación implica asumir que estos no son un «espejo» de la realidad, sino que, por el contrario, contribuyen a su existencia modelando sentidos preconfigurados históricamente a sus representaciones. Por ello, no hay nada de lo que circula en los medios que esté por fuera dedisputas y de relaciones de poder, y que no sea parte de luchas en los procesos de construcción de hegemonía y de contrahegemonía en una determinada situación histórica.

A propósito de esto, los modos de nombrar la historia están inscriptos, también, en discursos ideológicos o culturales que se encarnan en instituciones, en prácticas y en conductas. Justamente, qué pensar e, inclusive, qué sentir enrelación con lo vivido, se constituye en una escena de lucha por el sentido y por las identidades (Grüner, 2005).

La dimensión discursiva no es un registro completamente independiente de la trama social: es un aspecto que emerge, decisivamente, en una complicada síntesis de relaciones sociales y de poder. Volóshinov considera que «todo signo se estructura entre los individuos socialmente organizados enel proceso de su interacción» ([1929] 2009: 44). Un aspecto interesante de esta perspectiva, que ayuda a situar el análisis, se relaciona con que el discurso está condicionado por distintos grupos sociales que intentan acentuar sus "palabras», de manera que puedan expresar sus experiencias y sus aspiraciones colectivas. Al respecto, y trazando una analogía con el pensamiento de Antonio Gramsci ([1949] 1960), los consensos que se establecen en las sociedades no se presentan en total armonía: 
por el contrario, el discurso presenta temas y acentos (Volóshinov, [1929] 2009) vinculados con experiencias sociales antagónicas. Si seguimosesta línea, toda sociedad es heteroglósica (multiacentuada, dirá Grüner), ya que en ella conviven, conflictivamente, dentro de un mismo territorio, distintas lecturas en torno a losacontecimientos experimentados.

Una de las líneas de análisis que resulta útil para comprender de qué manera se construyen estos procesos de lucha por legitimar sentidos en la sociedad es la que nos ofrece lalectura crítica de los discursos mediáticos. Aquí se va a comprender al discurso situado bajo determinadas situacioneshistóricas y en medio de procesos de construcción de poder. El discurso, tal como es comprendido aquí, produce no sólo sentidos y/o ideas, sino que le da forma a la realidad, construyendo representaciones sobre aquello a lo que alude.

Por ello, nos interesa particularmente pensar al discurso desde la línea de trabajo de Ernesto Laclau y de Chantal Mouffe ([1985] 2004). El supuesto principal de esta perspectiva esque la sociedad puede considerarse una configuración discursiva, de manera que todo lo que ocurre en ella posee un significado. El mundo social está poblado de significantes y designificados que son históricos; esto es, variables, abiertos,contingentes (no necesarios), procesuales (no esenciales) (Huergo, 2002).

De manera sintética, se puede afirmar que los procesos de construcción de hegemonía, como sostiene Jorge Huergo (2002), trabajan a partir de la producción de un imaginario de orden que es coincidente con los intereses de los sectores dominantes, al que intentan presentar como algo «natural»y mediante la elaboración de una serie de equivalencias discursivas; esto es, la producción de significantes y la fijación de determinados significados que no deberían ser subvertidos. Estos procesos dinámicos tienden a naturalizarse, lo que lleva a perder de vista su carácter histórico y social, y logran sedimentarse en 
las formaciones culturales, que, en definitiva, terminan por legitimar modos de nombrar a la realidad.

Considerando la conceptualización de Moscovici, las representaciones sociales emergen en determinadas situaciones de conflictos y de disputas sociales (Mora, 2002). En el período analizado -junio de 2012 a junio de 2013-, la participación política y cultural de ciertos grupos y organizaciones sociales fueron focalizadas y acentuadas en el marco siempre presente de luchas por la construcción de hegemonía.

\section{Jóvenes y participación política}

De la indagación realizada en torno a las representaciones que la prensa gráfica seleccionada construye sobre las relaciones jóvenes y políticas se destaca la siguiente serie de temas:

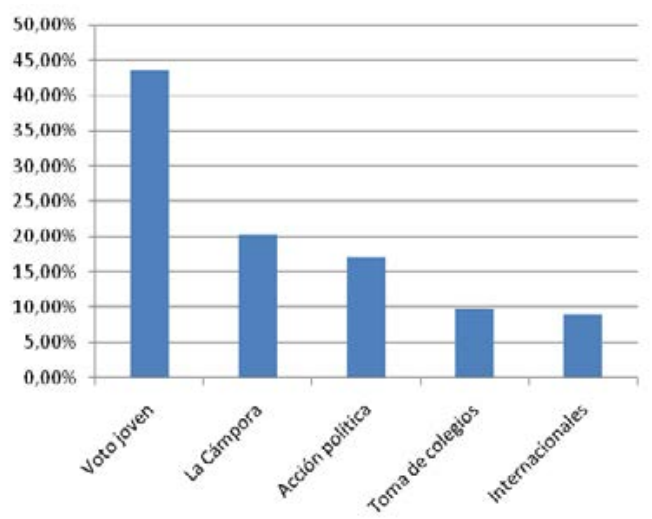


El tema «voto joven» hace referencia a los artículos que se publicaron sobre los debates en el proceso de discusión deproyecto de ley de ampliación de la ciudadanía a las y los jóvenes de 16 y 17 años, proyecto que el $1^{\circ}$ de noviembre de 2012 se convirtió en la Ley 26.774 de Ciudadanía Argentina.

Se decide incorporar a "La Cámpora» como tema, y no simplemente como organización, debido a que la prensa le ha dedicado una diversidad de artículos que permite pensar el modo en que es representada con cierta autonomía de aquello a lo que se la vincule. Es decir, y como veremos más adelante, las apariciones, los movimientos, las acciones, etcétera, de referentes y/o demás militantes de dicha organización, son nombrados una y otra vez en la prensa gráfica.

En «acción política» se condensan diversas actividades que involucran a las juventudes. Desde jornadas de discusión ydebates hasta marchas y reclamos, son incorporadas aquí porque el punto en común de las distintas manifestacioneses la praxis y la participación colectiva. Las «tomas de loscolegios» se desprende en tanto tema de "acción política»,pero debido a la extensión de estas medidas políticas de lasy los jóvenes de colegios secundarios de la ciudad de Buenos Aires, se consideró pertinente autonomizar esta práctica de otras acciones más generales y sin tanta especificidad.Con «internacionales» se hace referencia a todas aquellasnotas que relatan situaciones o acciones que involucran a juventudes de otros países de la región o del mundo.

La lectura crítica de los discursos mediáticos permite observar la lucha por legitimar ciertas representaciones sobre los jóvenes. Esto se produce, estratégicamente, para anudar a ciertos significantes determinados significados con el objetivo de fijar sentidos y de que estos se tornen naturales y verdaderos. Lo que analíticamente podemos denominar equivalencias discursivas.

Estableciendo una analogía con Volóshinov, los grupos mediáticos entran en tensión al querer adjudicarle a los significantes 
(o signos) un sentido eterno por encima de las clases sociales, «pretendiendo apagar y reducir al interior de la lucha las valoraciones sociales que se verifican en él» ([1929] 2009: 48) y universalizar una idea que surge desde los inte- reses de grupos particulares.

Del conjunto de los temas observados en torno a la dimensión participación política se trabajará sobre «voto joven» y «La Cámpora», con 40 artículos para realizar una interpretación cualitativa. Estos dos temas son elegidos porque surepercusión política fue central en la escena mediática.

\section{Discusión sobre el voto joven}

En el marco del proceso de discusión del «voto joven» en los cuatro medios relevados produjeron una gran cantidad de artículos (140 de un total de 321). Las posturas ante la capacidad de los jóvenes de elegir a sus representantes como,también, de los "oscuros" intereses del gobierno nacional deconvertir en ley el proyecto se visibilizaron claramente.

En los artículos relevados, se pueden distinguir dos grandes universos de sentidos en torno a los y las jóvenes en relación con el derecho a votar. Estos dos grupos pueden diferenciarse a partir de ciertas regularidades en el modo de nombrar a los jóvenes, en las maneras en las que son visibilizados por las agendas mediáticas.

Por un lado, tenemos un grupo conformado por los artículos de LA NACIÓN y de CLARÍN. La construcción realizada por estos medios apunta a criticar la propuesta política realizada porel Frente Para la Victoria y, por extensión, caracteriza a las y los jóvenes como incapaces.

Si tenemos en cuenta, tal como se indicó, que las representaciones se constituyen a partir de los discursos, y que uno de los objetivos de los grupos que luchan por la hegemonía es fijar ciertos significados en torno de un significante, se 
puede decir que sobre la idea «jóvenes», se realizaron las siguientes relaciones:

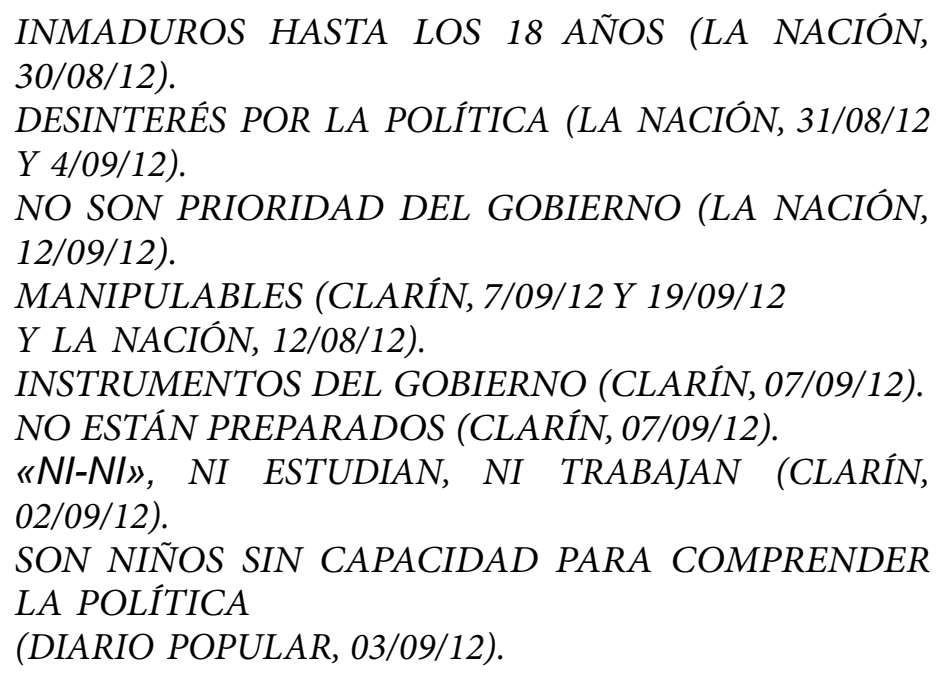

INMADUROS HASTA LOS 18 AÑOS (LA NACIÓN, 30/08/12).

DESINTERÉS POR LA POLÍTICA (LA NACIÓN, 31/08/12 $Y$ 4/09/12).

NO SON PRIORIDAD DEL GOBIERNO (LA NACIÓN, 12/09/12).

MANIPULABLES (CLARÍN, 7/09/12 Y 19/09/12

Y LA NACIÓN, 12/08/12).

INSTRUMENTOS DEL GOBIERNO (CLARÍN, 07/09/12).

NO ESTÁN PREPARADOS (CLARÍN, 07/09/12).

«NI-NI», NI ESTUDIAN, NI TRABAJAN (CLARÍN, 02/09/12).

SON NIÑOS SIN CAPACIDAD PARA COMPRENDER LA POLÍTICA

(DIARIO POPULAR, 03/09/12).

En el proceso de disputa en torno a la legitimación de las juventudes como sujetos capaces de elegir a sus representantes, se puede observar que en las publicaciones de CLARÍN y de LA NACIÓN (y un artículo en DIARIO POPULAR), los y las jóvenes son representados como «manipulados» por intereses que no son propios, sino de los adultos y de los dirigentes altamente politizados, que los utilizan como instrumentos para sus fines, que no declaran sino que los ocultan detrásde medidas que aparentan ser de inclusión. Como sostiene Saintout, «los jóvenes son vistos desde estas miradas paternalistas, como niños que necesitan de tutela y que nopueden tomar sus propias decisiones. La idea de que los usan, los victimizan y, a la vez, los inhabilitan como sujetos activos» (2012: 17). En la disputa por la construcción del sentido, y de fijar «verdades» allí donde no las hay o están en disputa, los grupos de poder intentan acentuar algunas significaciones porsobre 
otras con el objetivo de imponer una mirada de los procesos sociales; en este caso, de los jóvenes, ligándolosa una imagen de incapacidad y de ingenuidad con respectoa su acción política, quitándoles autoridad sobre sus decisiones y sobre su involucramiento en los procesos políticosdel país.

De todos modos, así como se observa un conjunto de significados ligados a la deslegitimación de las y los jóvenes, diversos artículos que se publicaron en PÁGINA/12 y en DIARIO POPULAR tienden a construir otras representaciones $y$ otros significados en torno a los jóvenes.

En estos medios hay significaciones ligadas con otras perspectivas ideológicas que entienden a la ley del «voto joven» como una ampliación de los derechos y a las juventudes conla capacidad necesaria de elegir por medio de las elecciones.

Principales equivalencias discursivas sobre las jóvenes producidas por PÁGINA/12 y por DIARIO POPULAR:

CON GANAS DE PARTICIPAR (PÁGINA/12, 24/07/12 $Y$ 02/05/13).

BUSCAN RENOVACIÓN Y CAMBIO (PÁGINA/12, 07/09/12).

MILITANTES (PÁGINA/12, 10/09/12 Y DIARIO POPU$L A R$, 06/04/13).

DEFIENDEN SUS DERECHOS (PÁGINA/12, 26/09/12). COMPROMETIDOS CON EL PAÍS (PÁGINA/12, 16/11/12). SOLIDARIOS (DIARIO POPULAR, 07/04/2013).

TRABAJAN PARA CAMBIAR LOS PROBLEMAS SOCIALES (DIARIO POPULAR, 21/11/12).

Estas relaciones (equivalencias) que establecen los distintos medios gráficos entran en tensión en forma permanente. La evidencia de las diferencias al momento de nombrar a los jóvenes en cada uno de los diarios referidos daría cuenta,también, 
que, de forma más o menos explícita, la prensa no se involucra objetivamente con la realidad, sino que piensay escribe sobre los acontecimientos sociales desde determinadas ideas y sentimientos que tiene poco que ver con la neutralidad, la imparcialidad o la tan mentada objetividad.

\section{La Cámpora, esos jóvenes (mal) interesados}

Otra de las representaciones está vinculada con los «malos» intereses que tiene la organización La Cámpora, en general, y sus militantes, en particular. Dicha agrupación se visibiliza como tema a partir de que de un total de 321 artículos, en 65, sus prácticas, sus acciones y sus referentes son nombrados. Estos jóvenes sólo «buscan poder» y «piensan en ocupar cargos», desde una supuesta ilegitimidad que le es conferida por estar vinculada al gobierno nacional. Esto es percibido en una serie de artículos publicados en los diarios CLARÍN y DIARIO POPULAR; particularmente en este último, cuyos artículos sobre la agrupación superan el $40 \%$ del total del tema.

Siguiendo el esquema anterior, en torno a La Cámpora circularon las siguientes significaciones:

TIENEN INTERESES OSCUROS (LA NACIÓN, 03/08/12). ADOCTRINAN EN LAS ESCUELAS (LA NACIÓN, 15/08/12). AVASALLAN LAS INSTITUCIONES (LA NACIÓN, 16/08/12 Y CLARÍN, 03/08/12).

OBLIGAN A LOS NIÑOS A SER KIRCHNERISTAS (LA NACIÓN,

17/08/12).

SON MANIPULADORES DE JÓVENES (LA NACIÓN, 23/08/12). 
En su libro Los jóvenes en la Argentina. Desde una epistemología de la esperanza, Saintout advierte que La Cámpora es «permanentemente demonizada como ninguna otra agrupación política» (2013) por algunos medios, entre ellos,CLARÍN y LA NACIÓN. Los modos en que son estigmatizados estos jóvenes por el discurso hegemónico puede observarse, nuevamente, en la cobertura de la situación de violencia que ocurrió el 6 de abril de 2013 en el barrio de Tolosa (LaPlata), durante los trabajos de reconstrucción y de ayuda a los damnificados por las inundaciones que ocurrieron en lacapital de la provincia de Buenos Aires el 2 de abril.

Allí, un grupo de entre 10 y 15 personas vinculadas a la seccional local de la UOCRA atacaron a militantes de La Cámpora. Varios de los jóvenes tuvieron que ser hospitalizados. A propósito del hecho, y si bien las cámaras de seguridad de la zona daban cuenta de una situación en la que unos jóvenes eran golpeados por otros, los diarios CLARÍN y LA NACIÓN presentaron en reiteradas oportunidades al hecho como un «enfrentamiento».

El 8 de abril, LA NACIÓN tituló «La Cámpora y la UOCRA se enfrentaron a palazos por el reparto de donaciones», y sostuvo queen el momento de entregar mercadería en el barrio Tolosa la UOCRA «se enfrentó a palazos y a piedrazos con militantes de la agrupación kirchnerista La Cámpora». El mismo día, CLARÍN publicó el artículo «La UOCRA y los grupos cristinistas, a los palazos por distribuir la ayuda», y el 12 de abril, otro titulado «Intentan evitar la detención de un gremialista». En ambos diarios, se caracteriza a la situación como "choque» $\mathrm{o}$ «enfrentamiento», dado que ambas organizaciones se disputan «el reparto y el rédito político, en medio de la catástrofe». Al mismo tiempo, se plantea que si hubo una situación de violencia por parte de los militantes de la UOCRA fue porque La Cámpora impedía que la distribución de los materiales en las zonas afectadas sea equitativa, dando cuenta de que su accionar estaba lejos de ser 
democrático, y de que, en todo caso, la acción de la UOCRA estuvo relacionada con una situación de injusticia generada por la organización vinculada con el gobierno nacional.

A diferencia de estos dos diarios, y desde una perspectiva prácticamente opuesta, PÁGINA/12 sostuvo que jóvenes de La Cámpora fueron agredidos por miembros de la Unión Obrera de la Construcción de La Plata, y publicó en el suceder de los días distintos artículos vinculados con la situación violenta que sufrieron los militantes («Militantes agredidos» $\mathrm{y}$ «Apoyos para La Cámpora», el 9 de abril; «Repudio al ataque de la UOCRA contra voluntarios de La Cámpora», «El hijo del Pata Medina fue detenido» $\mathrm{y}$ «El hijo del Pata Medina, comprometido», el 10 de abril; $y$ «A Patita lo metieron preso», el 11 de abril).

PÁGINA/12, ofrece mediante su producción de significaciones una construcción opuesta. En este caso, la relación militancia juvenil y solidaridad está enmarcada en un «universo» de significados diferentes, no solo en relación con el modode presentar la agresión que sufrieron los militantes de LaCámpora, sino en el modo de construir la actividad de los jóvenes en el trabajo pos inundaciones. En este último caso, se acentúa la necesidad de la participación de la juventuden el proceso de reconstrucción (PÁGINA/12, «Es buenísimo que haya militantes», 7 de abril). Dentro de este gran «universo» se «visibiliza» y se "celebra» la participación de distintas organizaciones sociales, políticas, religiosas y gremiales ante la urgencia de la población afectada. 


\section{A modo de final (abierto)}

El entrecruzamiento de construcciones distintas y hasta opuestas en torno a la participación de los jóvenes en la escena política y social responde a intereses y a perspectivasque buscan imponerse en la cultura, tal como lo ha afirmado Antonio Gramsci (2006). La necesidad de comprender y deproblematizar los sentidos que sobre los jóvenes circulan en la sociedad sigue siendo una tarea necesaria para pensar los modos en que algunos sujetos son marginados o son desautorizados para participar en la vida democrática.

Son poco los casos en los que los jóvenes no son estigmatizados. Las tensiones se profundizan y, a decir de Martín Barbero, se debe prestar atención a la «inclusión abstracta, exclusión concreta» que puede estar operando en los medios masivos y en las políticas regionales. Una inclusión política que permite a los jóvenes ser protagonistas de las disputas políticas y una exclusión cultural y mediática que relata a ciertos sujetos juveniles como incapacitados de decir supropia palabra.

Es necesario señalar que no existe una dicotomía entre discursos en general (y mediáticos en particular) y realidad. No son dos instancias que se mueven de formar paralela. Es decir, existen relaciones de implicancia, dialécticas, entre larealidad y los discursos, que se van dando forma.

En este sentido, se torna fundamental la afirmación del filósofo alemán Friedrich Nietzsche: «No existen hechos, solo interpretaciones». Las interpretaciones entran en colisión enforma permanente en la vida cotidiana buscando imponerse una sobre otra sin importar los costos o la verosimilitud entre lo que se dice y lo que efectivamente ocurrió.

En un momento histórico de producción, de circulación y de consumo de una gran cantidad de interpretaciones, la única manera de tratar de pensar cuáles son los modos en los quese 
construyen representaciones sobre los sujetos y sobre la realidad es mediante un trabajo permanente de relación y delectura crítica de lo que acontece.

\section{Los jóvenes y las políticas públicas}

Se entiende que las políticas públicas son «el conjunto de acciones $\mathrm{u}$ omisiones que manifiestan una determinada modalidad de intervención del Estado en relación con una cuestión» (Ozlack \& O’ Donnel, 1984). Teniendo en cuenta estaconceptualización, el relevamiento para el presente análisis se basa en la selección de las notas que hacen referencia a proyectos, a planes y a programas municipales, provinciales y nacionales destinados, específicamente, a jóvenes, así como a decisiones tomadas e impulsadas desde el Estado que han interpelado fuertemente a la juventud, como es el caso de la Ley Nacional 26.774 de Ciudadanía Argentina, que habilita el voto a ciudadanos de 16 y 17 años.

El análisis, realizado sobre un corpus de 351 textos, busca describir el modo en que los medios representan las intervenciones estatales que se planifican y se gestionan con el propósito de interpelar a los y las jóvenes a fin de promover sus derechos $\mathrm{y}$ de legislar y/o de regular sus actividades. En las noticias que cada medio elabora, las políticas públicas son representadas como eficaces o como ineficacesmedidas de inclusión social, como intentos de manipulacióno de reconocimiento de derechos, y como necesarias regulaciones de actividades peligrosas o de dispositivos de disciplinamiento.

Los jóvenes, en este caso, son caracterizados desde cinco lugares principales. Por un lado, son vistos como sujetos de riesgo (Mendes Diz, 2001), es decir, sus prácticas se abordan en relación con el peligro, en tanto describen actitudes que de- 
ben ser controladas. En este respecto, se hace referencia a su vínculo con el consumo de drogas y de alcohol,o a conductas sexuales consideradas perniciosas. En otras ocasiones, son vistos como sujetos del deterioro (Saintout, 2010) toda vez que aparecen como el sector que condensalas características negativas de la sociedad; por responsabilidad individual o como consecuencias social, las juventudes son las que no estudian ni trabajan, ni parecen aportar o hacer nada positivo o beneficioso para la sociedad. También están los jóvenes manipulados, narrados desde una postura paternalista y adultocéntrica que los victimiza y que, a la vez, los inhabilita como sujetos para la toma de decisiones(Saintout, 2013); desde este enfoque, algunos medios caracterizan a la Ley de Ciudadanía Argentina como un intento de manipulación. Por otro lado, los jóvenes son enfocadoscomo actores estratégicos del desarrollo (Krauskopf, 2000), cuando se describe su participación en programas estatales que parecen pivotear entre la inclusión y la contención. Finalmente, están los jóvenes como ciudadanos, como sujetos de derecho (Kriger, 2010), narrados en su vinculación con intervenciones que desde el Estado buscan construir ciudadanía y promover sus derechos.

\section{Consideraciones generales según medio de comunicación}

La mayoría de las notas que constituyen el corpus son publicadas por DIARIO POPULAR, específicamente, el $47 \%$ de las queintegran la muestra. En segundo y en tercer lugar se encuentran LA NACIÓN y PÁGINA/12, con 28\% y 16\%, respectivamente. En tanto, el medio que menor porcentaje de noticias publicasobre este eje es CLARÍN, con un 9\% del corpus. 
En términos generales, casi la mitad de las notas relevadas tiene como motivo principal la participación política de los jóvenes, lo que permite dimensionar, en el período deanálisis, el peso que en las agendas mediáticas adquirióla discusión sobre la ley que habilita a votar a ciudadanos de 16 y de 17 años. El segundo motivo con más presencia es el sistema educativo y las experiencias pedagógicas de los jóvenes, que aparece como tema principal en una cuarta parte del corpus. Las noticias que abordan como motivoprincipal el vínculo entre políticas de Estado, jóvenes y trabajo representan un $8 \%$. El resto de los temas que aparecenestán relacionados con el ámbito doméstico, con la salud ycon el deporte.

Un $40 \%$ de las notas hace referencia a todo el territorio nacional. Del resto, una amplia mayoría toma como referenciaa la provincia de Buenos Aires, específicamente el $64 \%$ de las que integran la muestra. Por otro lado, un $19 \%$ de las noticias corresponde a la Capital Federal. El resto de las provincias ocupa porcentajes menores, apenas destacándose Tucumán, Córdoba y San Juan, con entre el 3 y el $4 \%$.

DIARIO POPULAR se distingue por publicar una gran cantidad de noticias que hacen referencia a programas y a iniciativas municipales y provinciales relacionadas con la educación, con el deporte y con la formación laboral, correspondientes a diversos partidos del conurbano bonaerense. A estas notas las denominamos «Acciones municipales». La mitad de las notas publicadas por este medio, enmarcadas en el desarrollo de actos en los que participaban funcionarios, da cuenta de lanzamientos de cursos de oficios por parte de instituciones municipales, de aperturas para la inscripción en programas como Envión y Argentina Trabaja, entre otros, y de competencias deportivas llevadas a cabo por sociedades de fomento. En estas noticias, se advierte con frecuencia la estructura de las gacetillas de prensa elaboradas por municipios y por otras oficinas estatales. 
Respecto a la Ley de Ciudadanía Argentina, y a otras leyes similares en diversos distritos, este diario publica 22 notas.

El tratamiento que brinda sobre el tema no ofrece demasiadas variantes respecto al de otros medios, aunque en estecaso se privilegian las declaraciones formuladas por políticos justicialistas, en su mayor medida, ministros nacionales, gobernadores e intendentes del conurbano. El resto de las notas hace referencia a programas (creación de centros de estudiantes) y a manifestaciones $o$ a actividades juvenilesen el contexto de la vida escolar (la Noche de los Lápices,el Día de la Primavera). El diario también ofrece lecturas de estadísticas sobre desempleo juvenil y educación, y alusiones a iniciativas y a campañas que apuntan a resolver lo que desde el medio se consideran «problemáticas juveniles»: violencia, adicciones, acoso sexual, salud reproductiva, hábitos alimenticios.

LA NACIÓN, por su parte, le otorga un amplio espacio a la discusión de la Ley que habilitó el voto desde los 16 años, con 30 notas al respecto. En ellas, le otorga un lugar destacado a las declaraciones de distintas expresiones políticas sobre el tema. Este medio también trabaja, en un número considerable de narraciones, sobre diversas situaciones relacionadas con las problemáticas educativas, como sucede, por ejemplo, con las deficiencias en la implementación de programas educativos. Al respecto, el diario se posiciona sobre la participación juvenil al criticar el desempeño de funcionariosjóvenes en la gestión estatal. LA NACIÓN es el único medio que hace referencia a iniciativas desarrolladas por Organizaciones No Gubernamentales relacionadas con el campo educativo. Finalmente, una gran cantidad de noticias menciona la reglamentación o la prohibición de actividades desarrolladas por jóvenes y consideradas riesgosas -como el paintball y el longboard- y alude a situaciones de ejercicio de la violencia en instituciones educativas.

PÁGINA/12 publica 23 notas sobre la Ley de Ciudadanía Argentina y sobre otras iniciativas legislativas similares. La 
amplitud de voces recogidas por este medio es similar ala de LA NACIÓN, aunque en este caso se hace hincapié en la participación de los sujetos juveniles en los debates. En otra línea, el diario publica noticias sobre programas de diversos organismos estatales nacionales y provinciales destinados a la juventud, como el Conectar Igualdad, Jóvenes y Memoria y Sumar. Otro tema que se destaca son ciertas intervenciones estatales consideradas ilegítimas ante ciertos jóvenes:prejuicios de parte de médicos ante casos de aborto y condenas ilegales a jóvenes en conflicto con la ley penal.

CLARÍN, en tanto, publica una considerable cantidad de notas que tienen como objeto la ley que habilitó el voto a los 16 años: sólo 13 de 33 abordan otros temas, que se reducen aestadísticas sobre desempleo y sobre exclusión escolar. Laspiezas publicadas sobre la Ley 26.774 se caracterizan por la amplitud de testimonios recogidos en cuanto a expresionespolíticas, aunque la casi totalidad de las citas correspondea personas adultas. Por otra parte, el medio hace referencia explícita, y en forma constante, al carácter polémico de lainiciativa.

\section{¿Inclusivas o de manipulación? \\ ¿Necesarias o ineficaces?}

La mayoría de las de notas publicadas por DIARIO POPULAR describe intervenciones estatales tendientes a generar po sibilidades de inclusión para jóvenes en riesgo, desde la perspectiva de las instituciones.

«PARA NOSOTROS ES UN DÍA DE MUCHA ALEGRIAA, COMO SIEMPRE QUE TENEMOS QUE ENTREGAR ESTOS DIPLOMAS, PORQUE REPRESENTA UNA OPORTUNIDAD PARA TODOS ESTOS JÓVENES DE LOS CUALES MUCHOS HAN DEJADO LA ESCUELA, OTROS NO PUEDEN CONSEGUIR TRABAJO. NOSO- 
TROS APUNTAMOS A LA INCLUSIÓN DE ESTOS JÓVENES, A TRAVÉS DE LA FORMACIÓN Y LA CAPACITACIÓN»

(DIARIO POPULAR, 22 DE DICIEMBRE DE 2012).

«DANIEL GAMBINO, SECRETARIO DE PROMOCIÓN COMUNITARIA, ESTUVO PRESENTE EN LAS CLASES Y AGREGÓ: "ESTA APUESTA ES PARTE DE LAS POLÍTICAS DE INCLUSIÓN A TRAVÉS DEL DEPORTE Y LA VIDA SANA"»

(DIARIO POPULAR, 27 DE DICIEMBRE DE 2012).

En otras ocasiones, las políticas públicas que se presentan hacen referencia a los jóvenes como sujetos problemáticos.

"“EL OBJETIVO ES LLEVAR ADELANTE POLÍTICAS ACTIVAS PARA DISMINUIR LOS PROBLEMAS QUE AFECTAN A LA JUVENTUD, TENIENDO A LA CULTURA COMO UN FACTOR FUNDAMENTAL DE CONTENCIÓN Y DE INTERACCIÓN", REMARCÓ SCIOLI TRAS EL ENCUENTRO»

(DIARIO POPULAR, 17 DE JULIO DE 2012).

En la misma línea, algunas de las actividades que el mediopublica ubican a los jóvenes en el lugar de lo que se debe contener, configurando unos sujetos cuyo tiempo es necesario administrar para que no se vuelvan problemáticos.

«ESTA SEMANA COMENZARON LOS TALLERES QUE

2.104

VECINOS DE VILLA MAIPÚ Y BILLINGHURST VOTARON EL AÑO PASADO EN EL MARCO DEL PRESUPUESTO PARTICIPATIVO MUNICIPAL, A EJECUTAR EN 2013, Y QUE APUNTAN A DAR CONTENCIÓN A LOS JÓVENES»

(DIARIO POPULAR, 12 DE JUNIO DE 2013). 
En varias notas, en tanto, es explorada la narrativa sobre los jóvenes como sujetos del deterioro (Saintout, 2010). De esta manera es posible entender las piezas que desarrollan estadísticas sobre jóvenes que no estudian ni trabajan, enlas cuales es posible encontrar citas del siguiente tipo:

"'ES DIFÍCIL EXPLICAR EL CRECIMIENTO DE LOS JÓVENES EN SITUACIÓN DE EXCLUSIÓN EXTREMA, PERO POSIBLEMENTE TIENE QUE VER CON SU BAJO CAPITAL HUMANO. LA MAYORÍA SON DESERTORES TEMPRANOS DEL SISTEMA EDUCATIVO. LO QUE LES DIFICULTA COMPETIR EN EL MERCADO LABORAL", SOSTUVO ERNESTO KRITZ, QUE DIRIGIÓ EL TRABAJO DE LA CONSULTORA» (DIARIO POPULAR, 29 DE AGOSTO DE 2012).

Además, esta línea de discurso se profundiza con las noticias sobre iniciativas de control respecto a los jóvenes, como aquellas que, al dar cuenta de los festejos por el Díade la Primavera, hacen hincapié en que «se implementarán controles para asistir cuadros por intoxicación con alcohol o drogas» (DIARIO POPULAR, 21 de septiembre de 2012); o las que describen intervenciones destinadas a tratar jóvenes adic-tos, violentos, etcétera:

"'DE LAS 11.878 PERSONAS EN TRATAMIENTO POR CONSUMO DE SUSTANCIAS EN LA PROVINCIA, EL 20 POR CIENTO SON CHICOS MENORES DE 18 AñOS, ASEGURÓ COLLIA Y AFIRMÓ "ESTO NOS DA LA PAUTA DE QUE TENEMOS QUE ENFOCAR NUESTRA POLÍTICA A LOS JÓVENES, ANTE QUIENES PODEMOS LLEGAR DESDE LA ESCUELA, CON LOS PROFESORES $Y$ LOS PRECEPTORES"»

(DIARIO POPULAR, 9 DE MAYO DE 2013). 
No obstante, estas imágenes conviven con algunas intervenciones de funcionarios que buscan promover que los jóvenes se expresen:
«POR SU PARTE, SILEONI RESALTÓ QUE “QUEREMOS UNA EDUCACIÓN DONDE CIRCULEN LAS IDEAS, ES- TOS SON ESCENARIOS PROPICIOS PARA LA DISCU- SIÓN Y LA PARTICIPACIÓN" "
(DIARIO POPULAR, 11 DE SEPTIEMBRE DE 2012).

Esta cita, tomada en el marco de una conmemoración de la Noche de los Lápices, permite señalar la presencia en estemedio de referencias a políticas públicas escolares de ejercicio de la memoria, particularmente de la última dictadura cívico-militar. Detrás de PÁGINA/12, DIARIO POPULAR es el medio que mayor difusión otorga a este tema.

Por último, sobre la Ley 26.774 DIARIO POPULAR realiza una co bertura en la que no abunda la explicitación de opiniones o de valoraciones, ni en el tratamiento informativo ni en la selección de fuentes. De ese modo, es posible entender el siguiente fragmento:
"LA SESIÓN TUVO UN SIGNIFICADO ESPECIAL YA QUE LOS PALCOS ESTUVIERON COLMADOS POR JÓ- VENES QUE ENTONABAN CÁNTICOS A FAVOR DEL PROYECTO, LO QUE SUCEDE CUANDO SE PRODUCE UN DEBATE DE ALTO IMPACTO POPULAR, COMO ES LA HABILITACIÓN PARA EL VOTO OPTATIVO DE LOS JÓVENES DESDE LOS 16 AñOS» (DIARIO POPULAR, 30 DE OCTUBRE DE 2013).

Como particularidad, es posible señalar que hay citas a personajes por fuera de la política y de la academia, y que a diferencia de los otros medios, pero, sobre todo, de CLARÍN,se hace hincapié en el consenso que tuvo el proyecto: 
«SE MOSTRARON A FAVOR DE LA INICIATIVA DESDE AMADO BOUDOU Y ANÍBAL FERNÁNDEZ, A VICTORIA DONDA Y HORACIO RODRÍGUEZ LARRETA. TATI ALMEYDA PROPUSO "ESTUDIAR MUY BIEN" LA PROPUESTA»

(DIARIO POPULAR, 23 DE SEPTIEMBRE DE 2012).

Sin embargo, en una nota editorial se da cuenta de la postura del medio: por un lado, se describe el carácter, supuestamente, interesado de la iniciativa impulsada por el kirchnerismo, «de más está decir que el kirchnerismo estáconvencido de que el mayor porcentaje de esos nuevos votantes le será fiel» (DIARIO POPULAR, 2 de septiembre de 2012); y, por otro, se señalan otras problemáticas relacionadas con jóvenes que resultarían más urgentes:

«LOS JÓVENES DE TODO EL PAÍS QUE NO ESTUDIAN NI TRABAJAN ASCIENDEN A 900.000. SEGÚN UN ESTUDIO DEL OBSERVATORIO DE LA DEUDA SOCIAL ARGENTINA DE LA UCA, UN 19\% DE LOS JÓVENES NO VA AL COLEGIO, UN 36,8 VIVE EN HOGARES DEBAJO DE LA LÍNEA DE POBREZA Y UN 43,4\% NO TIENE COBERTURA DE SALUD»

(DIARIO POPULAR, 2 DE SEPTIEMBRE DE 2012).

Este ejercicio de describir lo juvenil como objeto de manipulación gubernamental, no obstante -que en CLARÍN, principalmente, y también en LA NACIÓN, es la estrategia explicativa dominante-, aparece en este medio de manera muy matizada.

Por último, DIARIO POPULAR explora un tema que sólo comparte con LA NACIÓN: el de las actividades relacionadas con educación o con campañas de bien público impulsadas desde Organizaciones No Gubernamentales. En las mismas, se suelen oponer las iniciativas de la sociedad civil a las intervenciones estatales: 
«EL GOBIERNO NACIONAL NO SERÁ EL ÚNICO QUE CONTARÁ CON JÓVENES PARA REALIZAR TAREAS DE CONTROL Y DE MONITOREO, EN ESTE CASO DE QUE LOS SÚPER E HIPERMERCADOS RESPETEN LOS PRECIOS ACORDADOS DE UNOS 500 PRODUCTOS, TAMBIÉN

ORGANIZACIONES AMBIENTALISTAS Y SOCIALES SUMARÁN A SUS PROYECTOS A ALUMNOS DE ESCUELAS SECUNDARIAS»

(DIARIO POPULAR, 28 DE MAYO DE 2013).

LA NACIÓN pareciera considerar la mayoría de los temas relacionados con políticas públicas de juventud según el siguienteesquema interpretativo: los jóvenes, en la actualidad, sonmuy importantes en la sociedad y es bueno reconocerlos, pero no pueden, porque son incapaces. De la primera parte de este eje dan cuenta las siguientes citas:

«LOS ADOLESCENTES, CADA VEZ MÁS ACTIVOS EN LA SOCIEDAD. "ES RIDÍCULO QUE HASTA UN DÍA ANTES DE CUMPLIR AÑOS NO PUEDA HACER UN TRÁMITE SOLO Y AL OTRO DÍA YA PUEDA ELEGIR AL PRESIDENTE O IR PRESO", CUESTIONA LUCAS» (LA NACIÓN, 17 DE OCTUBRE DE 2012 [A]).

«LO DISTINTIVO DE LA ENTIDAD ES QUE CONFÍA EN LA JUVENTUD COMO AGENTE TRANSFORMADOR DE LA REALIDAD» (LA NACIÓN, 11 DE MARZO DE 2013).

De la incapacidad dan cuenta las notas donde se hace referencia a que «en la Argentina y en el mundo los jóvenesestán en una situación difícil por los cambios y las dificultades económicas a nivel mundial» (LA NACIÓN, 1 de noviembre de 2012), así como las que aseguran que «los chicos estánen 
problemas. Los adultos no podemos garantizarles la mejor educación que imaginamos para ellos» (LA NACIÓN, 17 de octubre de 2012 [b]).

En esta narrativa de la juventud se teje, por un lado, una representación de las políticas públicas para jóvenes que oscila entre el intento de manipulación cuando se trata eldebate y la sanción de la Ley 26.774:

«DE ESTA MANERA, EL GOBIERNO SE PERDERÁ LA POSIBILIDAD DE ARRASTRAR EN LOS COMICIOS PROVINCIALES EL VOTO JOVEN PARA LAS ELECCIONES LEGISLATIVAS»1 (LA NACIÓN, 21 DE ENERO DE 2012).

Y la insuficiencia y la incapacidad de las intervenciones estatales para generar inclusión:

«MIENTRAS LA PRESIDENTA CRISTINA KIRCHNER SE VANAGLORIA DE LAS BONDADES DE SU "MODELO PRODUCTIVO CON DESARROLLO DIVERSIFICADO E INCLUSIÓN SOCIAL", [...] PESE A QUE EN LOS ÚLTIMOS TRES AÑOS EL GOBIERNO CUADRUPLICÓ EL MONTO DE LOS SUBSIDIOS DESTINADOS A ESA FRANJA POBLACIONAL»

(LA NACIÓN, 23 DE JULIO DE 2012).

En muchas otras ocasiones, estas miradas aparecen entre lazadas:

«ES MENESTER QUE LA SOCIEDAD ADULTA EN GESTIÓN TOME PLENA CONCIENCIA DE LAS NECESIDADES JUVENILES, DE LOS PROYECTOS DE VIDA QUE SE VAN FRUSTRANDO Y QUE QUEDAN POSTERGADOS O ABANDONADOS, PARA CAER EN LA ESPERA PASIVA DE AYUDAS GUBERNAMENTALES, SIEMPRE PRECARIAS O MOVIDAS POR INTERESES 
PROSELITISTAS»

(LA NACIÓN, 10 DE OCTUBRE DE 2012).

Es posible señalar otras dos aristas respecto del tratamiento mediático de la relación entre el Estado y los jóvenes. Por un lado, es posible percibir una perspectiva elitista, comúnmente asociada al diario, cuando se tejen relatos sobre asociaciones civiles conformadas por jóvenes de sectores acomodados que realizan tareas solidarias, así como en lasnotas que hacen referencia a programas de intercambio y en las que se alude a lo que no estaría haciendo el Estado:

«TAN IMPORTANTE COMO ENVIAR GENTE A ESTUDIAR AFUERA ES CONTAR CON ESTUDIANTES EXTRANJEROS EN NUESTRAS UNIVERSIDADES. MUCHOS DE ELLOS SERÁN LOS LIIDERES DE SUS RESPECTIVOS PAÍSES EL DÍA DE MAÑANA» (LA NACIÓN, 19 DE NOVIEMBRE DE 2012).

Por otro lado, son frecuentes las referencias a la sanción de normativas o de iniciativas que intentan regular actividades de riesgo caracterizadas como juveniles. En estas notas, las actividades juveniles son asociadas con lo riesgoso (Mendes Diz, 2001):

«MÉDICOS Y ESPECIALISTAS ESTÁN PREOCUPADOS POR LA ADOPCIÓN DE LA PÍLDORA DE EMERGENCIA COMO MÉTODO ANTICONCEPTIVO ENTRE LOS ADOLESCENTES»

(LA NACIÓN, 25 DE JUNIO DE 2013).

PÁGINA/12, por su parte, es el medio que más hincapié haceen describir las actuales políticas públicas de juventud como intervenciones que logran posicionar a los jóvenes como sujetos de derechos, en el marco de la construcción estatal de la ciudadanía. De esta manera, es posible encontrar numerosas notas 
de análisis y opinión, algunas de ellas firmadaspor funcionarios del gobierno nacional, referidas a logros en educación:

«LA EDUCACIÓN ARGENTINA ESTÁ MEJOR, TIENE MÁS ALUMNOS, MÁS DOCENTES, MÁS INVERSIÓN, MÁS ESCUELAS CON MEJOR EQUIPAMIENTO Y, ADEMÁS, SE EMPIEZAN A VER MEJORES APRENDIZAJES»

(PÁGINA/12, 14 DE AGOSTO DE 2012).

En algunas de estas notas, inclusive, se explicita que las mismas buscan responder a los datos publicados por otros medios, a los que considera falaces:

«EN LOS ÚLTIMOS DÍAS HEMOS ASISTIDO A LA DIFUSIÓN EN DIFERENTES MEDIOS DE COMUNICACIÓN DE UN CONJUNTO DE ESTADÍSTICAS EDUCATIVAS QUE NO SE AJUSTAN A LA REALIDAD DE LO QUE OCURRE EN EL PAIIS [...] LAS ESTADÍSTICAS DE LA UNESCO MUESTRAN QUE LA ARGENTINA POSEE LA MAYOR PROPORCIÓN DE EGRESADOS DE LA EDUCACIÓN SUPERIOR DE AMÉRICA LATINA, INCLUIDA CUBA, Y DUPLICA LA MEDIA DE LA REGIÓN» (PÁGINA/12, 17 DE AGOSTO DE 2012).

En este medio se expresan, además, una gran cantidad de especialistas y de académicos sobre la ley que habilitó el voto a los 16 años. Todos ellos, en sintonía con la postura editorial del medio, destacan el carácter positivo de la medida, valorizando lo que consideran nuevas y más masivas prácticas políticas juveniles y criticando la lectura de los jóvenes como sujetos manipulables.

FLORENCIA SAINTOUT: «LA ÉPOCA QUE HOY EN LA ARGENTINA LLAMA A LOS JÓVENES A LA VIDA PÚBLICA ESTÁ MARCADA POR UN HORIZONTE DE 
DERECHOS QUE LOS INTERPELA A HACER SUEÑOS» (PÁGINA/12, 4 DE SEPTIEMBRE DE 2012).

JULIÁN AXAT: «LA EMANCIPACIÓN DE LOS JÓVENES EN LA POLÍTICA IRRUMPE COMO ANOMALIAA INDOMEÑABLE PARA CUALQUIER ESPECULACIÓN ELECTORAL»

(PÁGINA/12, 11 DE SEPTIEMBRE DE 2012).

Otras notas ofrecen datos de encuestadores y de analistas que remarcan:

«EN TÉRMINOS ELECTORALES, MÁS ALLÁ DE LOS DISCURSOS ABSURDOS SOBRE MANIPULACIÓN

DE JÓVENES, EL NUEVO SEGMENTO DE VOTANTES DE 16 Y 17 AÑOS NO CAMBIA NADA»

(PÁGINA/12, 2 DE MAYO DE 2013).

Las noticias referidas a programas educativos también están construidas desde esta perspectiva que ve a los jóvenes como sujetos de derecho en un proceso de restitución y de profundización de los mismos, y utilizan como estrategia discursiva el protagonismo de los estudiantes en los procesos pedagógicos:

«LOS JÓVENES TRABAJAN DURANTE TODO EL AÑO EN INVESTIGACIONES SOBRE LA HISTORIA RECIENTE EN SUS COMUNIDADES Y EN LA PROMOCIÓN DE LOS DERECHOS HUMANOS, PARTICIPAN DE ENCUENTROS REGIONALES

Y CAPACITACIÓN. DURANTE EL AÑO REALIZAN UNA PRODUCCIÓN FINAL PARA LLEVAR AL ENCUENTRO DE CHAPADMALAL, DONDE EXPONEN SUS TRABAJOS, COMPARTEN EXPERIENCIAS Y REFLEXIONAN COLECTIVAMENTE SOBRE LA CONSTRUCCIÓN DE UNA DEMOCRACIA PLENA Y PARTICIPATIVA»

(PÁGINA/12, 20 DE MARZO DE 2013). 
Pero, además, los jóvenes mismos aparecen en las notas con voz propia, a través de diferentes recursos, como las encuestas - «Los chicos y chicas ven hoy TV haciendo la tareade la escuela ( 32 por ciento), o bien usan el celular ( 23 por ciento), la computadora (18 por ciento) o escuchan música(12 por ciento)» (PÁGINA/12, 23 de julio de 2012)- y las entrevistas-«"Primero la computadora no me gustaba, sentía que iba a meter mano y arruinaría todo, no la entendía", recuerdauno de los compañeros de curso de Elías, Ezequiel Salas, de 19 años, que vive en el pueblo de Tilcara» (PÁGINA/12, 2de julio de 2012)-.

En todas las notas, sea desde la adjetivación o desde las citas, es posible encontrar un interés por reconocer las experiencias y los puntos de vista juveniles. Como ejemplo, es posible señalar una nota donde se critican las políticas públicas de prevención de las adicciones de corte abstencionista y apocalípticas, y se cita a un funcionario cuando afirma que «esto causó una gran pérdida de credibilidad porque muchos estudiantes saben que otros consumen y no semurieron» (PÁGINA/12, 5 de junio de 2013).

CLARÍN es el medio que más se aleja de esta lectura de la Ley 26.774 de Ciudadanía Argentina, que posiciona a los jóvenes como sujetos de derecho y al Estado como la institución encargada de velar por los mismos. De esta manera, se observa cómo se distancia de las palabras de quienes describían así a la normativa:

\section{«CRISTINA LO DEFINIÓ COMO "UNA AMPLIACIÓN DE DERECHOS A NUESTROS JÓVENES”" (CLARÍN, 1 DE NOVIEMBRE DE 2012).}

Al mismo tiempo, y más que ningún otro medio, el diario hace explícita la representación de los jóvenes como sujetos factibles de ser fácilmente manipulados. 
«NO PODEMOS SER INGENUOS. DETRÁS DE UN DEBATE POR "MÁS DERECHOS", EL VOTO DE MENORES $Y$ EXTRANJEROS QUE IMPULSA EL GOBIERNO REVELA LA PRETENSIÓN DE "USARLOS” PARA MEJORAR LAS CHANCES ELECTORALES DE UNA REFORMA CONSTITUCIONAL QUE GARANTICE UN NUEVO MANDATO DE LA PRESIDENTA» (CLARÍN, 11 DE SEPTIEMBRE DE 2012).

“"QUEREMOS EDUCACIÓN Y NO ADOCTRINAMIENTO”. LA GENTE APLAUDÍA A SU PASO. ERA UNO DE LOS POCOS FOCOS DE ATENCIÓN EN UNA PLAZA SIN ESCENARIOS NI LIDERAZGOS. “¡ACÁ ESTAMOS LOS JÓVENES! ¡LA JUVENTUD NO ES DE LA CÁMPORA!", GRITÓ NACHO Y ERA CIERTO»

(CLARÍN, 14 DE SEPTIEMBRE DE 2012).

Además, junto con LA NACIÓN, es el medio que más lugar otorga a los funcionarios, a los legisladores y a los especialistas que esgrimen esta posición, en contraposición al resto de los medios que apelan, además, a voces que describen la nueva legislación electoral como una iniciativa de reconocimiento de derechos, a la vez que se alejan de caracterizar a los jóvenes como individuos más influenciables que el restode la sociedad.

Asimismo, si bien no es una estrategia narrativa común, en algunas ocasiones relaciona la nueva legislación electoral con datos estructurales sobre educación y empleo juvenil,con veladas impugnaciones a la capacidad y a la idoneidad de esos votantes.

«UNO DE CADA TRES JÓVENES VIVE EN HOGARES CON PLANES SOCIALES. SI SE LOS HABILITA A VOTAR DESDE LOS 16 AÑOS EN 2013 SUMARIAN 2,1 MILLONES DE NUEVOS ELECTORES. UN TERCIO DE ELLOS ES POBRE»

(CLARÍN, 2 DE SEPTIEMBRE DE 2012). 
Solo en una nota el diario matiza la construcción de sentidos predominante en torno al voto joven con un reconocimiento positivo.

«ESTÁ CLARO QUE QUIERE REFORMAR LA CONSTITUCIÓN SÓLO CON FINES REELECCIONISTAS Y QUE HUSMEA UN BUEN COTO DE CAZA EN LA COMARCA ADOLESCENTE. PERO ESO NO CONVIERTE EN DESCARTABLES TODAS LAS INICIATIVAS QUE PONE EN MARCHA PARA ALCANZAR ESOS FINES. Y EL VOTO JOVEN ES UNA DE ELLAS [...]. EL PROYECTO AMPLÍA DERECHOS Y, A SU MODO, CONSTRUYE CIUDADANÍA»

(CLARÍN, 3 DE SEPTIEMBRE DE 2012).

Por fuera del tema de la Ley 26.774, este medio no hace prácticamente ninguna mención a programas, a planes o a proyectos estatales que tengan como destinatarios a jóvenes. Apenas menciona en una nota:

«EN LA EXPO EMPLEO JOVEN, QUE LLEVA ADELANTE EL GOBIERNO PORTEÑO HASTA HOY EN EL CENTRO MUNICIPAL DE EXPOSICIONES (FIGUEROA ALCORTA Y PUEYRREDÓN), PRESENTARON AYER EL PORTAL DE EMPLEO DE LA CIUDAD, EL PRIMERO ESTATAL Y GRATUITO DE TODO EL PAÍS» (CLARÍN, 4 DE OCTUBRE DE 2012).

Todas las notas que este medio elabora a partir de estadísticas persiguen el objetivo de diagnosticar el nivel de fracaso en las políticas públicas de educación y empleo.

«LOS ÚLTIMOS DATOS DEL CENSO 2010, QUE DIO A CONOCER EL INDEC EN ESTOS DÍAS, DAN CUENTA DE QUE EL 18,4\% DE LOS CHICOS DE ENTRE 15 Y 17 AÑOS SIGUE SIN IR AL COLEGIO. Y QUE EL LEVE AU- 
MENTO DE LA MATRÍCULA EN ESA FRANJA -2,1\% CON RESPECTO A 2001- SÓLO ALCANZÓ A EQUIPARAR EL CRECIMIENTO POBLACIONAL»

(CLARÍN, 3 DE JULIO DE 2012).

Estas descripciones macroestructurales de unos jóvenes deteriorados y abandonados se complementan con testimonios de especialistas que hacen referencia a la incapacidadde la sociedad para incluir a ciertos sectores.

«TUÑON AGREGÓ QUE “A PARTIR DE LOS 15 AÑOS, MUCHOS CHICOS BUSCAN OTROS PROYECTOS QUE CONSIDERAN MÁS 'EXITOSOS' QUE EL SECUNDARIO, COMO UN TRABAJO, HACER CHANGAS O, EN EL CASO DE LAS CHICAS, FORMAR UNA FAMILIA"» (CLARÍN, 3 DE JULIO DE 2012).

También abundan las referencias a supuestas actitudes del estado nacional que darían cuenta de una falta de atenciónsobre las problemáticas de dichos sectores.

«EN EL CONGRESO YA HAY AL MENOS DIEZ PROYECTOS DE LEY QUE IMPULSAN EL BOLETO GRATUITO, TANTO DE LA OPOSICIÓN COMO DEL OFICIALISMO, PERO NINGUNO TIENE SIQUIERA DICTAMEN DE COMISIÓN»

(CLARÍN, 20 DE SEPTIEMBRE DE 2012).

«EL PROYECTO PERTENECE AL MISMO BLOQUE PARLAMENTARIO QUE SE HA NEGADO SISTEMÁTICAMENTE A DAR TRATAMIENTO A LA CONVENCIÓN

IBEROAMERICANA DE DERECHO DE LOS JÓVENES» (CLARÍN, 19 DE SEPTIEMBRE DE 2012). 


\section{De la desesperanza a la reconstrucción: al $70 \%$ de los jóvenes les interesa la política}

En este capitulo presentaremos el análisis de dos encuestas realizadas en la ciudad de La Plata. La tesis que subyace a este trabajo enfoca a la recuperación de la participación juvenil en el espacio público, ya que desde la política institucionalizada se esta convocando a los hijos de aquellos que pasionalmente habían dicho "que se vayan todos ". Saintout (2013) sostiene que "estos jóvenes (hermanos menores e hijos de los que rechazaron la política) responden asumiendo que tienen un lugar en la historia". Vemos con Saintout que la última década se caracteriza por la interpelación desde un proyecto político a los y las jóvenes como sujetos de derecho a través de un discurso que les asigna un lugar en la trama social al mismo tiempo que los habilita para la constitución de sus propios discursos. Es este un tiempo en el que se convoca a de los jóvenes a que participen de la vida pública con un horizonte de derechos que los interpela a realizar los sueños.

Es así que la primera lectura que podemos hacer de la encuesta realizada en octubre de 2012, muestra que el $70 \%$ de los jóvenes manifiestan interés por las cuestiones políticas : 


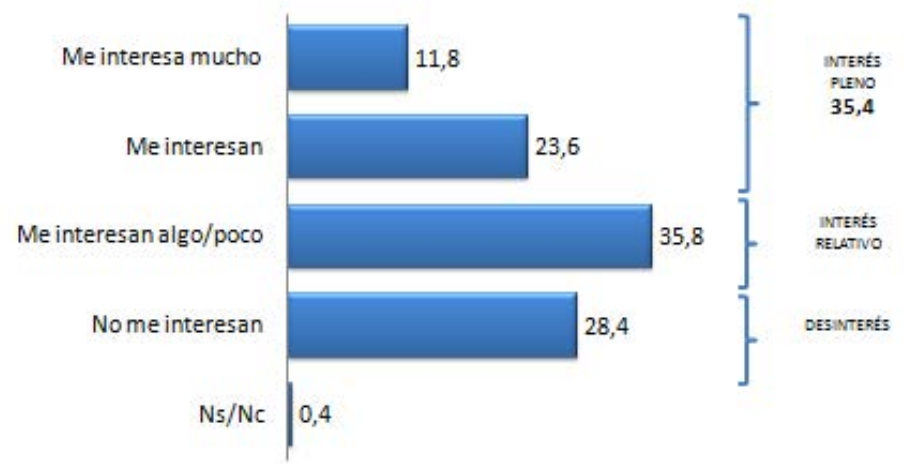

A pesar de ello, el discurso dominante a la hora de nombrar la relación entre política y juventud continúa siendo el de la comparación con los jóvenes de la década de '70, asi como el de la apatía y la incapacidad de agenciamiento político mas allá de las protestas estudiantiles ${ }^{1}$. A ello se le suma, una mirada acusadora que de un lado vincula el interés de la política ligado tanto a la profesionalización de la misma (en la medida en que se le atribuyen intereses que se vinculan a la política como un trabajo, pero también al ocultamiento ideológico) y del otro lado ubica a los jóvenes en el lugar de victimas, ingenuos o inocentes, usados por la política.

En un contexto como el argentino, ligado al proceso de reestructuración y recomposición del Estado a partir de 2003, la apuesta estatal estuvo orientada a reconquistar las capacidades territoriales, incluir a las organizaciones sociales y comunitarias en la recuperación de la participación y construc-

\footnotetext{
${ }^{1}$ Ver el capítulo Informe sobre las representaciones mediáticas de la participación política juvenil
} 
ción colectiva de ciudadanía, con un concepto claro: superar el concepto de "beneficiario" por el de "sujeto de derecho". En este sentido, los avances registrados en la última década respecto a la ampliación de derechos se tradujeron en leyes que garantizan importantes derechos sociales, políticos y civiles que permiten mayores niveles de inclusión de los jóvenes. Se destacan así la Ley de Protección Integral de los Derechos de Niños, Niñas y Adolescentes, La Ley de Creación del Consejo Federal de Juventud, la Ley de Educación Nacional (obligatoriedad de la escuela secundaria), la Ley de Ciudadanía Argentina (ampliación del derecho a voto a los jóvenes de 16 y 17 años) y la Ley de Conformación de Centros de Estudiantes Secundarios.

A la par de estos avances normativos se diseñaron políticas desde y con las juventudes, ejecutadas transversalmente por diversas áreas de gobierno.

A la par de estos avances normativos se diseñaron políticas desde y con las juventudes, ejecutadas transversalmente por diversas reas de gobierno. Por ejemplo, el Programa de Salud Sexual y Procreación Responsable, la Asignación Universal por Hijo, el Programa Conectar Igualdad y el Programa Jóvenes con Más y Mejor Trabajo. Todas estas son políticas con enfoque de derechos orientadas a garantizar condiciones de vida dignas de este sector mediante inversión pública en materia de seguridad social.

De este modo podemos ver que los jóvenes, también manifiestan mayoritariamente interesarse e informarse por cuestiones de índole políticas: 


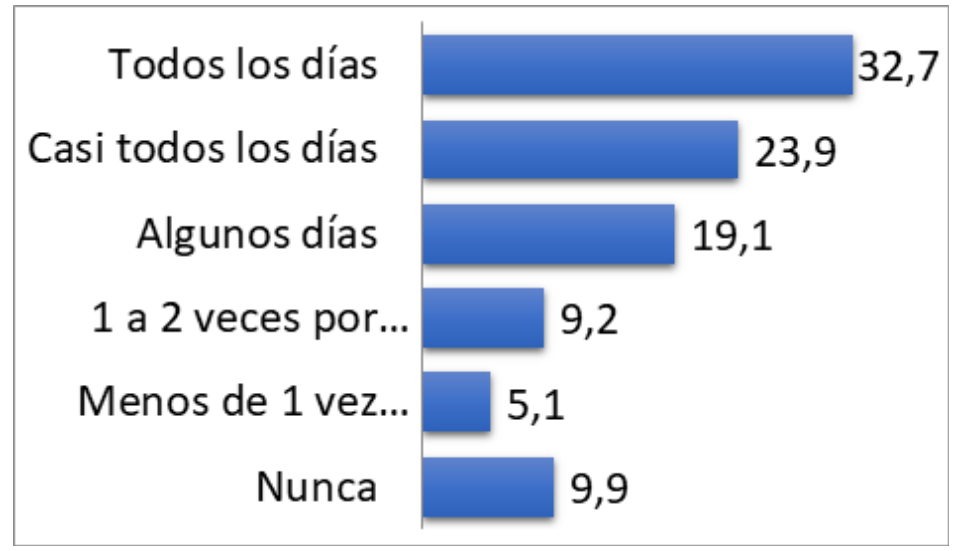

Este carácter inclusivo y redistributivo de las políticas económicas y sociales implementadas ha posibilita que amplios grupos de la población joven repiensen sus trayectorias de vida en los distintos ámbitos: sanitario, educativo, productivo, social, laboral y cultural. A su vez, de este modo se promueve el involucramiento de los jóvenes en el espacio político y social de su comunidad, y que responde a la necesidad de fortalecer prácticas y valores democráticos en la ciudadanía.

En este sentido y ante la pregunta por la participación en actividades políticas estudiantiles, el 47,9\% respondió que participa activamente:

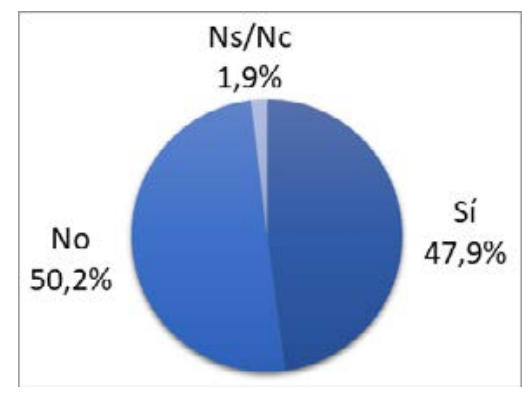


Avanzando en el análisis de la encuesta, que se desarrolló en dos periodos: octubre de 2012 y junio de 2013, relevando 727 casos en la primera etapa y 717 en la segunda, otra variable que vamos a analizar es aquella aquella que parte de la pregunta acerca del acuerdo o desacuerdo que los jóvenes manifiestan en relación al voto joven. La encuesta relevada en 2012 muestra mayor desacuerdo con la medida, casi el $36 \%$ de los encuestados de 2013 estuvieron de acuerdo con el proyecto de ley.
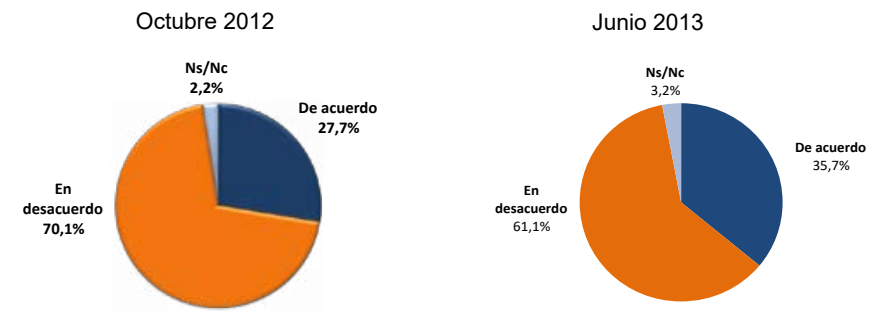

En este sentido, no podemos dejar de preguntarnos y de establecer vínculos entre el contexto mediático y la interpretación de los jóvenes respecto de la ley. Así, aquí se destaca en el relevamiento de artículos periodísticos, en el apartado ya mencionado, mas del $47 \%$ se refieren y enuncian respecto al voto joven y a las prácticas políticas juveniles, especialmente a la organización política juvenil La Cámpora, desde la deslegitimación y estigmatización.

Estas narrativas periodísticas reveladas en el informe, señalan que los jóvenes son manipulados por intereses que no son propios, sino de los adultos y dirigentes altamente po- 
litizados, que los utilizan como instrumentos para sus fines, que no declaran sino que los ocultan detrás de medidas que aparentan ser de inclusión. Además de presentar a los jóvenes como incapaces e inmaduros. Las posturas ante la capacidad de los jóvenes de elegir a sus representantes como también de los oscuros intereses del go- bierno nacional de convertir en ley el proyecto, se visibilizaron claramente. Por citar sólo algunos, mencionaremos los artículos del diario La Nación titulados "Fuerte ofensiva oficial para que se vote desde los 16 años" (30/6/12), "Fuerte polémica por el voto juvenil" (31/6/12), "La UCR y Moyano, contra la reforma" (10/9/12) y en Clarín "Jóvenes y extranjeros, ciudadanos solamente a la hora de votar" (11/9/12) y "Votar a los 16: ¿nuevo derecho o maniobra distractiva?" (19/9/12).

Sin embargo, a medida que pasaron los meses, y la ley de transformó en un derecho para los jóvenes, podemos ver como en la segunda etapa de la encuesta - realizada 8 meses después- el nivel de acuerdo con el llamado voto joven creció en un $10 \%$, en una clara coincidencia con el aumento de circulación de la información acerca del contenido y modo de implementación de la ley y el decrecimiento de los discursos mediáticos estigmatizantes sobre el tema: en este momento, los artículos al respecto se redujeron a un total de 17 (de los 130 publicados por la prensa durante la primera etapa). 


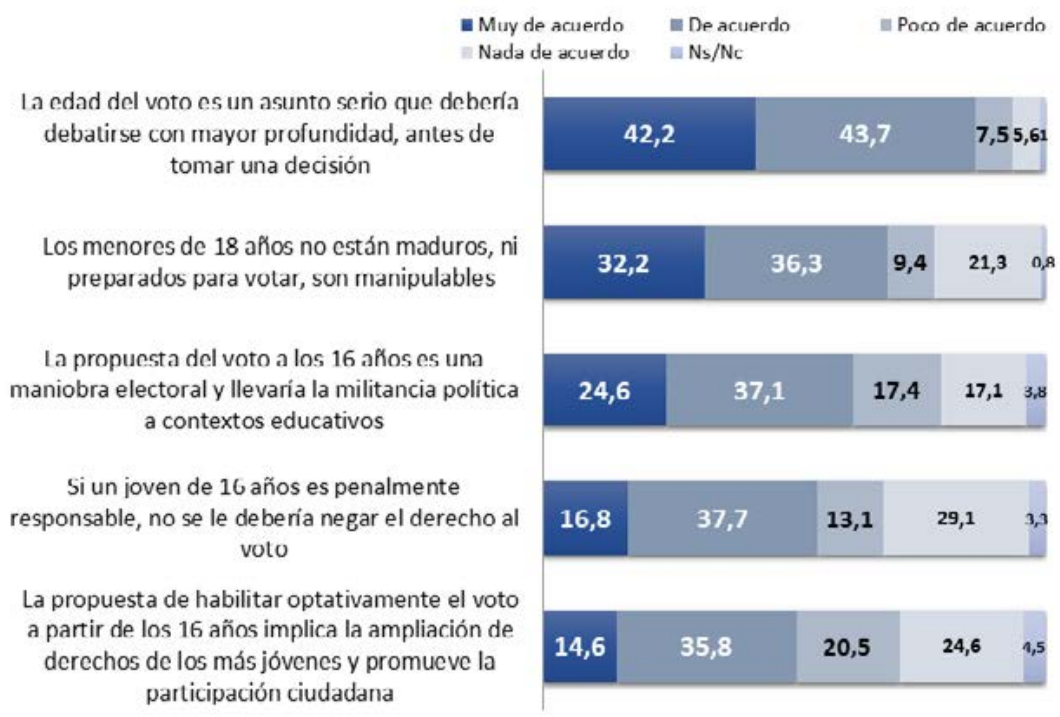

\section{La política y la masculinidad moderna}

Otro de los datos claves que aporta el análisis de los datos relevados por las encuestas tiene que ver con la dimensión del género. Ante la pregunta ¿vas a participar? las jóvenes mujeres respondieron por la negativa mayoritariamente $(51,1 \%)$ , mientras que los varones afirmaron que sí lo harían en un $48,8 \%$. Con relación al grado de acuerdo o desacuerdo con la ley se repite la tendencia: solo un $29.9 \%$ de las mujeres está. de acuerdo, mientras que entre los jóvenes varones el acuerdo supera el $41 \%$. Tales datos, históricamente situados, dan cuenta de que, a pesar de las transformaciones en el orden del reconocimiento de derecho de las mujeres, aún se hallan arraigadas las estructuras patriarcales que nos conducen a 
continuar preguntándonos acerca de cómo es que la política continúa siendo un asunto fuertemente ligado a la masculinidad (moderna, blanca, heterosexual).

¿Vas a participar?

Según Sexo, Nivel socio-económico y Zona

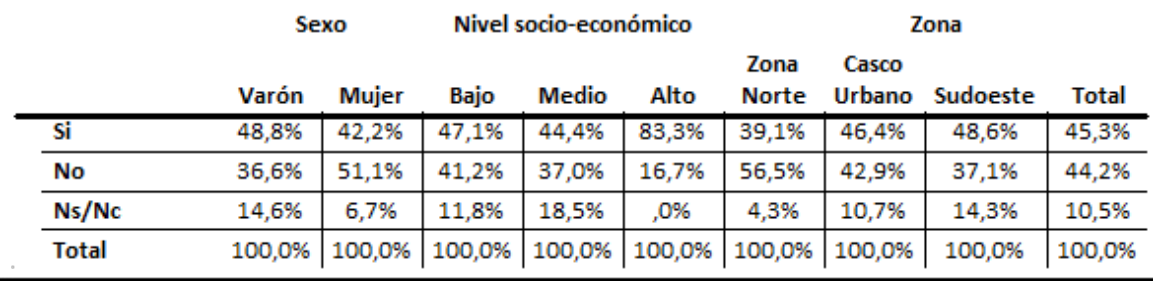

Finalmente, este estudio da cuenta de la relevancia de abordar la relación jóvenes, medios de comunicación y política atendiendo críticamente a cómo es que los relatos mediáticos, masivos y hegemónicos operan desde las lógicas de la ahistorización, la exclusión y la fragmentación. Las Ciencias Sociales tienen el deber de comprometerse con las demandas de los pueblos y de reflexionar desde una epistemología de la reconstrucción que permita desandar los modos en que son narrados los jóvenes y sus prácticas de participación política, a la vez que atienda a pensar nuevos caminos para la transformación, para la emancipación. 


\section{SONDEO 2012}

INFORMACION BASICA

\section{SONDEO JÓVENES}

OBJETIVO: ESTE RELEVAMIENTO BUSCA APORTAR UNA MIRADA SOBRE ALGUNOS INDICADORES DE INTERÉS, PERCEPCIÓN Y PRACTICA POLÍTICA ENTRE LOS JÓVENES DE 16 y 30 AÑOS RESIDENTES EN EL DEL PARTIDO DE LA PLATA.

ASPECTOS ANALÍTICOS ABORDADOS: INTERÉS POR LAS CUESTIONES POLÍTICAS, SEGUIMIENTO DE CUESTIONES POLÍTICAS, MEDIO DE SEGUIMIENTO DE LAS CUESTIONAES POLITICAS, DISCUSIÓN DE LA CUESTION POLITICA, PARTICIPACION EN PRACTICAS POLITICAS ESPECIFICAS, INFLUENCIS POLÍTICAS, USO DE INTERNET Y REDES SOCIALES. PERCEPCIONES SOBRE.

REFERENCIAS TÉCNICAS: ÁMBITO: PARTIDO DE LA PLATA, TIPO DE RELEVAMIENTO: ENCUESTA PERSONAL, INSTRUMENTO : CUESTIONARIO ESTRUCTURADO; POBLACIÓN 16 AÑOS o MÁS EN CONDICIONES 
DE VOTAR; MUESTREO: PROBABILÍSTICO, POR CONGLOMERADOS POLIETÁPICOS, CON SELECCIÓN DE LA UNIDAD FINAL SEGÚN CUOTAS DE EDAD y SEXO SEGÚN CENSO 2010; TAMAÑO DE LA MUESTRA: 727 CASOS EFECTIVOS; SUBMUESTRA JÓVENES: 300 CASOS; ERROR MUESTRAL GLOBAL: +/-3,1\%, NIVEL DE CONFIANZA: 95\%, FECHA DE RELEVAMIENTO: 13 y 14 DE OCTUBRE DE 2012

\section{INTERES POR LAS CUESTIONES POLITICAS}

GRAFICO 1.

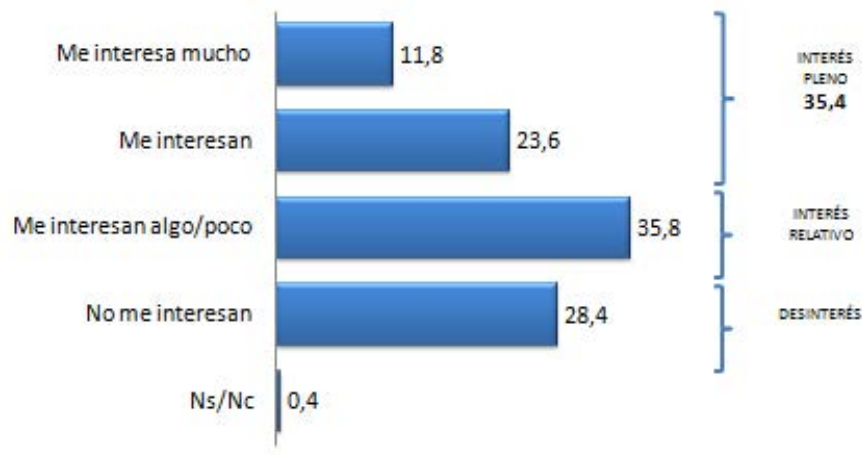


INTERÉS POR LAS CUESTIONES POLÍTICAS

GRAFICO 2.

FRECUENCIA DE INFORMACIÓN o SEGUIMIENTO DE LAS CUESTIONES POLÍTICAS

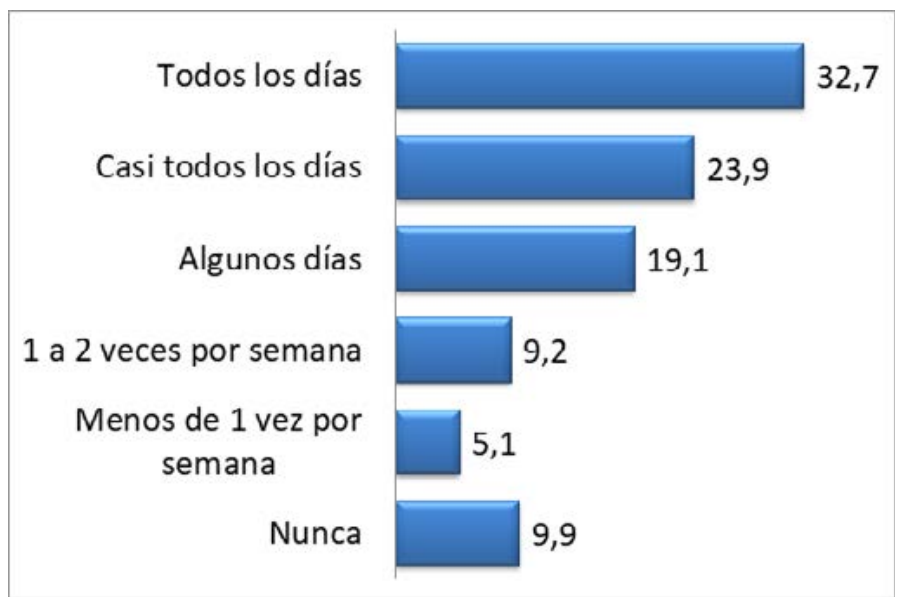

\section{GRAFICO 3.}

MEDIO DE INFORMACIÓN MÁS FRECUENTEMENTE USADO PARA INFORMARSE y/o SEGUIR LAS CUESTIONES POLÍTICAS

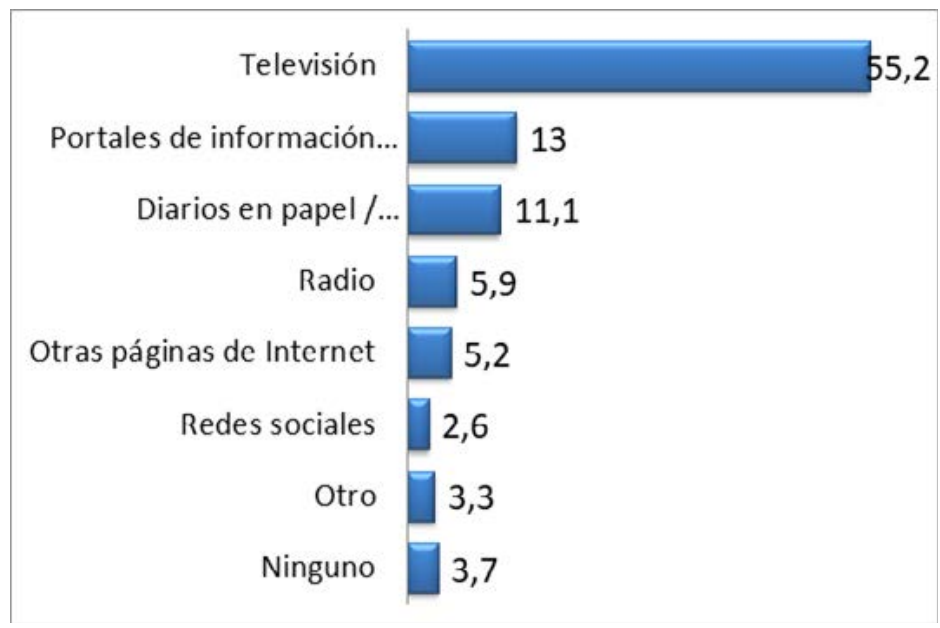


GRAFICO 4.

FRECUENCIA DE DISCUSIÓN DE CUESTIONES POLÍTICAS

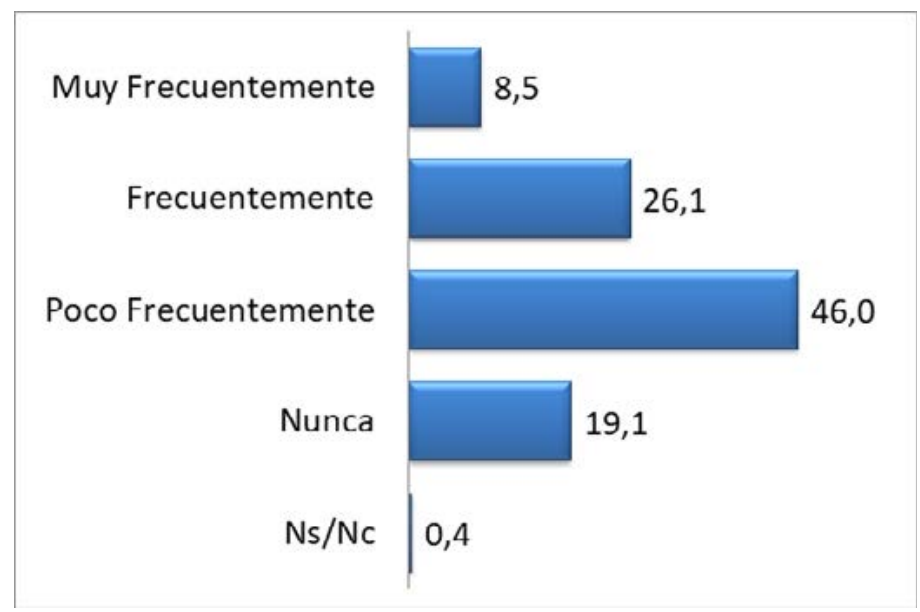

GRAFICO 6. PARTICIPACIÓN EN ACTIVIDADES POLÍTICAS ESTUDIANTILES

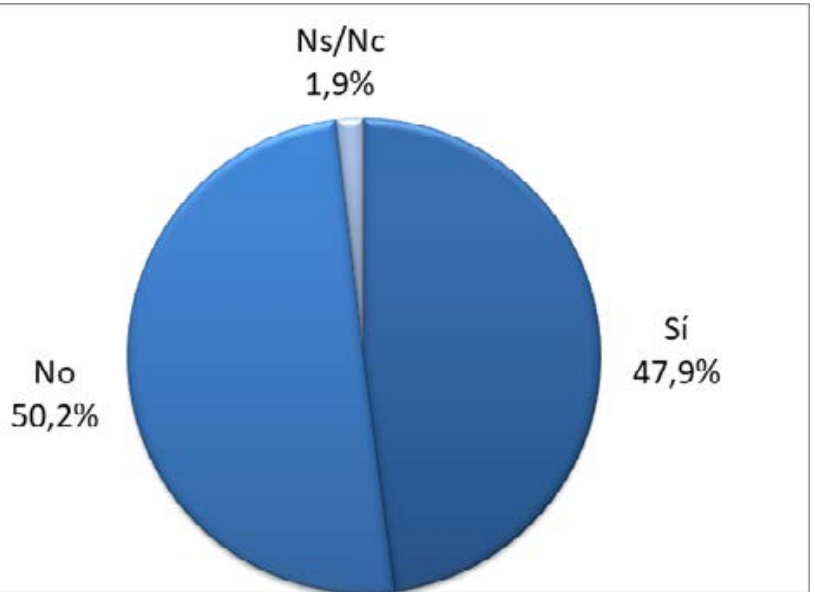

JÓVENES Y POLÍTICA: UNA MIRADA DESDE LA COMUNICACIÓN 
GRAFICO 7. TIPO DE PARTICIPACIÓN EN ACTIVIDADES POLÍTICAS ESTUDIANTILES

\begin{tabular}{|c|c|c|c|}
\hline \multirow[b]{2}{*}{$\begin{array}{l}\text { Asistir a una reunión o } \\
\text { asamblea estudiantil }\end{array}$} & & $\square$ NO & \\
\hline & 34,1 & 63,6 & 2,3 \\
\hline $\begin{array}{l}\text { Participar en una } \\
\text { protesta estudiantil }\end{array}$ & 22,6 & 75,5 & 1,9 \\
\hline $\begin{array}{l}\text { Ser representante del } \\
\text { curso / año / facultad }\end{array}$ & 18,5 & 79,6 & 1,9 \\
\hline $\begin{array}{c}\text { Ser miembro del centro } \\
\text { de estudiantes }\end{array}$ & 10,0 & 88,1 & 1,9 \\
\hline $\begin{array}{c}\text { Presentarte como } \\
\text { candidato en... }\end{array}$ & 6,1 & 92,0 & 1,9 \\
\hline
\end{tabular}

\section{AMPLIACION DEL VOTO}

¿Sabias que ya está vigente una Ley que permite a los jóvenes de 16 y 17 años, votar optativamente en las elecciones a partir de este año (optativamente)?

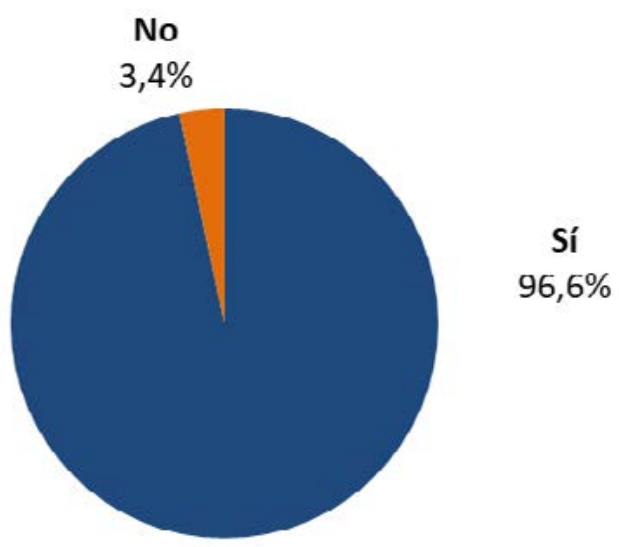


¿Vas a participar?

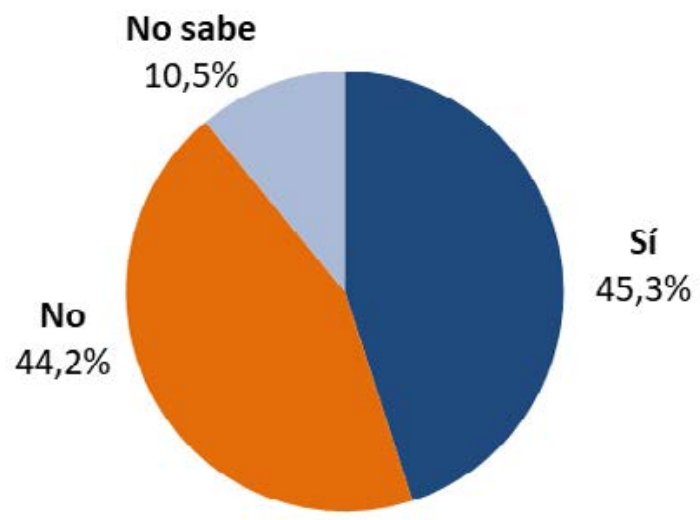

¿Vas a participar?

Según Sexo, Nivel socio-económico y Zona

\begin{tabular}{|c|c|c|c|c|c|c|c|c|c|}
\hline & \multicolumn{2}{|c|}{ Sexo } & \multicolumn{3}{|c|}{ Nivel socio-económico } & \multicolumn{4}{|c|}{ Zona } \\
\hline & Varón & Mujer & Bajo & Medio & Alto & $\begin{array}{l}\text { Zona } \\
\text { Norte }\end{array}$ & $\begin{array}{l}\text { Casco } \\
\text { Urbano }\end{array}$ & Sudoeste & Total \\
\hline $\mathrm{Si}$ & $48,8 \%$ & $42,2 \%$ & $47,1 \%$ & $44,4 \%$ & $83,3 \%$ & $39,1 \%$ & $46,4 \%$ & $48,6 \%$ & $45,3 \%$ \\
\hline No & $36,6 \%$ & $51,1 \%$ & $41,2 \%$ & $37,0 \%$ & $16,7 \%$ & $56,5 \%$ & $42,9 \%$ & $37,1 \%$ & $44,2 \%$ \\
\hline $\mathrm{Ns} / \mathrm{Nc}$ & $14,6 \%$ & $6,7 \%$ & $11,8 \%$ & $18,5 \%$ & $0 \%$ & $4,3 \%$ & $10,7 \%$ & $14,3 \%$ & $10,5 \%$ \\
\hline Total & $100,0 \%$ & $100,0 \%$ & $100,0 \%$ & $100,0 \%$ & $100,0 \%$ & $100,0 \%$ & $100,0 \%$ & $100,0 \%$ & $100,0 \%$ \\
\hline
\end{tabular}

\section{Acuerdo con la Ley que promueve el voto optativo de los} jóvenes de 16 y 17 años

\section{Comparación}



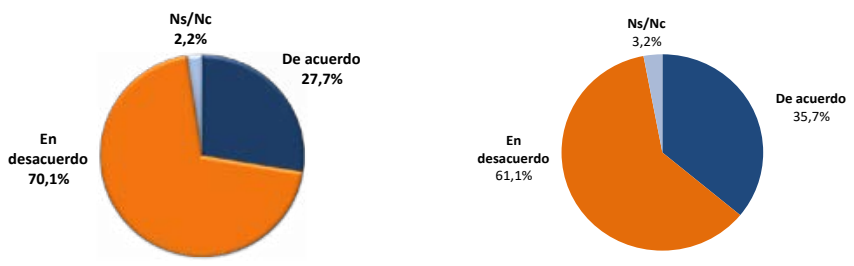

\section{GRAFICO 13. GRADO DE ACUERDO CON ARGUMENTOS SOBRE LA PROPUESTA DE HABILITAR EL VOTO A LOS 16 AÑOS}

Acuerdo/Desacuerdo con la Ley que promueve el voto optativo de los jóvenes de 16 y 17 años Según Sexo, Nivel socio-económico y Zona

\begin{tabular}{|c|c|c|c|c|c|c|c|c|c|}
\hline & \multicolumn{2}{|c|}{ Sexo } & \multicolumn{3}{|c|}{ Nivel socio-económico } & \multicolumn{4}{|c|}{ Zona } \\
\hline & Varón & Mujer & Bajo & Medio & Alto & $\begin{array}{l}\text { Zona } \\
\text { Norte }\end{array}$ & $\begin{array}{l}\text { Casco } \\
\text { Urbano }\end{array}$ & Sudoeste & Total \\
\hline De acuerdo & $41,5 \%$ & $29,9 \%$ & $47,6 \%$ & $33,0 \%$ & $35,2 \%$ & $38,3 \%$ & $29,7 \%$ & $38,6 \%$ & $35,7 \%$ \\
\hline En desacuerdo & $55,1 \%$ & $67,0 \%$ & $46,6 \%$ & $63,5 \%$ & $61,5 \%$ & $59,7 \%$ & $66,4 \%$ & $57,9 \%$ & $61,1 \%$ \\
\hline $\mathrm{Ns} / \mathrm{Nc}$ & $3,4 \%$ & $3,0 \%$ & $5,8 \%$ & $3,5 \%$ & $3,3 \%$ & $1,9 \%$ & $3,9 \%$ & $3,6 \%$ & $3,2 \%$ \\
\hline Total & $100,0 \%$ & $100,0 \%$ & $100,0 \%$ & $100,0 \%$ & $100,0 \%$ & $100,0 \%$ & $100,0 \%$ & $100,0 \%$ & $100,0 \%$ \\
\hline
\end{tabular}

Razón del Acuerdo con la Ley que promueve el voto optativo de los jóvenes de 16 y 17 años

\begin{tabular}{lc} 
& Porcentaje \\
\hline Están capacitados & $19,7 \%$ \\
\hline Iguala/amplía derechos y da mayor participación a los jóvenes & $17,3 \%$ \\
\hline Es una buena medida & $14,1 \%$ \\
\hline Los inserta en la vida política & $13,3 \%$ \\
\hline Tienen derecho a votar & $11,6 \%$ \\
\hline Son maduros como para elegir & $11,2 \%$ \\
\hline Otros & $7,2 \%$ \\
\hline Ns/Nc & $5,6 \%$ \\
\hline Total & $100,0 \%$ \\
\hline
\end{tabular}




\begin{tabular}{|c|c|c|c|c|c|c|c|c|c|c|}
\hline \multicolumn{11}{|c|}{$\begin{array}{l}\text { Razon del Acuerdo con la Ley que promueve el voto optativo de los jóvenes de } 16 \text { y } 17 \text { años } \\
\text { Seguin Sexo, Grupo de edad y Nivel socioeconómico }\end{array}$} \\
\hline & \multicolumn{2}{|c|}{ Sexo } & \multicolumn{4}{|c|}{ Grupo de edad } & \multicolumn{4}{|c|}{ Nivel socio-económico } \\
\hline & Varón & Mujer & 16 a 17 & 18 a 30 & 31 a 50 & $51 y$ & Bajo & Medio & Alto & Total \\
\hline Están capacitados & $18,2 \%$ & $21,9 \%$ & $16,7 \%$ & $14,5 \%$ & $23,7 \%$ & $19,5 \%$ & $14,6 \%$ & $25,3 \%$ & $14,3 \%$ & $19,7 \%$ \\
\hline $\begin{array}{l}\text { Iguala/amplia derechos y da mayor } \\
\text { participación a los jóvenes }\end{array}$ & $17,5 \%$ & $17,1 \%$ & $13,9 \%$ & $23,6 \%$ & $21,1 \%$ & $10,4 \%$ & $16,7 \%$ & $16,2 \%$ & $19,0 \%$ & $17,3 \%$ \\
\hline Es una buena medida & $11,2 \%$ & $18,1 \%$ & $25,0 \%$ & $10,9 \%$ & $15,8 \%$ & $9,1 \%$ & $12,5 \%$ & $11,1 \%$ & $23,8 \%$ & $14,1 \%$ \\
\hline Los inserta en la vida politica & $17,5 \%$ & $7,6 \%$ & $11,1 \%$ & $20,0 \%$ & $7,9 \%$ & $15,6 \%$ & $10,4 \%$ & $13,1 \%$ & $14,3 \%$ & $13,3 \%$ \\
\hline Tienen derecho a wotar & $8,4 \%$ & $16,2 \%$ & $13,9 \%$ & $10,9 \%$ & $14,5 \%$ & $9,1 \%$ & $20,8 \%$ & $13,1 \%$ & $2,4 \%$ & $11,3 \%$ \\
\hline Son maduros como para elegir & $13,3 \%$ & $8,6 \%$ & $2,8 \%$ & $10,9 \%$ & $9,2 \%$ & $18,2 \%$ & $12,5 \%$ & $12,1 \%$ & $9,5 \%$ & $11,2 \%$ \\
\hline Otros & $8,4 \%$ & $4,8 \%$ & $5,6 \%$ & $7,3 \%$ & $2,6 \%$ & $11,7 \%$ & $10,4 \%$ & $4,0 \%$ & $14,3 \%$ & $5,0 \%$ \\
\hline $\mathrm{Ns} / \mathrm{Nc}$ & $5,6 \%$ & $4,8 \%$ & $11,1 \%$ & $1,8 \%$ & $5,3 \%$ & $5,2 \%$ & $2,1 \%$ & $5,1 \%$ & $2,4 \%$ & $11,5 \%$ \\
\hline Total & $100,0 \%$ & $100,0 \%$ & $100,0 \%$ & $100,0 \%$ & $100,0 \%$ & $100,0 \%$ & $100,0 \%$ & $100,0 \%$ & $100,0 \%$ & $100,0 \%$ \\
\hline
\end{tabular}

Razón del Desacuerdo con la Ley que promueve el voto optativo de los jóvenes de 16 y 17 años Según Zona

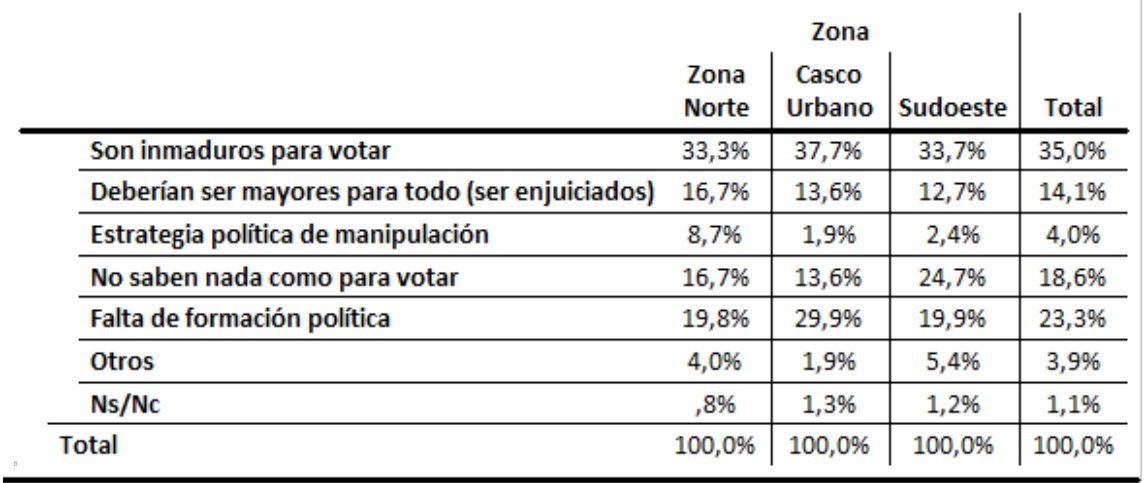




\section{TABLA Y CRUCES DE INDICADORES}

¿Cuál es el principal problema más grave de La Plata? * Nivel socio-económico

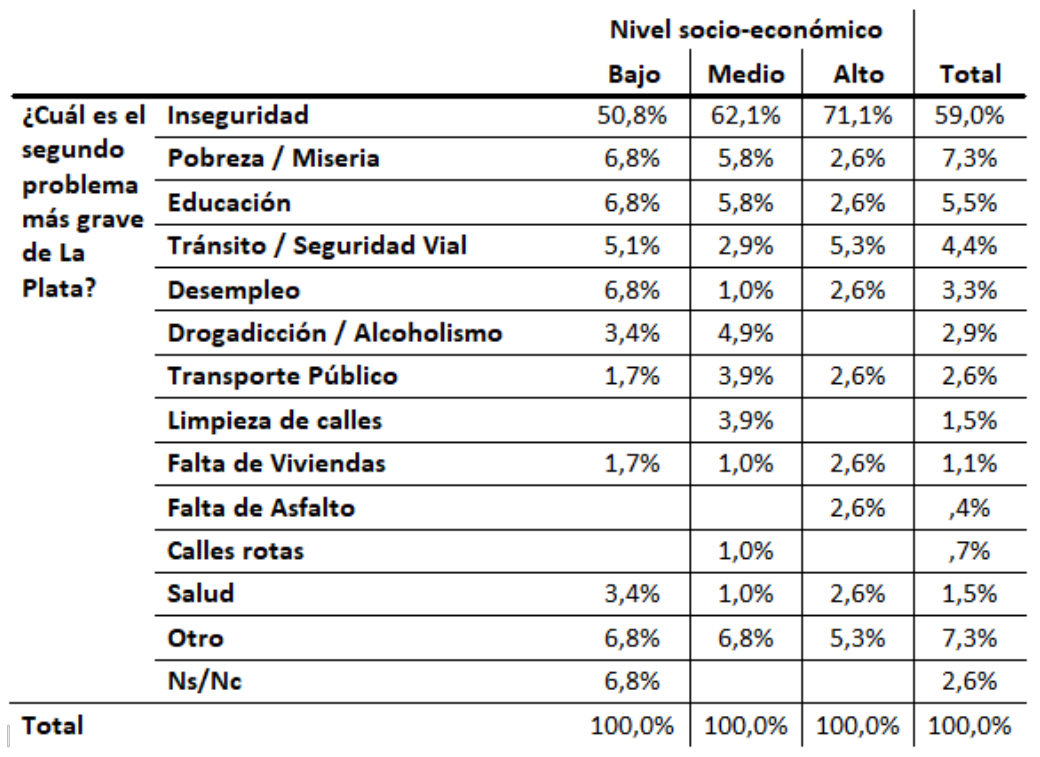




\section{LA PLATA JUNIO 2013}

- ÁMBITO GEOGRÁFICO: PARTIDO DE LA PLATA

- TIPO DE ESTUDIO: ENCUESTA POR TIMBREO

- INSTRUMENTO DE RECOLECCIÓN: CUESTIONARIO ESTRUCTURADO

- UNIVERSO: POBLACIÓN MAYOR DE 16 AÑOS EN CONDICIONES DE VOTAR

- MUESTREO: SE ESTRUCTURARON 3 CONGLOMERADOS GEOGRÁFICOS (CASCO URBANO, ZONA SUDOESTE Y ZONA NORTE) Y SE DESARROLLÓ UN MUESTREO PROBABILÍSTICO, POLIETÁPICO, CON SELECCIÓN DE LA UNIDAD FINAL SEGÚN CUOTAS DE EDAD Y SEXO

- TAMAÑO DE LA MUESTRA: 717 CASOS EFECTIVOS

- ERROR MUESTRAL: +/- 3,8\%

- NIVEL DE CONFIANZA: 95\%

- FECHA DE RELEVAMIENTO: 8 y 9 DE JUNIO DE 2013

¿Sabias que ya está vigente una Ley que permite a los jóvenes de 16 y 17 años, votar optativamente en las elecciones a partir de este año (optativamente)? 


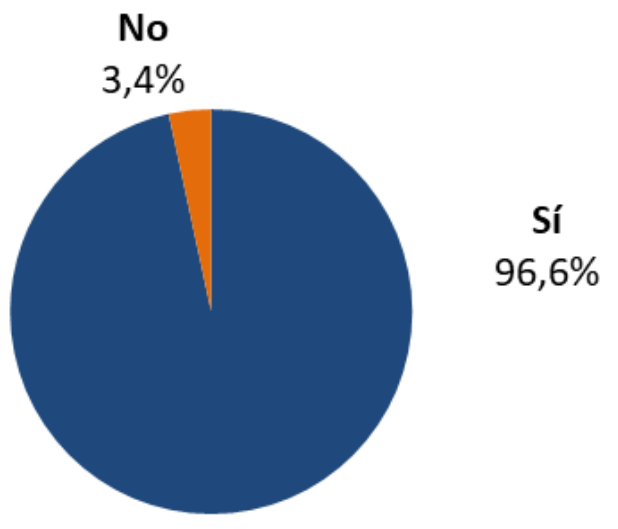

¿Sabias que ya está vigente una Ley que permite a los jóvenes de 16 y 17 años, votar optativamente en las elecciones a partir de este año (optativamente)?

Según Sexo, Nivel socio-económico y Zona

Sexo

Nivel socio-económico

Zona

Zona Casco

\begin{tabular}{|c|c|c|c|c|c|c|c|c|c|}
\hline & Varón & Mujer & Bajo & Medio & Alto & Norte & Urbano & Sudoeste & Total \\
\hline $\mathrm{Si}$ & $95,1 \%$ & $97,8 \%$ & $100,0 \%$ & $92,6 \%$ & $100,0 \%$ & $91,3 \%$ & $100,0 \%$ & $97,1 \%$ & $96,6 \%$ \\
\hline No & $4,9 \%$ & $2,2 \%$ & ,0\% & $7,4 \%$ &, $0 \%$ & $8,7 \%$ & ,0\% & $2,9 \%$ & $3,4 \%$ \\
\hline $\mathrm{Ns} / \mathrm{Nc}$ &, $0 \%$ & ,0\% & ,0\% & ,0\% & ,0\% & ,0\% & ,0\% & ,0\% & ,0\% \\
\hline Total & $100,0 \%$ & $100,0 \%$ & $100,0 \%$ & $100,0 \%$ & $100,0 \%$ & $100,0 \%$ & $100,0 \%$ & $100,0 \%$ & $100,0 \%$ \\
\hline
\end{tabular}

\section{¿Vas a participar?}

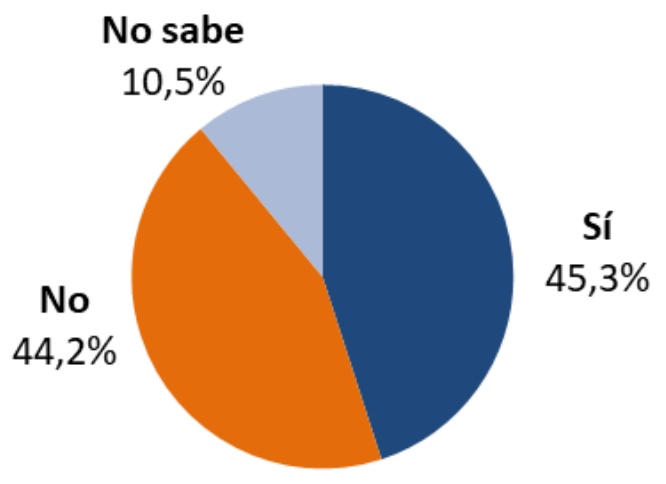

JÓVENES Y POLÍTICA: UNA MIRADA DESDE LA COMUNICACIÓN 
¿Vas a participar?

Según Sexo, Nivel socio-económico y Zona

\begin{tabular}{|c|c|c|c|c|c|c|c|c|c|}
\hline & \multicolumn{2}{|c|}{ Sexo } & \multicolumn{3}{|c|}{ Nivel socio-económico } & \multicolumn{4}{|c|}{ Zona } \\
\hline & Varón & Mujer & Bajo & Medio & Alto & $\begin{array}{c}\text { Zona } \\
\text { Norte }\end{array}$ & $\begin{array}{c}\text { Casco } \\
\text { Urbano }\end{array}$ & Sudoeste & Total \\
\hline $\mathrm{Si}$ & $48,8 \%$ & $42,2 \%$ & $47,1 \%$ & $44,4 \%$ & $83,3 \%$ & $39,1 \%$ & $46,4 \%$ & $48,6 \%$ & $45,3 \%$ \\
\hline No & $36,6 \%$ & $51,1 \%$ & $41,2 \%$ & $37,0 \%$ & $16,7 \%$ & $56,5 \%$ & $42,9 \%$ & $37,1 \%$ & $44,2 \%$ \\
\hline $\mathrm{Ns} / \mathrm{Nc}$ & $14,6 \%$ & $6,7 \%$ & $11,8 \%$ & $18,5 \%$ & $0 \%$ & $4,3 \%$ & $10,7 \%$ & $14,3 \%$ & $10,5 \%$ \\
\hline Total & $100,0 \%$ & $100,0 \%$ & $100,0 \%$ & $100,0 \%$ & $100,0 \%$ & $100,0 \%$ & $100,0 \%$ & $100,0 \%$ & $100,0 \%$ \\
\hline
\end{tabular}

Pregunta realizada a la totalidad de los encuestados

El Congreso de la Nación aprobó la Ley que promueve el voto optativo de los jóvenes de 16 y 17 años, y en estas elecciones ya se va a implementar. Ud., esta de acuerdo o en desacuerdo con esta medida?

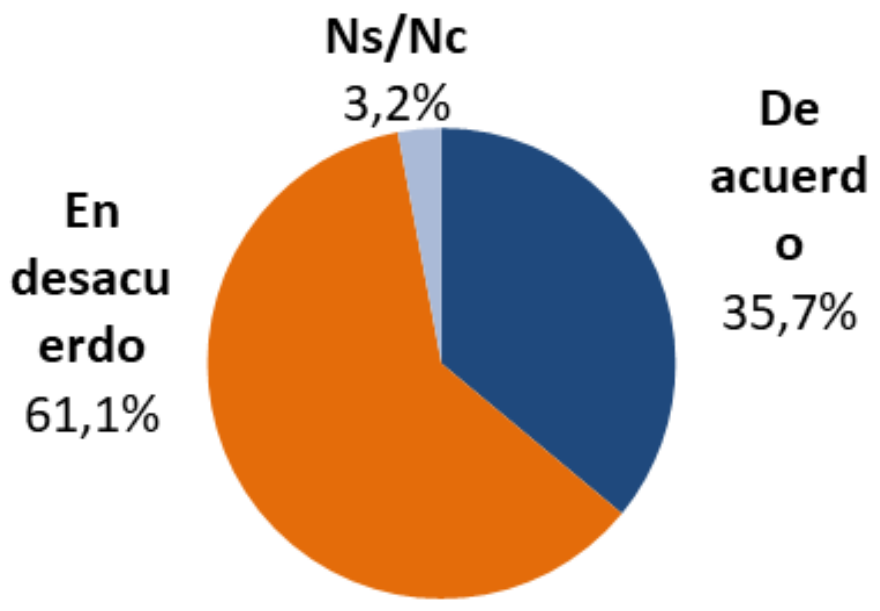




\section{Acuerdo con la Ley que promueve el voto optativo de los jóve- nes de 16 y 17 años \\ Comparación}

Octubre 2012

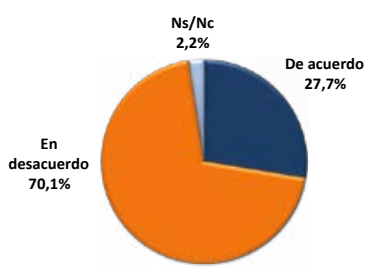

Junio 2013

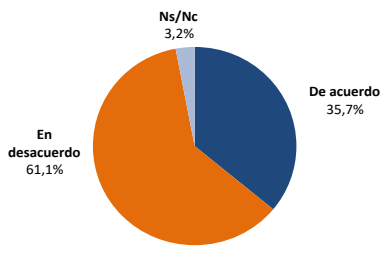

Acuerdo/Desacuerdo con la Ley que promueve el voto optativo de los jóvenes de 16 y 17 años Según Sexo, Nivel socio-económico y Zona

\begin{tabular}{|c|c|c|c|c|c|c|c|c|c|}
\hline & \multicolumn{2}{|c|}{ Sexo } & \multicolumn{3}{|c|}{ Nivel socio-económico } & \multicolumn{4}{|c|}{ Zona } \\
\hline & Varón & Mujer & Bajo & Medio & Alto & $\begin{array}{l}\text { Zona } \\
\text { Norte }\end{array}$ & $\begin{array}{l}\text { Casco } \\
\text { Urbano }\end{array}$ & Sudoeste & Total \\
\hline De acuerdo & $41,5 \%$ & $29,9 \%$ & $47,6 \%$ & $33,0 \%$ & $35,2 \%$ & $38,3 \%$ & $29,7 \%$ & $38,6 \%$ & $35,7 \%$ \\
\hline En desacuerdo & $55,1 \%$ & $67,0 \%$ & $46,6 \%$ & $63,5 \%$ & $61,5 \%$ & $59,7 \%$ & $66,4 \%$ & $57,9 \%$ & $61,1 \%$ \\
\hline $\mathrm{Ns} / \mathrm{Nc}$ & $3,4 \%$ & $3,0 \%$ & $5,8 \%$ & $3,5 \%$ & $3,3 \%$ & $1,9 \%$ & $3,9 \%$ & $3,6 \%$ & $3,2 \%$ \\
\hline Total & $100,0 \%$ & $100,0 \%$ & $100,0 \%$ & $100,0 \%$ & $100,0 \%$ & $100,0 \%$ & $100,0 \%$ & $100,0 \%$ & $100,0 \%$ \\
\hline
\end{tabular}

Razón del Acuerdo con la Ley que promueve el voto optativo de los jóvenes de 16 y 17 años

Porcentaje

\begin{tabular}{lc}
\hline Están capacitados & $19,7 \%$ \\
\hline Iguala/amplía derechos y da mayor participación a los jóvenes & $17,3 \%$ \\
\hline Es una buena medida & $14,1 \%$ \\
\hline Los inserta en la vida política & $13,3 \%$ \\
\hline Tienen derecho a votar & $11,6 \%$ \\
\hline Son maduros como para elegir & $11,2 \%$ \\
\hline Otros & $7,2 \%$ \\
\hline Ns/Nc & $5,6 \%$ \\
\hline Total & $100,0 \%$ \\
\hline
\end{tabular}


Razon del Acuerdo con la Ley que promueve el voto optativo de los jóvenes de 16 y 17 años Segün Sexo, Grupo de edad y Nivel socioeconómico

Sexo Grupo de edad Nivel socio-económico Varón Mujer 16 a $17 \quad 18$ a $30 \quad 31$ a $50 \quad 51 y \quad$ Bajo Medio Alto Total

\begin{tabular}{|c|c|c|c|c|c|c|c|c|c|c|}
\hline Están capacitados & $18,2 \%$ & $21,9 \%$ & $16,7 \%$ & $14,5 \%$ & $23,7 \%$ & $19,5 \%$ & $14,6 \%$ & $25,3 \%$ & $14,3 \%$ & $19,7 \%$ \\
\hline $\begin{array}{l}\text { Iguala/amplia derechos y da mayor } \\
\text { participación a los jóvenes }\end{array}$ & $17,5 \%$ & $17,1 \%$ & $13,9 \%$ & $23,6 \%$ & $21,1 \%$ & $10,4 \%$ & $16,7 \%$ & $16,2 \%$ & $19,0 \%$ & $17,3 \%$ \\
\hline Es una buena medida & $11,2 \%$ & $18,1 \%$ & $25,0 \%$ & $10,9 \%$ & $15,8 \%$ & $9,1 \%$ & $12,5 \%$ & $11,1 \%$ & $23,8 \%$ & $14,1 \%$ \\
\hline Los inserta en la vida politica & $17,5 \%$ & $7,6 \%$ & $11,1 \%$ & $20,0 \%$ & $7,9 \%$ & $15,6 \%$ & $10,4 \%$ & $13,1 \%$ & $14,3 \%$ & $13,3 \%$ \\
\hline Tienen derecho a votar & $8,4 \%$ & $16,2 \%$ & $13,9 \%$ & $10,9 \%$ & $14,5 \%$ & $9,1 \%$ & $20,8 \%$ & $13,1 \%$ & $2,4 \%$ & $11,3 \%$ \\
\hline Son maduros como para elegir & $13,3 \%$ & $8,6 \%$ & $2,8 \%$ & $10,9 \%$ & $9,2 \%$ & $18,2 \%$ & $12,5 \%$ & $12,1 \%$ & $9,5 \%$ & $11,2 \%$ \\
\hline $\mathrm{Ns} / \mathrm{Nc}$ & $5,6 \%$ & $4,8 \%$ & $11,1 \%$ & $1,8 \%$ & $5,3 \%$ & $5,2 \%$ & $2,1 \%$ & $5,1 \%$ & $2,4 \%$ & $11,5 \%$ \\
\hline Total & $100,0 \%$ & $100,0 \%$ & $100,0 \%$ & $100,0 \%$ & $100,0 \%$ & $100,0 \%$ & $100,0 \%$ & $100,0 \%$ & $100,0 \%$ & $100,0 \%$ \\
\hline
\end{tabular}

Razón del Acuerdo con la Ley que promueve el voto optativo de los jóvenes de 16 y 17 años Según Zona

\begin{tabular}{|c|c|c|c|c|}
\hline & $\begin{array}{c}\text { Zona } \\
\text { Norte }\end{array}$ & $\begin{array}{c}\text { Zona } \\
\text { Casco } \\
\text { Urbano }\end{array}$ & Sudoeste & Total \\
\hline Están capacitados & $20,8 \% 6$ & 18,296 & 19,896 & $19,7 \%$ \\
\hline Iguala/amplía derechos y da mayor participación a los jóvenes & 23,496 & $13,6 \% 6$ & $15,1 \%$ & 17,396 \\
\hline Tienen derecho a votar & $7,8 \%$ & $4,5 \%$ & 18,996 & 11,686 \\
\hline Es una buena medida & 14,396 & $10,6 \% 6$ & $16,0 \% 6$ & $14,1 \% 6$ \\
\hline Los inserta en la vida política & $11,7 \%$ & $10,6 \%$ & $16,0 \%$ & $13,3 \%$ \\
\hline Son maduros como para elegir & 13,096 & 24,296 & $1,9 \%$ & $11,2 \%$ \\
\hline Otros & $5,2 \%$ & $9,1 \%$ & $8,5 \%$ & 7,696 \\
\hline $\mathrm{Ns} / \mathrm{Nc}$ & 3,996 & $9,1 \%$ & $3,8 \%$ & 5,296 \\
\hline Total & 100,056 & 100,096 & $100,0 \%$ & $100,0 \% 6$ \\
\hline
\end{tabular}

Razón del Desacuerdo con la Ley que promueve el voto optativo de los jóvenes de 16 y 17 años

\section{Porcentaje}

\begin{tabular}{lc}
\hline Son inmaduros para votar & $35,0 \%$ \\
\hline Falta de formación política & $23,3 \%$ \\
\hline No saben nada como para votar & $18,6 \%$ \\
\hline Deberían ser mayores para todo (ser enjuiciados) & $14,1 \%$ \\
\hline Estrategia política de manipulación & $4,0 \%$ \\
\hline Otros & $3,8 \%$ \\
\hline Ns/Nc & $1,1 \%$ \\
\hline Total & $100,0 \%$ \\
\hline
\end{tabular}




\begin{tabular}{|c|c|c|c|c|c|c|c|c|c|c|}
\hline \multicolumn{11}{|l|}{$\begin{array}{l}\text { Razón del Desacuerdo con la Ley que promueve el vo } \\
\text { Según Sexo, Grupo de edad y Nivel socioeconómico }\end{array}$} \\
\hline & \multicolumn{2}{|c|}{ Sexo } & \multicolumn{4}{|c|}{ Grupo de edad } & \multicolumn{4}{|c|}{ Nivel socio-económico } \\
\hline & Varón & Mujer & 16 a 17 & 18 a 30 & 31 a 50 & 51 y más & Bajo & Medio & Alto & Total \\
\hline Son inmaduros para votar & $37,0 \%$ & $33,1 \%$ & $27,9 \%$ & $35,0 \%$ & $33,1 \%$ & $37,7 \%$ & $32,7 \%$ & $36,6 \%$ & $32,9 \%$ & $35,0 \%$ \\
\hline Falta de formación politica & $22,0 \%$ & $24,5 \%$ & $32,6 \%$ & $22,0 \%$ & $18,5 \%$ & $26,0 \%$ & $20,4 \%$ & $22,0 \%$ & $27,6 \%$ & $23,3 \%$ \\
\hline No saben nada como para votar & $18,5 \%$ & $18,8 \%$ & $16,3 \%$ & $16,3 \%$ & $23,4 \%$ & $17,5 \%$ & $20,4 \%$ & $20,5 \%$ & $21,1 \%$ & $18,6 \%$ \\
\hline Deberian ser mayores para todo (ser enjuiciados) & $11,5 \%$ & $16,3 \%$ & $7,0 \%$ & $19,5 \%$ & $14,5 \%$ & $11,7 \%$ & $14,3 \%$ & $14,6 \%$ & $9,2 \%$ & $14,1 \%$ \\
\hline Estrategia politica de manipulación & $5,0 \%$ & $3,3 \%$ & $4,7 \%$ & $2,4 \%$ & $4,8 \%$ & $4,5 \%$ & $8,2 \%$ & $2,4 \%$ & $5,3 \%$ & $4,0 \%$ \\
\hline Otros & $3,5 \%$ & $3,7 \%$ & $2,3 \%$ & $3,3 \%$ & $5,6 \%$ & $2,6 \%$ & $4,1 \%$ & $2,9 \%$ & $3,9 \%$ & $3,8 \%$ \\
\hline $\mathrm{Ns} / \mathrm{Nc}$ & $1,5 \%$ & $.4 \%$ & $7,0 \%$ & $.8 \%$ & $.0 \%$ &, $0 \%$ &, $0 \%$ &, $5 \%$ & $0 \%$ & $1,1 \%$ \\
\hline Total & $100,0 \%$ & $100,0 \%$ & $100,0 \%$ & $100,0 \%$ & $100,0 \%$ & $100,0 \%$ & $100,0 \%$ & $100,0 \%$ & $|100,0 \%|$ & $100,0 \%$ \\
\hline
\end{tabular}

Razón del Desacuerdo con la Ley que promueve el voto optativo de los jóvenes de 16 y 17 años Según Zona

\begin{tabular}{lc|c|c|c} 
& \multicolumn{2}{c|}{ Zona } & \\
& $\begin{array}{r}\text { Zona } \\
\text { Norte }\end{array}$ & $\begin{array}{c}\text { Casco } \\
\text { Urbano }\end{array}$ & Sudoeste & Total \\
\hline Son inmaduros para votar & $33,3 \%$ & $37,7 \%$ & $33,7 \%$ & $35,0 \%$ \\
\hline Deberían ser mayores para todo (ser enjuiciados) & $16,7 \%$ & $13,6 \%$ & $12,7 \%$ & $14,1 \%$ \\
\hline Estrategia política de manipulación & $8,7 \%$ & $1,9 \%$ & $2,4 \%$ & $4,0 \%$ \\
\hline No saben nada como para votar & $16,7 \%$ & $13,6 \%$ & $24,7 \%$ & $18,6 \%$ \\
\hline Falta de formación política & $19,8 \%$ & $29,9 \%$ & $19,9 \%$ & $23,3 \%$ \\
\hline Otros & $4,0 \%$ & $1,9 \%$ & $5,4 \%$ & $3,9 \%$ \\
\hline Ns/Nc &, $8 \%$ & $1,3 \%$ & $1,2 \%$ & $1,1 \%$ \\
\hline Total & $100,0 \%$ & $100,0 \%$ & $100,0 \%$ & $100,0 \%$ \\
\hline
\end{tabular}




\section{BIBLIOGRAFIA.}

ALVARADO, Sara Victoria y VOMMARO, Pablo (comps.) (2010): Jóvenes, Cultura y Política en América Latina: Algunos trayectos de sus relaciones, experiencias y lecturas. Presentación y Capítulo 1 "Del Cordobazo al kirchnerismo... Rosario: Homo Sapiens Ediciones

ARIÈS, Phillipe (1990). El niño y la vida familiar en el antiguo régimen. Madrid: Taurus.

AUYERO, Javier (1993). Otra vez en la vía: notas e interrogantes sobre la juventud de sectores populares. Buenos Aires, Espacio Editorial. BAUMAN, Z (1999), En busca de la política. Buenos Aires, FCE. BECK, U (2001), La individualización. Buenos Aires, FCE. BOURDIEU, P (2000), Poder, derecho y clases sociales. Barcelona, Desclee de Bower.

BOURDIEU, P. (1984). La juventud no es más que una palabra. En Sociología y cultura. México: Grijalba. En https://existenciaintempestiva.files.wordpress.com/2014/03/bourdieu-sociologia-y-cultura.pdf

BOURDIEU, Pierre (1998). La dominación masculina. Barcelona: Anagrama.

BOURDIEU, Pierre (2002). «La “juventud” no es más que una palabra». Sociología y cultura, pp. 163-173. México D. F.: Grijalbo. BUTLER, Judith (1990). El género en disputa. Madrid: Paidós.

CALETTI, Sergio (2006). «Comunicación y espacio público. Notas para repensar la democracia en la sociedad contemporánea». Bue- nos Aires: mimeo.

CEA D'ANCONA: Metodologia cuantitativa Estrategias y técnicas de investigacion social. Síntesis, 1998

CEBRELLI, Alejandra; ARANCIBIA, Víctor (2005). «Representaciones sociales. Modos de mirar y de hacer». Salta: CIUNSa-CEPHIa. 
CHAVES, Mariana (2010) Jóvenes, territorios y compliidades: una antropología desde la juventud urbana. Buenos Aires. Espacio Editorial.

DUSCHATZKY, Silvia y COREA, Cristina (2002) Chicos en banda. Los caminos de la subjetividad en el declive de las instituciones. Buenos Aires, Paidós.

FARRELL, Jeff (2010) "Aburrimiento, crimen y criminología" en Revista Delito y Sociedad, N²9, Universidad Nacional del Litoral. Buenos Aires-Santa Fe.

FEIXA, Carles (1999) De Jóvenes, bandas y tribus. Capítulo I.

FEIXA, Carles y Carmen LECCARDI (2011), "El concepto de generación en las teorías sobre la juventud", en Última Década No 34. Valparaíso, CIDPA, pp. 11-32.

FERNÁNDEZ, Ana María (1992). La mujer de la ilusión. Buenos Aires: Paidós.

FOUCAULT M. Y DELEUZE G. (1992) Un diálogo sobre el poder en Microfísica del poder, La Piqueta, Madrid

GARCÍA CANCLINI, Néstor [1999] (2006). «El consumo cultural: una propuesta teórica». En Sunkel, Guillermo (coord.). El consumo cultural en América Latina (pp. 72-95). Bogotá: Convenio Andrés Bello.

GIDDENS, A (1998), Teoría de la Estructuración. Buenos Aires, FCE. GROSSBERG, Lawrence (2012). Estudios culturales en tiempo futuro. Buenos Aires: Siglo XXI.

GRÜNER, Eduardo (2005). El fin de las pequeñas historias. Buenos Aires: Paidós.

HALL, Stuart (1980). Culture, Media and Language. Londres: Hutchinson.

HALL, Stuart (1981). «La cultura, los medios de comunicación y el "efecto ideológico"». En Curran, James y otros (comps.) Sociedad y comunicación de masas (pp. 357-392). México D. F.: Fondo de Cultura Económica. 
HALL, Stuart y JEFFERSON, Tony (2010), Resistencia a través de la cultura. Subculturas juveniles en la Gran Bretaña de la pos-guerra. Observatorio de Jóvenes, Comunicación y Medios, Facultad de Periodismo y Comunicación Social, UNLP, La Plata.

HEBDIGE, Dick (2004), Subcultura. El significado del estilo. Barcelona, Paidós.

HOPENHAYN, Martín (2004). La juventud en iberoamérica. Tendencias y urgencias. Santiago de Chile: CEPAL.

HUERGO, Jorge (2002). Hegemonía, un concepto clave para comprender la comunicación. Apunte de la cátedra Comunicación y Educa- ción. La Plata: Facultad de Periodismo y Comunicación Social, UNLP.

Informe del Ministerio de Educación, Ciencia y Tecnología, Programa Escuela y Medios. "Los medios de comunicación en la escuela: un abordaje reflexivo, una actitud crítica" (2006).

ISLA, Alejandro; MIGUEZ, Daniel (2003). Heridas Urbanas. Violencia delictiva y transformaciones sociales en los noventa. Buenos Aires: Editorial de las Ciencias.

JEFFREY Alexander, (1989). “¿Qué es la teoría?”, en Las teorías sociológicas desde la segunda guerra mundial, Barcelona, Gedisa, 1997. JODELET, Denise (1986). «La representación social: fenómeno, concepto y teoría». En Moscovici, Serge (ed.). Psicología Social, II (pp. 469-493). Barcelona: Paidós.

KATZ, Jack (1988), Seductions of crime: The moral and sensual attractions of doing evil. New York, Basic Books.

KESSLER, Gabriel (2004), Sociología del delito amateur. Buenos Aires, Paidos.

KRIGER, Miriam (2010), Jóvenes de escarapelas tomar. Escolaridad, comprensión histórica y formación política en la Argentina contemporánea. La Plata, Observatorio de Jóvenes, Comunicación y Medios, Facultad de Periodismo y Comunicación Social, UNLP. 
KRIGER, Miriam (2012), "La invención de la juventud, entre la muerte de las naciones y su resurrección”, en M. Kriger, op.cit. KROPFF, Laura (2011a), "Debates sobre lo político entre jóvenes mapuche en Argentina”, en Revista Latinoamericana de Ciencias Sociales, Niñez y Juventud, 1 (9), pp. 83 - 99.

KROPFF, Laura (2011b), "Los jóvenes mapuche en Argentina: entre el circuito punk y las recuperaciones de tierras", en Alteridades, vol. 21, No 42, julio-diciembre, pp. 77-89. Univer-

LACLAU Ernesto; MOUFFE, Chantal [1985] (2004). Hegemonía y estrategia socialista. Buenos Aires: Fondo de Cultura Económica. MAFFESOLI, Michel (1998), El tiempo de las tribus. El ocaso del individualismo en las sociedades posmodernas. México, Siglo XXI. MANZANO, V. (2011), Cultura, política y movimiento estudiantil secundario en la Argentina de la segunda mitad del siglo XX en Revista Propuesta Educativa (35). Buenos Aires, FLACSO-Argentina, pp. 41-52.

MARGULIS, M. Y URRESTI, M. (1996). La juventud es más que una palabra: ensayos sobre cultura y juventud. Prólogo y Capítulo 1. Buenos Aires: Biblos.

MARRADI, A., ARCHENTI, N., PIOVANI, J. (2010). Metodología de las ciencias sociales. Buenos Aires : Cengage Learning.

MATTELART, A. Y MATTELART, M. 1997. Historia de las teorías de la comunicación, Barcelona: Paidós.

MATTHEUS, Roger (2002) "Armed Robbery" en Delinquency and Drift. New York,

MAYER, L (2007), Juventud y Legitimidad Política. Tesis de Maestría en Investigación en Ciencias Sociales. Facultad de Ciencias Sociales, Universidad de Buenos Aires. Buenos Aires, mimeo.

MAYER, L (2009), Hijos de la Democracia. ¿Cómo viven y piensan los jóvenes? Buenos Aires, Paídos.

MAYER, L (2012), La conflictividad escolar cotidiana. Un análisis 
de las estrategias para su prevención y/o minimización. Tesis de Doctorado defendida en el Programa de Doctorado en Ciencias Sociales, Facultad de Ciencias Sociales, Universidad de Buenos Aires. Buenos Aires, mimeo.

MENDES DIZ, Ana María (2001). El riesgo en los jóvenes. Una alternativa de vida. Buenos Aires: Corregidor.

MORDUCHOWICZ, Roxana (2012). Los adolescentes y las redes sociales. Conexión pediátrica.

MOSCOVICI, Serge (1981). «On Social Representation». En Forgas, Joseph (comp.). Social cognition. Perspectives in everyday life (pp. 181-209). Londres: Academic Press.

NATANSON, José (2012), ¿Por qué los jóvenes están volviendo a la política? De los indignados a La Cámpora. Buenos Aires, DEBATE.

NUÑEZ, P. (2010), Política y poder en la escuela media. La socialización política juvenil en el espacio escolar. Tesis doctoral, Posgrado en Ciencias Sociales UNGS/IDES.

OBSERVATORIO DE JÓVENES, COMUNICACIÓN Y MEDIOS (2012). «Jóvenes nombrados. Estrategias comunicacionales contra la violencia institucional y mediática». La Plata: Ediciones de Periodismo y Comunicación.

OPCIÓN (2O13), Estudio de coyuntura, Opinión Pública y Comunicación. Buenos Aires, mimeo.

OSZLAK, Oscar; O’ DONNELL, Guillermo (1984). «Notas críticas para una teoría de la burocracia estatal». En Oszlak, Oscar (comp.). Teoría de la burocracia estatal. Buenos Aires: Paidós.

PECHÍN, J. (2009), “¿Hacia el fin de la escolaridad militarizada? El nuevo paradigma jurídico-legal y la crisis del absolutismo tutelar de la patria potestad sobre lxs jóvenes" en Revista Argentina de Juventud No 2, Observatorio de Juventud y Medios de Comunicación, UNLP. 
PEREYRA, A. (2009), Las representaciones de adolescentes sobre la historia reciente de Argentina. Un estudio exploratorio de la conciencia histórica entre estudiantes de escuelas medias públicas de la Ciudad de Buenos Aires. Tesis doctoral aprobada ante FLACSO-Argentina

RAGGIO, S. (2011), “Los jóvenes y las memorias” en Revista El Monitor No 28, Ministerio de Educación de la Nación.

REGUILLO CRUZ, Rossana (2000), Emergencia de culturas juveniles. Estrategias del desencanto. Bogotá, Norma.

RODRÍGUEZ, Esteban (2009), Por los caminos del rock. Azulpluma, La Plata.

ROSANVALLON, P. (2012), La sociedad de iguales. Buenos Aires, Manantial.

SAINTOUT, F; VARELA, A; Y SÁNCHEZ NARVARTE, E., (2014): Jóvenes y política. Por una epistemología de la reconstrucción, en Angelini, Anahí y Sánchez Narvarte, Emiliano (Comp.) Jóvenes y política. Reflexiones en torno al voto joven en Argentina. La Plata: Ediciones de Periodismo y Comunicación.

SAINTOUT, F. (comp.) (2011), Jóvenes argentinos: pensar la política. Buenos Aires, Prometeo Libros.

SAINTOUT, Florencia (2006): El futuro llegó hace rato. Comunicación y estudios culturales, Ediciones de Periodismo y Comunicación, UNLP.

SAINTOUT, Florencia (2012), "Los medios hablan de los jóvenes... y ellos responden”, en Juventudes en América Latina: abordajes multidisciplinares sobre identidades, culturas y políticas del siglo XX al siglo XXI/ Miriam Elizabeth Kriger [et.al.]. Buenos Aires, Centro Argentino de Información Científica y Tecnológica - Caicyt.

SAINTOUT, Florencia (2013), Jóvenes en Argentina. Contra el discurso mediático. Desde una epistemología de la esperanza. Quilmes, UNQUI. 
SÁNCHEZ NARVARTE, R. Emiliano (2012), "Los jóvenes y la representación mediática: ¿espejos?, ¿espejismos? Relevamiento del 2011 y una ventana con vista al 2012", en Informe Anual 2012 del Observatorio de Jóvenes, Comunicación y Medios, Tomás Viviani (editor). La Plata, Ediciones de Periodismo y Comunicación.

SIBILA, Paula (2008). La intimidad como espectáculo. Fondo de cultura económica, Buenos Aires.

TENTI FANFANI, Emilio y Ricardo SIDICARO (1998), La Argentina de los jóvenes. Entre la indiferencia y la indignación. Buenos Aires, Unicef, Losada.

TONKONOFF, Sergio, "Microdelitos, juventudes y violencias: La balada de los pibes chorros" en Revista Delito y Sociedad,Reflexiones en torno al voto joven en argentina $\mathrm{N}^{\circ} 18 / 19$. Buenos Aires, Santa Fe, 2003.

TONKONOFF, Sergio, "Tres movimientos para explicar por qué los pibes chorros visten ropas deportivas" en La sociología ahora. Buenos Aires, Siglo XXI, 2007.

TORRE, J. C. (2003), "Los huérfanos de la política de partidos. Sobre los alcances y la naturaleza de la crisis de representación partidaria" en Desarrollo Económico. Revista de Ciencias Sociales, No 168, Vol. 42, Enero-Marzo, Buenos Aires, IDES.

URRESTI, M. Paradigmas de participación juvenil: un balance histórico, en Balardini, Sergio (2000): La participación social y política de los jóvenes en el horizonte del nuevo siglo, CLACSO, Buenos Aires.

URRESTI, Marcelo (2008). Ciberculturas juveniles. Editorial: La Crujía Ediciones. Buenos Aires.

VARELA, Andrea y RUIZ, Adela (2003). Los jóvenes. La construcción de una mirada comunicacional. En: Saintout, Florencia (2003). Abrir la comunicación. Tradición y movimiento en el campo académico. La Plata: EPC.

JÓVENES Y POLÍTICA: UNA MIRADA DESDE LA COMUNICACIÓN 
VÁZQUEZ, M. Y VOMMARO, P. (2008), La participación juvenil en los movimientos sociales autónomos. El caso de los Movimientos de Trabajadores Desocupados (MTDs) en Revista Latinoamericana de Ciencias Sociales, Niñez y Juventud, 6 (2). Manizales, Colombia.

VIVIANI, Tomás (2012); Informe Anual 2012 Observatorio de Jóvenes, Comunicación y Medios. La Plata: EPC.

VIVIANI, Tomás (2013); Jóvenes Nombrados. Observatorio de Jóvenes, Comunicación y Medios. La Plata. EPC.

VOMMARO Y ALVARADO (2010). "Jóvenes, cultura y política en América Latina: algunos trayectos de sus relaciones, experiencias y lecturas 1960-2000". Carri; Roberto (1968) Isidro Velázquez: Formas prerevolucionarias de la violencia. Buenos Aires, Editorial Sudestada.

VOMMARO, P. Y VAZQUEZ, M. (2012), "La fuerza de los jóvenes. Aproximaciones a la militancia kirchnerista desde La Cámpora" en Natalucci, Ana y Perez, Germán Vamos las bandas. Organizaciones y militancia kirchnerista. Buenos Aires, Nueva Trilce.

VVAA (2008), La escuela media en foco. Indagaciones sobre convivencia y política, lectura y escritura y formación para el trabajo. Buenos Aires: Dirección de Investigación Educativa del Ministerio de Educación del GCBA.

WALLERSTEIN, Immanuel (1999), Abrir las ciencias sociales, CENDES, UNESCO, Caracas. Bourdieu; Pierre; Wacquant, Loic: Respuestas por una antropología reflexiva, en Más allá de la antinomia entre física social y fenomenología social. Grijalbo, INCA, México.

WILLIS, P., (1979). Aprendiendo a trabajar. Cómo los chicos de la clase obrera consiguen trabajos de clase obrera. Birmingham: Saxon House.

YOUNG, Jock (2012), El vértigo de la modernidad tardía. Buenos Aires, Ediciones Didot. 


\section{Referencias notas periodísticas}

\section{Clarín}

"La Cámpora dio otro paso en el manejo de los medios del Estado», 3 de agosto de 2012.

Disponible en <http://www.clarin.com/sociedad/Campora-dio-paso-manejo-medios_0_748725239.html>

«Generación Ni-Ni: casi medio millón de jóvenes que ni estudia ni trabaja», 2 de septiembre de 2012. Disponible en <http://www.clarin.com/ zona/Generacion-Ni-Ni-jovenes-estudia-trabaja_0_766723423.html>

«Jóvenes y extranjeros, ciudadanos solamente a la hora de votar», 7 de septiembre de 2012.

Disponible en <http://www.clarin.com/politica/Jovenes-extranjeros-ciudadanos-solamente-votar_0_772122817.html>

«Sileoni defendió en el Congreso el voto a los 16», 19 de septiembre de 2012.

Disponible en <http://www.clarin.com/politica/Arrancan-audiencias-voto_0_776922459.html>

«La UOCRA y los grupos cristinistas, a los palazos por distribuir la ayuda», 8 de abril de 2013.

Disponible en <http://www.clarin.com/ciudades/UOCRA-grupos-cristinistas-palazos-distribuir_0_897510248.html>

«Intentan evitar la detención de un gremialista», 12 de abril de 2013. Disponible en <http://www.clarin.com/politica/Intentan-evitar-detencion gremialista_0_899910066.html> 


\section{Diario Popular}

«Tinelli criticó el voto a los 16 años», 3 de septiembre de 2012.

Disponible en <http://www.diariopopular.com.ar/notas/128600-tinelli-critico-el-voto-los-16-anos $>$

«Más de 2000 jóvenes debatieron en Almirante Brown», 21 de noviembre de 2012.

Disponible en <http://www.diariopopular.com.ar/notas/137786-mas 2000-jovenes-debatieron-almirante-brown>

"Ayuda a damnificados empieza a llegar a las casas», 6 de abril de 2013.

Disponible en <http://www.diariopopular.com.ar/notas/152296-ayuda-damnificados-empieza-llegar-las-casas $>$

«Temporal: Cristina estuvo en la Universidad de La Plata», 7 de abril de 2013.

Disponible en <http://www.diariopopular.com.ar/notas/152400-temporal-cristina-estuvo-la-universidad-la-plata $>$

\section{La Nación}

«La estrecha relación de Vatayón Militante con La Cámpora», 3 de agosto de 2012.

Disponible en <http://www.lanacion.com.ar/1495919-la-estrecha-relacion-de-vatayon-militante-con-la-campora $>$

«La Cámpora realiza talleres políticos en escuelas públicas», 12 de agosto de 2012.

Disponible en <http://www.lanacion.com.ar/1498643-la-campora-realiza-talleres-politicos-en-escuelas-publicas $>$. 
«Adoctrinamiento en las escuelas», 15 de agosto de 2012.

Disponible en <http://www.lanacion.com.ar/1499319-avalo-la-presidenta-los-talleres-de-la-campora-en-las-escuelas $>$

«Otro camporista en un puesto clave del Gobierno», 16 de agosto de 2012.

Disponible en $<$ http://www.lanacion.com.ar/1499764-otro-camporista-en-un-puesto-clave-del-gobierno $>$

«¿Quién es el camporista que lleva el Nestornauta a la escuela?», 17 de agosto de 2012.

Disponible en <http://www.lanacion.com.ar/1499996-quien-es-elcamporista-que-lleva-el-nestornauta-a-la-escuela>

«Militar y adoctrinar en la escuela», 23 de agosto de 2012.

Disponible en $<$ http://www.lanacion.com.ar/1501561-militar-y-adoctrinar-en-la-escuela $>$

«Fuerte ofensiva oficial para que se vote desde los 16 años», 30 de agosto de 2012.

Disponible en <http://www.lanacion.com.ar/1503748-fuerte-ofensiva-oficial-para-que-se-vote-desde-los-16-anos>

«Un joven séquito mudo en el Congreso», 31 de agosto de 2012. Disponible en <http://www.lanacion.com.ar/1503492-un-joven-sequito-mudo-en-el-congreso $>$

«De la Sota reveló que en Córdoba el voto desde los 16 años "es un fracaso, porque nunca fueron" ", 4 de septiembre de 2012. Disponible en <http://www.lanacion.com.ar/1505257-de-la-sota-revelo-queen-cordoba-el-voto-desde-los-16-anos-es-un-fracaso-porque- nunca-fueron> 
«El voto joven genera divisiones», 12 de septiembre de 2012.

Disponible en <http://www.lanacion.com.ar/1507562-el-voto-joven-genera-divisiones $>$

«La Cámpora y la UOCRA se enfrentaron a palazos por el reparto de donaciones», 8 de abril de 2013.

Disponible en <http://www.lanacion.com.ar/1570662-la-campora-yla-uocra-se-enfrentaron-a-palazos-por-el-reparto-de-donaciones>

\section{Página 12}

«Entre el optimismo y las ganas de votar», 24 de julio de 2012.

Disponible en <http://www.pagina12.com.ar/diario/sociedad/3-199396-2012-07-24.html>

«La juventud quiere renovación y cambio», 7 de septiembre de 2012. Disponible en <http://www.pagina12.com.ar/diario/elpais/1-202837-2012-09-07.html>

«Los votos de la juventud», 10 de septiembre de 2012.

Disponible en <http://www.pagina12.com.ar/diario/elpais/1-203021-2012-09-10.html>

«Unas palabras antes de la marcha», 26 de septiembre de 2012.

Disponible en <http://www.pagina12.com.ar/diario/ultimas/20-204278-2012-09-26.html>

«Para que los jóvenes también voten», 16 de noviembre de 2012. Disponible en <http://www.pagina12.com.ar/diario/elpais/1-207953-2012-11-16.html> 
«Es buenísimo que haya militantes», 7 de abril de 2013.

Disponible en <http://www.pagina12.com.ar/diario/economia/ subnotas/217497-63089-2013-04-07.html>

«Militantes agredidos», 9 de abril de 2013.

Disponible en <http://www.pagina12.com.ar/diario/elpais/1-217615-2013-04-09.html>

«Apoyos para La Cámpora», 9 de abril de 2013.

Disponible en <http://www.pagina12.com.ar/diario/elpais/1-217604-2013-04-09.html>

«Repudio al ataque de la uocra contra voluntarios de La Cámpora», 10 de abril de 2013.

Disponible en <http://www.pagina12.com.ar/diario/ultimas/subnotas/20-63137-2013-04-10.html>

«El hijo del Pata Medina fue detenido», 10 de abril de 2013.

Disponible en <http://www.pagina12.com.ar/diario/ultimas/20-217713-2013-04-10.html>

«El hijo del Pata Medina, comprometido», 10 de abril de 2013.

Disponible en <http://www.pagina12.com.ar/diario/elpais/1-217677-2013-04-10.html $>$

«A Patita lo metieron preso», 11 de abril de 2013.

Disponible en <http://www.pagina12.com.ar/diario/elpais/1-217740-2013-04-11.html $>$

«El rumbo del nuevo votante», 2 de mayo de 2013.

Disponible en <http://www.pagina12.com.ar/diario/elpais/1-219155-2013-05-02.html> 


\section{Anexos}

Libro: Jóvenes piqueteros y encapuchados. Algunas preguntas sobre las marcas de lo plebeyo en las formas de la acción colectiva

Autora: Lucía Corsiglia Mura

Año: 2013

Editorial: Observatorio de Jóvenes, Comunicación y Medios - EDULP - EPC

La investigación se propone indagar los procesos de subjetivación relacionados a la acción colectiva de los jóvenes que participan del dispositivo de autodefensa de una organización piquetera. Con la crisis sociopolítica de fines de siglo $\mathrm{XX}$, la irrupción en la escena pública de los sectores subalternos por vías alternativas a los espacios formales de participación fue ampliamente abordada por las ciencias sociales. Sin embargo, en la última década, a medida que los indicadores macroeconómicos fueron mejorando y se recuperaba la gobernabilidad por medio de las formas tradicionales de representación, el piqueterismo perdió poder disruptivo. La autora se propone mostrar cómo este tipo organizacional político sigue vigente en sectores de pobreza estructural y sus connotaciones en la construcción de sociabilidad.

El libro pone en tensión y diálogo las transformaciones en el ámbito de la domesticidad con las novedosas formas de politicidad. Se pregunta por el universo de sentidos que estos sujetos activan en sus prácticas a través de tres indicadores 
principales: las formas de vivenciar la juventud, la condición de pobreza y la participación colectiva. Adopta la noción de subjetividad para pensar la intermediación entre sujeto y estructura, como proceso móvil que articula códigos cognitivos, emotivos, éticos y estéticos heterogéneos. Asimismo, las alteraciones en los espacios en los que se generan los lazos sociales -el trabajo, el territorio, el tiempo libre, la afectividadimplican modificaciones en las experiencias y en la construcción del proyecto biográfico.

En tal sentido, señala las limitaciones de, por un lado, la sociología política, que desde las teorías de los movimientos sociales en clave identitaria relegaron los distintos tipos de inserción al interior de los colectivos de acción beligerante; y por otro, del cruce de la sociología cultural y la antropología, que centralizados en las culturas populares y las formas de integración alternativa tendieron a obturar los procesos de politización. La autora busca indagar en las formas de intersubjetividad plebeya donde se yuxtaponen los procesos de sociabilización política y cotidiana: a través de la inscripción en una organización de desocupados, estos jóvenes tienen la tarea de "defender" de un "otro" amenazante -especialmente, las fuerzas de seguridad represivas-, a la vez que presentan maneras transgresoras de aparición pública -el palo en la mano, el rostro cubierto con capucha-, que irritan el sentido hegemónico de orden, lo que es visible en el prototipo de piquetero "violento", "salvaje" o "bárbaro" construido mediáticamente. El trabajo de campo se realizó a través de observaciones, cinco entrevistas en profundidad y dos entrevistas grupales con jóvenes de entre 15 y 35 años, miembros de la autodefensa de la Coordinadora de Trabajadores Desocupados Aníbal Verón, de barrios de Gran Buenos Aires y Gran La Plata 


\section{Marcas de la pobreza, la juventud y la acción colectiva}

En el capítulo 2, se rastrean las representaciones de los sujetos sobre el lugar ocupado en la sociedad. La pobreza se vivencia como un universo eternizado, como "pobres desde siempre". Esto los sitúa en una condición de exclusión -como ontología de lo social que impacta en la constitución identitaria-, principalmente a partir de la marginación laboral y educativa, la segregación simbólica-cultural y la habitación en barrios periféricos.

La autora entiende que los rasgos de juventud aparecen como un momento particular de la vida donde se define el proyecto biográfico y la identidad como sujeto social, que por la exclusión en las instituciones tradicionales se reduce a la inserción territorial y a las experiencias militantes. La autora destaca que no hay un auto-reconocimiento de los investigados como jóvenes, aunque si distinguen haberse sumado a la organización "de pibes" y haber realizado un crecimiento generacional en el interior del dispositivo militante. Al mismo tiempo, en la organización caracterizan a la autodefensa con un componente visual juvenil, a la vez que su relación con la violencia urbana se asocian a su carácter de jóvenes pobres (criminalización de la pobreza) y su participación militante (criminalización de la protesta).

Por último, la participación en la organización implica ampliar los universos de sociabilidad, con importante peso de la inscripción barrial. Dicha territorialización significa una politización de las redes de sociabilidad primaria, en donde la pertenencia piquetera se superpone con la inserción familiar, afectiva, material e ideológica. La desigualdad es desnaturalizada y se percibe la posibilidad de la movilidad social a partir de proyectos colectivos. La autora critica los estudios 
sobre la participación juvenil comunitaria que resaltan elementos organizacionales provenientes de representaciones acerca del trabajo de las clases medias, como lo cooperativo y el valor de lo asambleario. Por el contrario, la investigación da cuenta de fuertes elementos normativos y disciplinares en la participación colectiva, que funcionan como un "rescate" del mundo del alcohol y la droga, de "la esquina" y el ocio forzado. Asimismo, cuestiona las perspectivas que hablan de reciprocidad entre el sujeto y el colectivo desde una perspectiva utilitaria: si bien se referencia a las cuestiones materiales que la organización provee, la lucha colectiva aparece como un valor que media la conquista de sus demandas. En la inscripción colectiva se construye un horizonte futuro, a la vez que provee un sentido trascendente al proyecto biográfico, a través de narrativas de heroicidad en función del riesgo que supone la autodefensa.

\section{La autodefensa: historia, normas, subjetividades}

En el capítulo 3, la autora contextualiza sobre el lugar de la CTD Aníbal Verón en la cartografía piquetera, reconstruyendo su historicidad y sus definiciones políticas, por caso, su filiación con la orgánica política de Quebracho. Entre los objetivos de la organización es ser un espacio de referencia piquetera no conciliador, lo que ha motivado la construcción de mecanismos de seguridad por dos razones: las recurrentes experiencias represivas y conflictivas y como dispositivo identitario simbólico. La necesidad de estructuras de seguridad fue impulsada desde la cúpula de la militancia, pero encontró predisposición en la organización territorial y fue adoptada como una división de tareas en el interior de la CTD A. Verón. La denominación de "autodefensa" fue impulsada 
alrededor del 2004 por los referentes de la organización, para darle legitimidad a estas formaciones. En algunos integrantes, con mayor apropiación de la discursividad militante, la defensa resulta legítima respecto a un orden injusto en cuestionamiento del monopolio de la fuerza por el Estado; en otros, predomina su representación como tarea para "cuidar a nuestra gente", con nudos de sentido que valorizan la fortaleza, la transgresión, el poner el cuerpo y el aguante. Si bien se trata de sectores socioeconómicos atravesados por la violencia horizontal como articuladora de relaciones sociales, no se puede hablar de una adhesión a la autodefensa por su simbología violenta, puesto que la participación de los jóvenes en estas formaciones es posterior a su inserción en la organización piquetera.

En el capítulo 4, se realiza una descripción de la autodefensa, sus formas de funcionamiento y de integración de sus miembros y las representaciones sobre su praxis política. Se destaca un sentido común compartido en torno a lo justo del reclamo, de hacerse oír, y la injusticia de la situación socioeconómica, de la institucionalidad que reprime. La alteridad con la legalidad, especialmente con la policía, preexiste en la mayoría de los casos a la inserción organizacional, pero ésta la potencia. Hay diversos grados de membresía en la autodefensa, siendo miembros plenos los que participan de las instancias de discusión y formación, así como escalas de responsabilidad, un funcionamiento jerárquico y voces de mando. El palo y la capucha no son sólo instrumentos defensivos, sino elementos simbólicos identitarios, platean que "es como nuestra escarapela". Los integrantes explican haberse interesado por gustarles "el quilombo"; sin embargo, el incumplimiento de las normas conlleva sanciones o incluso la suspensión o separación de la tarea. Se alude también a una estética particular, 
asociada a lo juvenil y lo plebeyo, el "estar todo escrachado" por los tatuajes. Pese a la importancia de la fuerza física en la tarea, generalmente asociada a la masculinidad, la mitad de los integrantes son mujeres; incluso algunas ocupan lugares de mando por encima de sus maridos y aluden no sentir discriminación.

En el capítulo 5, se recorre la atribución de sentidos hacia la propia experiencia, que superpone la dimensión de la domesticidad y la de la politicidad. Se trata de emergentes de las propias entrevistas, sin relación a las preguntas de investigación que guiaron el proceso. En primer lugar, aparece una certidumbre sobre la posibilidad de muerte o encarcelamiento como parte de la tarea de autodefensa, aunque revestida de un aura de heroicidad. Elementos cotidianos para los sectores populares se resignifican: la muerte como medio para trascender y la cárcel se asocia al prestigio de la solidaridad del resto de los militantes. En segundo lugar, se le otorga especial valor al respeto, en referencia a la sensación de sentirse respetado en el propio barrio y a la necesidad respetar las jerarquías y al conjunto del grupo. Por último, existe entre los entrevistados un sentimiento participativo con respecto a las discusiones y decisiones tomadas, a ser escuchados y tenidos en cuenta en el espacio.

El capítulo 6 desarrolla una experiencia de observación participante de una movilización en repudio al procesamiento de integrantes de la organización por un escrache, en la cual tocó la banda Pibes Chorros, oportunidad para entrecruzar una demanda política con la dimensión de los consumos culturales de los jóvenes investigados. La investigadora destaca una agresión entre dos jóvenes de la organización, donde la violencia era naturalizada en la mediación del conflicto. Luego, el grupo se mostraría reticente para hablar del tema, situando 
lo sucedido en el ámbito de lo cotidiano, a la vez que ajeno a la lógica política del colectivo.

\section{Conclusiones}

En la construcción de la subjetividad de estos jóvenes de ámbitos cotidianos de pobreza y exclusión, resulta central la inserción en espacios de interrelación que los contengan, especialmente, ante el déficit de integración por las vías tradicionales, como el trabajo y la educación. Estos espacios colectivos, de carácter beligerante y comunitario, aportan nuevos horizontes de sociabilidad en lo cotidiano, con la presencia de familiares y tareas realizadas en el barrio. Con la praxis políti$\mathrm{ca}$, situaciones antes naturalizadas son leídas como agraviantes, lo que le otorga legitimidad a la autodefensa.

Las lógicas del aguante, la naturalización de la violencia y la transgresión normativa como características de sociabilización subalterna son recodificadas a través de la participación política. Estos códigos culturales atraviesan un proceso de normativización colectiva, mediada por una definición orgánica de la alteridad. La identificación del joven pobre como "piquetero" profundiza el estigma, pero, a la vez, lo convierte en marca de orgullo al verse contenido por un "nosotros". La simbología identificatoria -el palo y la capucha- sólo son inteligibles dentro de la organización, como filiación a "una lucha" y no a un tipo de tarea. Los entrevistados poseen, en distintos grados, discursos estructurados militantemente que construyen un relato épico de la organización, desnaturalizan la desigualdad y focalizan en la necesidad de acción disruptiva para hacer oír las demandas.

En los jóvenes se visibiliza un proceso de subjetivación políti$\mathrm{ca}$, que disputa la institucionalidad del orden social, al mismo 
tiempo que las relaciones de subordinación propias del orden hegemónico. La subversión se acentúa por la superposición de lo popular con lo político, es decir, la marca plebeya de la acción colectiva. 


\section{Anexo: Estado actual de la investigación sobre juventud. Condiciones de emergencia de los estudios sobre juventud. Perspectivas e investigaciones.}

En los últimos años la producción, la investigación y los estudios sobre juventud, han tenido un importante desarrollo, siendo varios los enfoques temáticos en las investigaciones: percepciones y representaciones sobre la vida cotidiana; consumos, usos sociales y prácticas culturales; participación social y política; educación y juventud; usos del espacio urbano entre otros. Se podría decir, corriendo el riesgo de una fuerte generalización, que en el conocimiento producido en torno a los jóvenes pueden reconocerse dos abordajes fundamentales: uno descriptivo, caracterizado tanto por acercamientos de tipo émic -específico, finalista, punto de vista interior- como por acercamientos de tipo etic -genérico, predictivo y exterior-; y otro de carácter constructivista/ relacional (Reguillo, 2000) que trata de ir más allá de la descripción de la anécdota o el dato empírico, tratando de problematizar no sólo el plano simbólico sino también las condiciones materiales de su existencia.

El primer acercamiento -temporalmente ubicado en la primera mitad de la década del ochenta- tiene que ver fundamentalmente en América Latina con los trabajos de los organismos no gubernamentales y en menor medida con las crónicas periodísticas. El segundo acercamiento -cuyas producciones se ubican desde fines de los años ochenta y principios de los noventa- realizado desde distintas saberes en las ciencias sociales, especialmente desde la sociología, la antropología, la sociología de la cultura y los estudios culturales, trata de pensar a los sujetos juveniles desde la problematización histórica y sociocultural, analizando e indagando en la configuración de las representaciones, en los sentidos que los actores juveniles atribuyen a sus prácticas. 
La investigación que aquí presentamos se sitúa en el campo de estudios socioculturales en América Latina, tomando específicamente como antecedentes aquellos trabajos en que a partir de problematizar el lugar de los jóvenes se abordan los modos de estructuración y recreación de la vida social. ${ }^{1}$ En ellos, los investigadores interrogan las prácticas y percepciones de los jóvenes sobre el mundo colectivo priorizando el trabajo de relación entre una dimensión subjetiva y otra objetiva de la acción social, entre la agencia y la estructura. Este trabajo de investigación doctoral, se ubica entonces, en el marco de estos estudios interpretativos de las culturas juveniles, desde una perspectiva sociocultural.

\section{Los jóvenes desde la historia cultural}

Las sociedades en las distintas épocas históricas, han ido clasificando a las personas, ubicándolas en distintos segmentos etarios, nombrándolas de diferentes formas, dotándolas de significaciones y roles particulares, marcando el pasaje de una etapa a otra mediante determinados ritos de entrada y salida al mundo adulto. Incluso no en todas las sociedades ha existido la categoría de juventud. El historiador francés Philippe Ariés (Ariés, 1987), ha señalado que la infancia-adolescencia, como una fase separada del desarrollo no existía en la Edad Media. En consecuencia, dice el autor, la juventud fue la respuesta al desarrollo productivo de la sociedad burguesa a partir del siglo XIII, donde el sistema escolar en tanto base del desarrollo de la sociedad moderna fue el contexto crucial para el sujeto juvenil."El individuo burgués tuvo que desarrollar sus potencialidades individuales

\footnotetext{
${ }^{1}$ Algunos representantes pioneros de esta corriente de estudio en América Latina son Rossana Reguillo, José Manuel Valenzuela Arce, en México; Mario Margulis, Marcelo Urresti, Sergio Balardini, en Argentina; Alonso Salazar y Jesús Martín Barbero en Colombia. Estos autores serán retomados a lo largo del trabajo.
} 
para encarar la vida productiva y política y para administrar sus propios intereses en esta vida. La juventud se desarrolló en el sistema escolar, que se volvió el principal agente del 'desarrollo de las potencialidades individuales'.

Como se dijo, la juventud constituye una condición históricamente construida y determinada; es decir, no siempre existió tal como la conocemos y conceptualizamos hoy día. $\mathrm{Si}$ bien en tanto etapa de la vida, la juventud comienza a cobrar cuerpo a partir de los siglos XVIII y XI, la irrupción definitiva de este nuevo sujeto en el escenario social occidental puede ubicarse a mediados del siglo XX, en el período posterior a la Segunda Guerra mundial. De esta manera, no definimos la juventud de una vez y para siempre, sino que como el resto de las edades de la vida, es una construcción social, histórica y cultural. Para revelar este aspecto, uno de los caminos transitados ha sido el de una historización de las formas de nominación de la juventud. Una " historia cultural de la juventud", que al develar las relaciones sociales de fuerza que crean las divisiones sociales de clase y de edad e n procesos históricamente situados (...) permite ubicar la problemática juvenil en una perspectiva que no se agota en el dato biológico. (Reguillo, 2000)

Desde una perspectiva de investigación histórica, en el campo de estudios sobre la juventud ha sido profundamente revelador el trabajo realizado por el italiano Giovanni Levi y el francés Jean-Claude Schmitt (Levi, Schmitt, 1996), que en Historia de los jóvenes centran la atención en la liminalidad de la juventud como característica que la diferencia de las otras edades de la vida: se sitúa como objeto móvil entre la dependencia infantil y la autonomía de los adultos. Esta condición, los momentos liminales de los ritos de paso previos a la entrada del mundo adulto en las diferentes épocas históricas, es planteada por ellos como objeto privilegiado 
de estudio: la juventud depende de unas determinaciones culturales que difieren según las sociedades humanas y las épocas, imponiendo cada una de ellas un orden y un sentido a lo que parece transitorio, desordenado y caótico.

La investigación recorre desde la Antigüedad hasta el mundo contemporáneo, las distintas construcciones y conceptualizaciones a modo de cronología de "larga duración", resultando un referente para la comprensión histórica de las diferentes condiciones juveniles de las sociedades occidentales.

\section{La emergencia de la juventud}

Al revisar las producciones einvestigaciones sobre juventud, podemos observar claramente, que los investigadores acuerdan en el reconocimiento de un período social e histórico concreto, la segunda posguerra, como el momento que permite otorgar visibilidad a los jóvenes tal como los conocemos en la actualidad, reivindicándolos como sujetos de derechos, pero fundamentalmente pasibles de control.

Como adelantáramos en apartados anteriores, fue el aumento de la esperanza de vida que se produjo después de la Segunda Guerra mundial lo que determinó la irrupción en el escenario occidental de un colectivo que, en tanto categoría social, resultaba inexistente hasta el momento. Este cambio dentro de la estructura social ocasionó, entre una de sus consecuencias, la necesidad de reacomodar el orden que hasta ese entonces orientaba la vida socialmente productiva. No obstante, como este nuevo segmento no podía insertarse de manera inmediata en los circuitos tradicionales de producción -y lo que se procuraba era evitar los desequilibrios que supondría su inclusión en la balanza de población económicamente activa-, la sociedad 
optó por postergar la incorporación de los jóvenes que, en relativamente poco tiempo, se habían convertido en un grupo social independiente (Hobsbawn, 1996).

En este sentido, la investigadora mexicana Rossana Reguillo, en su libro Estrategias del desencanto, que constituye uno de los trabajos de base de esta tesis, pero fundamentalmente de los estudios socioculturales sobre juventud en la actualidad, sostiene que son tres los elementos que "hacen visibles" a los jóvenes en el mundo contemporáneo: los dispositivos sociales se socializacióncapacitación de la fuerza de trabajo -paso por las instituciones de socialización-; la industria cultural -acceso a bienes de consumoy el discurso jurídico -definiendo su estatuto de ciudadano para el control o protección- (Reguillo, 2000).

A la vez, el sociólogo argentino Marcelo Urresti (2002), enuncia dos acontecimientos culturales, que ponen en un lugar protagónico a la juventud, en el contexto de los años dorados de bienestar:

1- El surgimiento del rock and roll, el surgimiento de una música cuyo mensaje excede el mero hecho musical (...) La cultura del rock, profundamente fue el vehículo que identificó a los jóvenes en términos generacionales: las mitologías, los mártires y los modelos que de allí surgieron acompañaron imaginarios -no siempre ajenos a la fetichización- que conquistaron el mundo a través de la industria cultural. Esta temática en particular ha sido muy bien trabajada por el historiador argentino Sergio Pujol (Pujol, 2002) en su libro La década rebelde, los años sesenta en la argentina.

2. La revolución sexual, que si bien se circunscribió al comienzo a sectores universitarios, se generalizó hasta convertirse en una bandera juvenil contra la represión. Esto no tardó en llegar a la política: el cuestionamiento generacional en todos los ámbitos llevó a la gran rebelión juvenil de la década de 1960. En estos años, caracterizados por el confort 
y el bienestar y el avance de los medios de comunicación, rápidamente se produce una internacionalización de los modelos juveniles de identificación. Emerge en este escenario, una cultura juvenil masiva, con un fuerte anclaje en el consumo cultural:

Los últimos años de los cincuenta y principios de los sesenta están teñidos por una acelerada modernización cultural y política y en especial la de los usos y costumbres de la sociedad. Muchas voces caracterizan este periodo como "norteamericanización" de la vida urbana y cultural, donde se hizo posible la identificación de ciertos jóvenes con el modelo de juventud estadounidense construido por las industrias culturales y difundido por los medios de comunicación: rebeldes sin causa y rockanroleros. Algunos autores relacionan directamente su origen con la proyección de películas estadounidenses como El Salvaje con Marlon Brando, Semilla de Maldad (1955) y Rebelde sin Causa (1957) de Nicolas Ray con James Dean, Natalie Wood y Sal Mineo o El prisionero del rock y El rey criollo con Elvis Presley. Desde entonces y cada vez con mayor autoridad, la industria cultural tomará un peso fundamental en la socialización juvenil, como lo han trabajado, entre otros, Urteaga Castro - Pozo, XXX)

Por último, el investigador mexicano José Antonio Pérez Islas (1998) sostiene que la emergencia de los jóvenes como agentes sociales, se puede sintetizar como la historia de una representación social, que se va conformando en la interrelación de dos fuerzas: la del control, ejercidas por las instituciones de poder adultas; y la de resistencia, elaborada por parte de las nuevas generaciones. 


\section{Conceptualizando a la juventud: las categorías}

Juventud: construcción histórica, sociocultural y relacional Conceptualizar la noción de juventud, y reflexionar acerca de qué es lo que se entiende por jóvenes, constituye sin duda uno de los principales desafíos que debe enfrentar cualquier estudio que se orienta a la descripción y problematización de esta cuestión. Engañosamente autoevidente en un primer acercamiento, este concepto suele conducir a múltiples confluencias de sentido; de allí que, según el tipo de indagación de que se trate, el investigador deberá dar cuenta en cada caso de las heterogeneidades y diversidades que asume un significante que resulta por demás complejo. Puede señalarse, incluso, que la noción de juventud no sólo no resulta "evidente" sino que cuanto más se profundiza en sus evocaciones y significados más inaprensible pareciera tornarse. Semejante constatación no supone, empero, postular un abandono en el abordaje de los temas vinculados a la juventud; por el contrario, vuelve aún más ineludible y atractiva la necesidad de su reflexión.

Desde la sociología de la cultura, podemos pensar la juventud como categoría que nos habla de una construcción sociohistórica particular sobre un rasgo etario. Así cuando Bourdieu (1990, Margulis, 1996)

La investigadora Rossana Reguillo (2000), sostiene que la conceptualización de la juventud no debe hacerse solamente desde los referentes biológicos como la edad, sin que debemos recurrir a su carácter discontinuo y dinámico. Es así que sostiene que al no compartir todo los jóvenes los modos de inserción en la estructura social, sus esquemas de representaciones configuran campos de acción diferenciales y desiguales.

Acordando con esta advertencia, el antropólogo mexicano José Manuel Valenzuela Arce (1997), señala que la juventud es un concepto vacío de contenido fuera de su contexto sociohistórico y cultural. En consecuencia, existe una amplia 
variedad de acotaciones y rangos temporales a partir de la cual se destaca la condición juvenil en diferentes países, dependiendo de su avance social, económico y cultural. El investigador enfatiza en el clivaje de clase para pensar la categoría juvenil. "El concepto de juventud se inscribe en las características fundamentales de la clase social de pertenencia. Esta afirmación puede parecer anacrónica para quienes se adscriben a algunas de las vertientes que han enterrado las condiciones estructurales como condicionantes centrales de conductas sociales. No obstante, la realidad de nuestros países muestra grandes

diferencias en los procesos de envejecimiento a partir de la adscripción de clase" (Valenzuela Arce, 1997).

Desde la sociología de la cultura, Margulis y Urresti (1996), sostienen que es necesario dotar de "materialidad" e "historicidad" al uso de la categoría juventud: "La juventud es una condición que se articula social y culturalmente en función de la edad, con la generación a la que se pertenece, con la clase social de origen, con el género y con la ubicación en la familia. Pero también hay que tener en cuenta la malla de las instituciones en las que se pone en juego la vida social.

3.2 La idea de moratoria: del condicionamiento social al condicionamiento vital

Es en el marco de los intentos por penetrar el espesor de este concepto de juventud, es que surgen los planteos ligados a la denominada moratoria social, noción que puede traducirse como una tentativa por "procesar socialmente la condición de edad" (Bourdieu, 1990), y a partir de la cual se toman en cuenta las diferencias económicas, sociales y culturales y todas aquellas heterogeneidades que hacen a las distintas maneras de ser joven.

Es Mario Margulis, en su trabajo La juventud es más que una palabra, que lo plantea de modo pionero dentro de la sociología de la juventud en la Argentina. 
Ahora bien, resulta claro que la noción de moratoria social no es aplicable a todos los jóvenes por igual sino que es preciso establecer distinciones entre los sujetos jóvenes atendiendo, especialmente, a lo que sucede con aquellos que no cuentan con las condiciones económicas y materiales que les permitan hacer usufructo de esta mentada tolerancia social. Como señaláramos en el caso de la edad, si se pretendiera tomar a la noción de moratoria como un rasgo que permite hacer hablar a la juventud, sólo se estaría dando lugar a aquellos jóvenes de sectores medios-altos que, siguen contando con la posibilidad de postergar su pasaje a la vida adulta.

Es en este sentido, que Margulis y Urresti (2000) realizan una crítica a la noción de moratoria social y proponen en cambio, trabajar desde el concepto de moratoria vital: "La juventud como plus de energía, moratoria vital, y no sólo social, como dicen todos los estudios, ó crédito temporal es algo que depende de la edad, y esto es un hecho indiscutible. A partir de ahí comienza la diferencia de clase y de posición en el espacio social, lo que determina el modo en el que se procesará posteriormente. Cómodijimos antes, no se puede obviar ninguna de las dos rupturas -la cronológica y la cultural- si se quieren evitar los peligros del etnocentrismo de clase y del fetichismo de la fecha de nacimiento".

Es en función de lo anterior, pues, que de acuerdo al sector social de que se trate, o de acuerdo al grupo juvenil que se pretenda abordar en un estudio, la idea de juventud en tanto período en el cual se posterga la asunción plena de responsabilidades económicas y familiares, tampoco puede ser asumida como una característica cerrada u homogénea que se mantenga ajena a las diferencias sociales y a los condicionamientos mencionados.

3.3 La memoria generacional: procesamiento social y cultural de las edades 
Ahora bien, las limitaciones que presenta el elemento etario para tratar de circunscribir la noción de juventud no intentan negar las vinculaciones que el factor biológico mantiene con esta problemática; o lo que es lo mismo, negar que la edad como dato físico, concreto y material escapa a la manipulación social y constituye, aunque no de manera determinante, un rasgo claramente diferenciador, incluso con todas aquellas variaciones que este segmento social pueda presentar. Es en este punto donde desde los estudios de juventud se hace un alto y se considerara el concepto de generación, que si bien hace posible retomar ciertos rasgos etarios no lo hace ya desde la biología sino desde la historia. Dice Margulis: "La generación, alude a la época en que cada individuo se socializa, y con ello, a los cambios culturales acelerados que caracterizan nuestro tiempo. Cada generación puede ser considerada, hasta cierto punto, como parte de una cultura diferente, en la medida en que los más jóvenes incorporan en su socialización nuevos códigos y destrezas, lenguajes y formas de percibir, de apreciar, de clasificar y distinguir. Cada época tiene su episteme, y las variaciones epistémicos son percibidas y apropiadas, durante su proceso de socialización, por los nuevos miembros que va incorporando la sociedad. (Margulis, 2003)

De este modo, más que constituir una categoría estadística relacionada con la biología, la noción de generación remite a la edad pero procesada por la cultura y la historia. De este modo si se considerara toda una población, una alineación vertical la agruparía de acuerdo a las características socioeconómicas, en tanto que una alineación horizontal la clasificaría considerando el plano generacional (Margulis, Urresti: 2001). Dicho de otro modo, la generación persevera y acompaña en la vida, y considerada dentro de ella la juventud es sólo uno de sus estadios. Lo que hace la generación es 
remitir a la historia, y dar cuenta del momento social en que una cohorte se incorpora a la sociedad; es esto lo que define características comunes en el proceso de socialización y hace que sus miembros incorporen los códigos culturales que imperan en una época dada y junto con ellos factores y elementos políticos, sociales, tecnológicos, etc.

He aquí la importancia de considerar, en un estudio sobre jóvenes, la pertenencia generacional como vía de acceso a la memoria, la historia que la atraviesa y la forma de percibir que la caracterizan. Y por qué puede afirmarse que pertenecer a una generación, y no a otra, supone poseer códigos culturales diferentes que orientan las percepciones, los gustos, los valores y los modos de apreciar, todo lo cual desemboca en mundos simbólicos heterogéneos, con distintas estructuraciones de sentido.

Ahora bien, lo que se busca sostener con esta noción es que la idea de "delimitación generacional" -si no se quiere emplear el término de pertenencia generacional- lo que permite es deconstruir la sociedad en un momento dado reconociendo la importancia de la diversidad, el contexto y la historia en los procesos de "reproducción social empírica" (Giddens, 1991). Es decir, si bien estos hacen intersección entre sí de distintas maneras lo hacen en un cierto contexto espacio-temporal, frente a una cierta generación y distribución de poder y a una cierta reflexividad institucional.

\section{Antecedentes en el estudio de las culturas juveniles.}

En este apartado, haremos un breve recorrido por las principales corrientes teóricas que desde la antropología y la sociología, han tenido a la juventud como objeto de estudio. Desde distintas perspectivas y enfoques, ya sea situándolos como horizonte de crítica o asumiendo las categorías propuestas, estas han sido retomadas por los investigadores latinoamericanos dedicados a temas de juventud y cultura. 
Los primeros estudios antropológicos acerca de la juventud, los encontramos hacia 1920, años en que simultáneamente los jóvenes -en ese entonces se usaba el término adolescencia mayoritariamente- son el foco de debate y atención de distintos investigadores: el psicólogo norteamericano Stanley Hall, la antropóloga norteamericana Margaret Mead y antropólogos pertenecientes a la Escuela de Chicago, como Frederik Trasher y William Foote White 2 .

Stanley Hall, inspirado en el darwinismo e influenciado por las ideas roussonianas ${ }^{3}$ fue el fundador de la pedagogía evolucionista y pionero de la introducción del psicoanálisis en los Estados Unidos. Publica en 1905 Adolescencia, siendo esta la primera elaboración conceptual y académica de este periodo de la vida, considerado por el autor como un proceso de crisis, de transición, confusión y estados anímicos cambiantes, que además alcance universal. Este primer abordaje acerca de la juventud será de gran influencia e impacto en el imaginario social y en estudios posteriores, asociando a la juventud con determinadas patologías y período de crisis. Para estos años, las proposiciones psicobiologicistas para explicar los comportamientos juveniles, se evidenciaban como hegemónicas en el campo académico e intelectual. Para el autor, la adolescencia -que se extiende de los doce a

\footnotetext{
${ }^{2}$ Para este recorrido, se retoman algunos elementos de la clasificación realizada por Carles Feixa (Feixa, 1998)

${ }^{3}$ En "El Emilio" de Jean- Jaques Rousseau define a la juventud como el "segundo nacimiento" y la sitúa entre los doce y los veinte años. Dice "aquí nace de verdad el hombre a la vida, y ya nada humano está fuera de él. Hasta este momento nuestros afanes no han sido otra cosa que juegos de niños, y es ahora cuando adquieren verdadera importancia”. Y describe los cambios ocurridos en los niños varones: "A los signos morales de un humor que se altera se unen cambios sensibles en su exterior. Su fisonomía se desenvuelve y se imprime en ella su sello característico; el vello escaso y suave que crece bajo sus mejillas toma consistencia, su voz cambia o mejor es otra; no es niño ni hombre y no puede tomar el habla de uno ni de otro".
} 
los veintidós, veinticinco años- es considerada una categoría natural, universal, previa a la vida adulta (Feixa, 1998).

Estas ideas, serán refutadas por la antropóloga Margaret Mead, quien al realizar su trabajo de campo en Samoa hacia 1925, intenta mostrar y comprobar como ese universal norteamericano de "turbulencia y tempestad" no estaba presente en todas las culturas: "La adolescencia en Samoa no representaba un período de crisis o tensión, sino, por el contrario, el desenvolvimiento anómico de un conjunto de intereses y actividades que maduraban lentamente" (Mead, 1973).

En el clásico y best seller Adolescencia, sexo y cultura en Samoa (1973) Mead se pregunta si las perturbaciones que sufren los jóvenes en la sociedad norteamericana corresponden al ámbito de la naturaleza o muy por el contrario al ámbito de la cultura. Dejará bien en claro, que la dimensión cultural y social será determinante en la conformación de la personalidad de los adolescentes.

Franz Boas, quien había sido profesor de Margaret Mead y su acompañante en las investigaciones antropológicas con las adolescentes samoanas, sostiene en el prólogo del libro: "Los resultados de esta seria investigación confirman la sospecha largamente alimentada por los antropólogos sobre el hecho de que mucho de lo que atribuimos a la naturaleza humana no es más que una reacción frente a las restricciones que nos impone nuestra civilización" (Boas, 1973: Prólogo).

El tema de la juventud, ya no adolescencia, es retomado por la antropóloga hacia 1971, cuando en Cultura y Compromiso, estudia la ruptura generacional, como un fenómeno totalmente nuevo, planetario y universal: "Nuestro pensamiento nos ata todavía al pasado, al mundo tal como existía en la época de nuestra infancia y juventud, nacidos y criados antes de la revolución electrónica, la mayoría de nosotros no entiende lo que esta significa. Hoy, súbitamente, 
en razón de que todos los pueblos del mundo forman parte de una red de intercomunicación con basa electrónicas, los jóvenes de todos los países comparten un tipo de experiencia que ninguno de sus mayores tuvo o tendrá jamás. A la inversa, la vieja generación nunca verá repetida en la vida de los jóvenes su propia experiencia" (Mead, 1971).

En Cultura y Compromiso, diferencia entre tres tipos de cultura que coexisten en las sociedades contemporáneas:

a) culturas postfigurativas, -o tradicionalistas- en las que los niños aprenden de sus mayores, el cambio es lento e imperceptible. La hipótesis de fondo en este tipo de cultura, es que la forma de vida es inmutable, eternamente igual, por ende el futuro reside en el pasado.

b) culturas cofigurativas, en las que tanto los niños como los adultos aprenden de sus pares, de sus contemporáneos. Esto permite a los más jóvenes introducir cambios respecto de sus mayores.

c) culturas prefiguratias, emergen a fines de los años sesenta, en estas culturas los adultos también aprenden de los niños y los pares reemplazan a los padres: "Ahora ingresamos en un período sin precedentes en la historia, en el que los jóvenes asumen una nueva autoridad mediante su captación prefigurativa del futuro aún desconocido. Debemos aprender junto con los jóvenes la forma de dar los próximos pasos, pero para proceder así, debemos reubicar el futuro. A juicio de los occidentales el futuro está delante de nosotros. A

juicio de muchos de los pueblos de Oceanía el futuro reside atrás. Para construir una cultura prefigurativa, en la que el pasado sea útily no coactivo, debemos modificar la ubicación del futuro: el Futuro Es Ahora (Mead, 1971)"

Estas conceptualizaciones acerca de las culturas prefigurativas y de la ruptura generacional, donde los jóvenes son quienes están mejor dotados y con más capacidades 
para enfrentar el futuro que se torna incierto; y que además posibilita pensar en una reubicación del futuro, son retomadas por la mayoría de los investigadores latinoamericanos, cuando sostienen que las prácticas y representaciones juveniles deben ser leídas como "metáforas del cambio social" (Feixa, 1998), como anuncios y expresión de los cambios sociales y culturales (Barbero, 1998). En tal sentido, se produce el desplazamiento de una mirada lineal de las prácticas juveniles hacia otra de tipo compleja, que permita entender las nuevas concepciones de la política, de lo social, de lo cultural, de las instituciones; dimensiones que revelan las formas que puede ir adquiriendo la sociedad. En el campo de los estudios socioculturales en comunicación, es Jesús Martín Barbero quien propone como objeto de estudio privilegiado para pensar las culturas contemporáneas a la juventud desde esta óptica a principio de la década del noventa. Asumiendo la propuesta, Rossana Reguillo sostiene que lo distintivo que comportan las culturas juveniles en la actualidad, es la capacidad y velocidad en el procesamiento de la información que circula por el planeta, capacidad a la que llamó "metabolismo acelerado" en sus investigaciones realizadas en los años 90 . Hoy sustituye esa metáfora orgánica, por una tecnológica: la del videoclip ${ }^{4}$ (Reguillo, 2000). Jesús Martín Barbero (1998) y su desarrollo en tormo a los palimpsestos de identidad y Marcelo Urresti $(1998,2002)$, y sus investigaciones sobres los usos sociales del espacio urbano, también recogen las conceptualizaciones sobre la ruptura generacional y la captación prefigurativa del futuro en las prácticas y sentidos juveniles.

\footnotetext{
${ }^{4} \mathrm{Al}$ respecto, Reguillo explica: "decir que los jóvenes piensan en videoclip, es una forma de aludir a los modos condensados de representación y acción de la culturas juveniles, que con sus prácticas y acciones cotidianas han rebasado las culturas post y cofigurativas" (Reguillo, 2000)
} 
Ahora bien, retomaremos los párrafos iniciales de esta apartado sobre los antecedentes que tuvieron a los jóvenes como objeto de reflexión. Mientras Mead estudiaba a las adolescentes en Samoa, en Estados Unidos nos encontramos con la Escuela de Chicago o de la "ecología urbana", quienes pioneramente trabajaron las culturas juveniles urbanas, en términos de subculturas, producto de su creciente visibilización en el espacio público. Este grupo de investigadores, liderados por Robert Park y Ernest Burguess, hacia los años veinte, en un contexto de explosión demográfica, creciente industrialización, de un aluvión inmigratorio que se trasladaba desde norte de Europa hacia los Estados Unidos y de expansión de barrios pobres; centrarán la atención en los síntomas de marginación, desviación y aculturación de las ciudades y en este contexto harán foco en las pandillas urbanas juveniles. El objetivo era desentrañar las estructuras de esas pequeñas microsociedades juveniles, con reglas y lazos de pertenencia propios (Urresti, 2002). La época, se tornaba propicia para los estudios de tipo criminológico y las pandillas juveniles se entendían como un síntoma de anomia.

En este marco se resaltamos dos trabajos: The Gang, de Frederik Trasher, publicado en 1929, que se centraba en el estudio de las pandillas juveniles emergentes en los barrios populares de Chicago, sosteniendo que la ciudad favorecía los comportamientos desviados y posteriormente hacia 1943, La sociedad de las esquinas de William Foote Whyte, quien desde un trabajo etnográfico, cuestiona la idea naturaleza delincuencial de la juventud, enfatizando el vinculo y el sentimiento de solidaridad, donde las desviaciones deben ser encausadas en beneficio de la funcionalidad del sistema (Feixa, 1998). 


\section{Los estudios sociológicos y culturales}

Una otra línea de reflexión en la temática es la que proviene de la sociología estructural funcionalista, en los años de posguerra, con Talcot Parsons como principal exponente. Este enfoque acude a la edad y a la generación como principio clasificatorio y explicatorio de la juventud en las sociedades. De esta forma se abordaba una definición homogénea e interclasista de la juventud, que enfatizaba en el tema de la transición a la adultez y su postergación cada vez más evidente debido a algunos factores: mayor tiempo de ocio, la escolarización masiva y la moda, son factores que permiten sustentar esta definición de una "cultura generacional".

Serán representantes de la heterogénea Escuela de Birmingham, del Center for Contemporary Cultural Studies de la Universidad de Birmingham, quienes propongan en contraposición a la edad como principio clasificatorio, la clase y fracciones de clase, como explicación del conflicto y del cambio social. Desde la sociología interaccionista, con aportes del marxismo gramsciano y la semiología francesa; en los años setenta, nombres como los de Stuart Hall, Tony Jefferson, John Clarke, Dick Hedbige, van a estudiar en Gran Bretaña a las culturas juveniles de posguerra y sus distintas agrupaciones, desde la idea de clase -aunque van a ir incorporando los factores de género, etnia y raza- como factor estructurante: teds, mods, skin, freaks, rockers, hippies. Estos autores se expresan en términos de sub-culturas juveniles, concepto que retoman de la Escuela de Chicago: "Las subculturas juveniles, pueden entenderse como tentativas ritualistas o simbólicas de resistir el poder de la hegemonía burguesa, mediante la adopción de comportamientos que parecen amenazantes para el establishment" (Hall y Jefferson, 1993, trad. de Mariana Chavez). 
En 1976, en Resistance Through Rituals, estos investigadores, ahondarán en el carácter contrahegemónico y alternativo de las subcultura juveniles. Rescatarán las resistencias simbólicas que operan en las diversas expresiones y manifestaciones juveniles, en tanto grupos subordinados en relación a la cultura adulta dominante. Los rituales juveniles, que refuerzan el sentimiento de identidad grupal, se expresan mediante los diferentes estilos (teds, mods, skin, punks), que los investigadores entienden como metáforas del cambio social.

Otro trabajo clave en la temática, que además se convirtió en uno de los libros de mayor circulación de los Cultural studies, es Subculture. The Meaning of style (1979) de Dick Hebdige. Se abordan en este trabajo etnográfico, las subculturas juveniles y la fragmentación de los estilos de vida del mundo obrero.

Los Cultural studies, se constituyen en un referente obligado por sus contribuciones acerca del universo social juvenil y las manifestaciones del conflicto generacional, abarcando un amplio espectro de subculturas, no solo de las clases obreras, sino también las colonias de inmigrantes y la pequeña burguesía. Sus aportes serán retomados por antropólogos, sociólogas, comunicadores, que desde Latinoamérica tendrán en las culturas juveniles su objeto de estudio. Algunos de ellos son José Manuel Valenzuela Arce (1997), Rossana Reguillo (2002), Jesús Martín Barbero (1987), Carles Feixa (1999), Mario Margulis (1996), Marcelo Urresti (2002), Jorge Elbaum (1996), entre otros.

\section{Culturas Juveniles y estudios culturales en América Latina: una propuesta constructivista y relacional}

Este apartado intentará dar cuenta de la emergencia de un campo de estudios sobre las culturas juveniles en 
América Latina y Argentina. Realizaremos dos recorridos: 1) presentaremos los factores, los condicionantes, los escenarios que han posibilitado el surgimiento de este campo de estudios y 2) mediante una revisión bibliográfica sistematizaremos las principales producciones sobre juventud en correspondencia con las temáticas abordadas en nuestra tesis, a saber, la familia, el trabajo, la política y la escuela.

Las investigaciones y producciones revisadas, proceden desde la sociología fundamentalmente, pero también desde la comunicación, la educación y la antropología. La mayoría son producciones argentinas y en menor medida latinoamericanas y europeas.

\section{Escenarios y condiciones de surgimiento de la relación jóvenes/cultura ${ }^{5}$}

En América Latina, los estudios sobre juventud, desde una perspectiva sociocultural, podemos ubicarlos a partir de la segunda mitad de la década de 1980. Esto no quiere decir, que previamente no existieran estudios o investigaciones dedicadas a la temática, sino que en muchos casos la juventud no era abordaba en clave de análisis socio cultural, prevalecía el carácter descriptivo de las producciones; no se problematizaban los presupuestos teóricos y metodológicos implicados. Los jóvenes eran entendidos en términos de delincuentes, contestatarios o consumistas, siempre como sujetos pasivos, sin capacidad de agencia.

En las ciencias sociales, y la comunicación en particular, es a partir de la década de 1980, sacudidas por una ruptura epistemológica, pero también política, cuando van a desplazar la mirada hacia nuevos objetos de estudio. Los jóvenes, de esta manera, comienzan en estos años a ser entendidos y "construidos", en términos socioculturales desde las ciencias

${ }^{5}$ Estas ideas se encuentran profundizadas en el capitulo III de esta tesis doctoral. 
sociales. Se comienza a reconocer a la juventud como un sector social, con rutinas culturales particulares, con capacidad de apropiarse de objetos, tanto materiales como simbólicos, es decir, como sujetos de discurso (Reguillo 2000, Pérez Islas 1998).

Los aportes de la Escuela de Birmingham y del antropólogo catalán Carles Feixa, quien dice que una antropología de la juventud apunta a una doble dirección: en primer lugar al estudio de la construcción cultural de la juventud, es decir, de las formas mediante las cuales cada sociedad modela las maneras de ser joven; en segundo lugar, al estudio de la construcción juvenil de la cultura es decir, de las formas mediante serán las cuales los jóvenes participan en los procesos de creación y circulación culturales, son vertientes fundamentales en la constitución y emergencia del campo de estudios socioculturales latinoamericano sobre jóvenes.

En países como México ó Colombia, la aparición de las llamadas bandas juveniles (Perez Islas, 1998) y su exposición periodística, hizo que la academia y las autoridades se replantearan el abordaje de la temática.

En América Latina, las primeras producciones desde una perspectiva cultural, reconocen como pioneros al antropólogo mexicano José Manuela Valenzuela Arce (1988, 1999) y sus investigaciones sobre la cultura de la violencia, las expresiones identitarias de los jóvenes de sectores populares; la mexicana Rossana Reguillo $(1997,2000)$ con la línea de trabajo sobre las culturas juveniles, sus expresiones culturales, identidades y agrupaciones, en tanto formas de acción política no institucionalizada. El español-colombiano Jesús Martín Barbero (1998) ha ayudado a pensar la los "modos de estar juntos" y las cuestión identitaria en los jóvenes.

También son fundamentales como antecedentes de este campo de estudios, el aporte que proviene del periodismo 
y la crónica o ensayo. Así podemos mencionar a Alonso Salazar (1998) periodista colombiano, cuyos trabajos están relacionados con las grandes problemáticas sociales de la ciudad, especialmente con los temas de juventud, violencia y narcotráfico; Carlos Monsiváis (1988) periodista y ensayista mexicano, quien trabaja las culturas juveniles y las ciudades; los venezolanos José Roberto Duque y Boris Muñoz (1995) que en sus trabajos ponen en escena la vida de los jóvenes venezolanos de precaria condición social y la violencia en Caracas. Podemos agregar aquí también, aunque su trabajo es más reciente, pero se encuentra en sintonía con este perfil investigativo, al periodista chileno-argentino Cristian Alarcón (2003) quien desde la crónica periodística retrata la exclusión y la violencia a través de la vida cotidiana de "los pibes chorros" argentinos en las villas del Gran Buenos Aires.

En 1985, la Asamblea General de las Naciones Unidas declara el Año Internacional de la Juventud, en respuesta a la crítica situación que lo jóvenes atraviesan a nivel mundial (Szulik, Kuasñosky; 1996), situación que les otorga un protagonismo, del cual no habían gozado en años anteriores, en el ámbito de las políticas estatales.

En Argentina, los jóvenes no fueron considerados desde el Estado como un sector social con problemas específicos cuando protagonizaron vanguardistamente movimientos sociales de liberación, sino que fue recién con la crisis estructural acaecida en los años ochenta lo que motivó desviar la atención hacia la juventud. Con posterioridad al advenimiento de la democracia, hacia 1986 se publica una de las primeras piezas conceptuales sobre juventud en Argentina: La juventud argentina. Informe de situación, de Cecilia Braslavsky (1986). ${ }^{6}$ No obstante, es recién en la década de 1990,

\footnotetext{
${ }^{6}$ Este trabajo se ha tornado de referencia ineludible para los estudios sobre
} 
cuando se va a empezar a producir de manera importante bibliografía sobre juventud en nuestro país. Es el trabajo del sociólogo Mario Margulis (1994, 2000, 2003), quien se revela como el fundador de la línea de investigación en culturas juveniles en Argentina, junto a Marcelo Urresti (1994, 2000, 2003), Jorge Elbaum $(1994,2000)$ y su equipo de investigación que trabajarán desde el Instituto de Investigaciones Gino Germani. Desde la sociología de la cultura, este investigador y su equipo, le otorgan estatuto sociológico a la categoría de juventud, estudiando la dimensión subjetiva del mundo juvenil, las apropiaciones del espacio urbano, las relaciones afectivas, la sexualidad, el mundo de la noche, entre otras variables. Es a partir de este momento que comienza a nacer en el país una línea de investigación sociocultural en la temática juventud, adquiriendo este grupo de investigación, un lugar de referencia ineludible para las siguientes investigaciones que llegarán al campo académico.

Otras investigaciones que han ayudado a la conformación del campo de estudios en culturas juveniles, han sido las tempranamente realizadas por los sociólogos Ana Wortman (1991) y Javier Auyero (1993) cuyos trabajos han incursionado en la vida cotidiana y el mundo de los jóvenes "de la periferia" y los sectores populares. Por otro lado, las dimensiones del consumo y el rock nacional, han sido trabajadas pioneramente por Pablo Alabarces (1995), Pablo Vila $(1985,1999)$ y Pablo Semán (1999), y Eva Giberti (1998). Asimismo una línea vinculada al estudio de la juventud, vida cotidiana y trabajo/ delito, ha sido la desarrollada por Gabriel Kessler $(1997,2002)$

\footnotetext{
juventud en Argentina. Braslavsly venía pensando en cuestiones de juventud desde comienzos de la década de 1980. Además tempranamente pensó la condición de la mujer en un trabajo publicado en 1984 bajo el título "Las mujeres jóvenes argentinas entre la participación y la reclusión”. Hacia el año 1986 publica también "La juventud argentina: entre la herencia del pasado y la construcción del futuro".
} 
y Sandra Gayol (2002), Daniel Miguez (2002); la participación política y social ha sido producida fundamentalmente por Sergio Babardini (2000). Desde la sociología de la educación, Emilio Tenti Fanfani $(1996,2000)$ ha abordado la cuestión educacional y la juventud y por último queremos subrayar la temática salud, vida reproductiva y sexualidad, que ha sido la trabajada por Edith Pantelides (1995), Ana Kornblit (1994) y Ana M, Mendez Diz (1994), entre muchos otros.

\section{Antecedentes sobre juventud y política}

Para este trazado, en primer lugar tomaremos aquellos trabajos que han diagnosticado un nuevo sentido de la política en las culturas juveniles, junto con el renacer y la puesta en escena de la subjetividad y de las emociones. En este sentido, retomamos el trabajo de Ulrich Beck (1999) quien avizora que en tiempos de crisis y desconcierto a la juventud la conmueve aquello que la política en gran parte excluye. Los intereses, las consignas, los emblemas que hoy mueven a los jóvenes permiten pensar, según el sociólogo alemán, que éstos practican una negación de la política altamente política ..

Así mismo Rossana Reguillo (2000) se pregunta por la diversidad y hetrogeneidad de las formas organizativas juveniles, sus maneras de entender y de ubicarse en el mundo, sus prácticas cotidianas, sus grupalidades. Señala que a partir de la década de los 80 , los jóvenes han ido buscando formas autogestivas de organización (bandas, punks, taggers), que sin negar la vigencia de las organizaciones tradicionales (partidos políticos, clubes barriales, entre otros) sostiene que expresan como "nuevos" signos de lo político, que mediante una nueva concepción del poder se van alejando del autoritarismo. Las diferentes agregaciones juveniles, y sus manifestaciones, las formas de gestión, las interacciones con oreas instituciones, los lenguajes con los que se expresan, pertenecen al "nuevo" orden de de lo político. 
Es en este sentido que los trabajos realizados por Sergio Balardini realizan un balance de la participación juvenil a través de las décadas del sesenta, setenta y la actualidad y da cuenta de los cambios acaecidos en las formas de participación social y política de los jóvenes. Advierte el sociólogo que a pesar de que algunos analistas han interpretado ante el desgaste de los partidos políticos tradicionales, el rechazo de los jóvenes hacia este terreno esto no quiere decir que los jóvenes estén confinados a la vida privada y que tengan desinterés por lo público. Enuncia que han emergido nuevos espacios de reunión y acción social de los jóvenes, algunos de los cuales tiene una finalidad política directa, y otros solamente expresiva. Dice el investigador: "Agotada la marea juvenil de los sesenta y parte de los setenta, y bloqueados los cauces participativos auténticos de una sociedad en vigoroso proceso de cambio, fue emergiendo una diversidad juvenil, traducción de una búsqueda identitaria basada, principalmente, en la proliferación de las particularidades culturales, estilísticas y de consumo".

En este trabajo de Balardini (Balardini, 2000), se presentan experiencias de participación juvenil en distintos países. Del alemán René Bendit (2000) ofrece un panorama de la participación social y cultural de los jóvenes en países de la Unión Europea, en un contexto social caracterizado por el cambio constante, por la modernización tecnológica y social y por el desarrollo avanzado hacia una sociedad de servicios. El investigador concluye que "tanto en jóvenes como en adultos, existe la articulación de un sentimiento de compromiso social y político 'frenado': estando en principio dispuestos a comprometerse social y políticamente, la mayoría de los jóvenes consideran que les faltan organizaciones y estructuras que consideren adecuadas, es decir, con las cuales puedan identificarse y generar cambios efectivos en la sociedad". 
Asimismo, la costarricense Dina Kraukspof (2000) indaga en la participación social efectiva de los jóvenes, que llama "participación protagónica", es una meta que demanda abandonar el adultocentrismo, tomar en cuenta las diversas situaciones de exclusión, permitir y escuchar abiertamente la voz de las juventudes de los más diversos ámbitos. Los cambios sociales han sustituido las bases del llamado conflicto generacional que se expresaba en la lucha de los jóvenes por el poder adulto. Mucho de lo que se ha dado en llamar la desafección política juvenil es el abandono de esa lucha. En el viejo paradigma las identidades colectivas están en función de códigos socioeconómicos, e ideológicos - políticos -estudiantes, jóvenes urbano populares, socialistas, etc.-. En el nuevo paradigma, lasidentidades se construyen en relación con espacios de acción y mundos de vida como: sexo, preferencia sexual, sobrevivencia de la humanidad (medio ambiente) y derechos indígenas, de las mujeres, democráticos, etc. En este artículo se reconoce como característica de la juventud actual el hecho de pensar globalmente y actuar localmente. La participación social real de las juventudes discurre en contextos informales y en metas innovadoras. La ausencia de una programación social que integre constructivamente la fase juvenil puede ser considerada parte de una crisis social que incluye la fractura de los paradigmas y supuestos que sostienen el modelo de juventud.

Un otro acercamiento hacia la participación social de los jóvenes chilenos, la ofrece Gabriela Fernández (2000) quien realiza una serie de reflexiones sobre la participación política de los jóvenes chilenos, surgidas de experiencias académicas y de un estudio al respecto realizado en 1999, llevado a cabo desde el Centro de Investigaciones y Desarrollo dela Educación por encargo del Instituto Nacional de la Juventud de Chile. Fernández intenta problematizar el concepto de participación 
política, además de introducir una definición de juventud que sobrepasa lo estrictamente demográfico, considerando también elementos sociológicos. Se desprende de aquí la idea de que existen características de los jóvenes de algunas generaciones que los distinguen de los de otras, y ello tiene que ver con el contexto en el que les toca vivir y socializarse. De esta forma varía la relación con la participación política de acuerdo al factor generacional, y dicha relación también depende de la situación económica, del sexo, de la educación, etc. Todo este conjunto de elementos hace evidente que no se puede pensar en un prototipo de joven, sino en distintos tipos y formas de ser joven. A lo largo del trabajo se muestra el desencanto de los jóvenes respecto de la forma en que opera la política y, sobre todo, de quienes la representan como los gobernantes y los partidos políticos. También se observa la influencia de los medios de comunicación en la opinión de los jóvenes, quienes otorgan gran credibilidad al llamado "cuarto poder".

Otra aproximación a la realidad juvenil chilena y la participación social, la procura Mario Sandoval (2000) quien problematiza el concepto de juventud teniendo en cuenta su multidimensionalidad y sus variaciones contextuales, y los modos de participación que ponen en juego los jóvenes chilenos a fines del siglo XX. Al observar la realidad chilena, Sandoval plantea que los jóvenes se repliegan cada vez más hacia su vida privada, lo que resulta razonable ya que la acción política partidista no tiene legitimidad en el mundo juvenil frente a la centralidad y eficiencia que presenta el mercado y la ausencia del Estado en materia de seguridad social. Los jóvenes, dice el sociólogo, perciben a la política en términos prácticos, más asociada con las posibilidades de logros individuales que con ideales o identificaciones colectivos. Los jóvenes se encuentran desencantados con los mecanismos 
de representación, y le dan escasa relevancia a los partidos políticos en el mantenimiento de la vida democrática. Al parecer, hoy día la juventud no estaría adhiriendo ni al antiguo modelo cultural basado en la razón social, ni tampoco completamente al nuevo, fundado en la autorrealización autónoma, que no termina de imponerse. La preocupación por la participación política de los jóvenes se corresponde con una visión del distanciamiento "patológico" entre jóvenes y política, en un país donde la inscripción al voto es voluntaria, y donde, según a las cifras, los jóvenes constituyen el grupo más numeroso de la población chilena.

Un siguiente grupo de investigaciones, son aquellas que han puesto énfasis, han evidenciado, han dado cuentas de las nuevas agregaciones juveniles, las llamadas "tribus urbanas", bandas, pandillas, grupos juveniles. En fin, nos referiremos en este apartado a las "nuevas" y heterogéneas formas de ocupación del espacio público y la vida cotidiana de los jóvenes.

Es el sociólogo Michel Maffesoli (1988), quien primero ha nombrado cierta condición actual de las sociedades a partir de la idea de neotribalización y su influencia ha sido de considerable importancia en los estudios sobre los nuevos modos de concebir lo político de los jóvenes. Mediante la metáfora de las tribus explica que la constitución de los microgruposjuveniles que empiezan a ser cada vez más visibles, tiene que ver con un proceso de "desindividualización" y con nuevas formas de socialidades, con el "estar juntos sin más". Ante contextos de mayor globalización, emergen procesos de interacciones fuertes, tribales, con un sentimiento de pertenencia y proximidad espacial.

Los rasgos del neotribalismo para el autor son los siguientes: 1) Comunidades emocionales: predominan aquílos elementos de tipo emocional, pasional y afectivo al interior de los 
grupos que la conforman. Las comunidades emocionales, se enfrentan a las comunidades racionales, instrumentales, que caracterizan a las sociedades contemporáneas. 2) Energía subterránea: describe mediante este tópico a las prácticas sociales de resistencia y alternativas, para responder a la uniformidad y pasividad que la sociedad de consumo le impone al individuo. Esa energía subterránea va buscando vías de expresión, grupalidades, desde las cuales emerger y oponer al poder tradicional. 3) Sociabilidad dispersa: con esta noción, se refiere a unas nuevas formas fluidas y desarticuladas de sociabilidad, distinguidas de lo social moderno, que se caracteriza por la individualidad y un marco rígido de actuación para los individuos Esa sociabilidad tribal se abre paso desde los intersticios y se opone a la lógica dominante. Y finalmente 4) Fisicidad de la experiencia: aquí se hace referencia a la importancia del entorno urbano, de la ciudad, en tanto determina las pautas de nuestro comportamiento. El espacio-físico predominante, en tanto influencia y modela "las formas de ser." A mayor globalización y cosmopolitismo de las ciudades, mayor necesidad de surgimiento de espacios de identificación localista, intimista y proximidad espacial.

Entre los investigadores que han abordado el estudio de "tribus urbanas", encontramos a Rossana Reguillo (2000) quien desde un trabajo etnográfico describe el comportamiento, las cuestiones identitarias y las expresiones de diversas agregaciones juveniles mexicanas: anarcopunks, taggers, raztecas y los raves.

También José Manuel Valenzuela Arce (1997) pone en escena los elementos centrales de una heterogénea gama de grupalidades juveniles de sectores marginales, favelas y cinturones de miseria, en el Brasil de los 90: los funks, punks y graffiteros.

Por otro lado el periodista Alonso Salazar (1998) ha penetrado en el mundo de la violencia juvenil, el narcotráfico 
y el sicariato en Colombia. El analista explica el modo de retroceso de los procesos tradicionales de identificación, situación por la cual los delincuentes juveniles buscan reconocimiento social y construcción de identidad. Al decir de Salazar "los jóvenes se asoman a la sociedad que les devuelve una imagen gris, $\tan$ gris como las que ven en sus familias, la Iglesia, en la religión, la escuela y el Estado, instituciones y discursos desvalorizados; $y$ entornos donde no funcionan las leyes ni las normas esenciales de la convivencia”.

Asimismo, los españoles Oriol Costa, Pérez Tornero y Tropea (1996) estudian el fenómeno de las "tribus urbanas", haciendo una historización, pero también abarcan las sociedades actuales, atendiendo al estudio de la cultura urbana contemporánea, sus tensiones y zonas oscuras.

En el ámbito local, el trabajo de Marcelo Urresti (1997) realizado en el marco de una investigación sobre la cultura de la noche de los jóvenes, describe la presencia de un grupo llamado "modernos", denominados también "bohemia vanguardista", que marca su propio territorio en la ciudad de Buenos Aires. Sus circuitos nocturnos, las relaciones interpersonales, sus expresiones, serán analizadas por el investigador. También Jorge Elbaum (1997) aborda la cultura bailantera, de los jóvenes que concurren a "boliches de bailanta", para analizar a este género musical como fenómeno social desde la idea de tribu.

Un último trabajo a mencionar aquí es el efectuado por la antropóloga Mariana Chaves (2005) quien describe y analiza, una grupalidad juvenil en la ciudad de La Plata, denominada "alternativos". La forma de ocupación del espacio urbano y la dimensión identitaria serán trabajadas desde aquí.

También algunos investigadores han mirado al movimiento murguero como otra de las formas de expresión y ocupación del espacio público. Un trabajo como el de Alfredo Alfonso y 
Magali Catino (2002) estudia el fenómeno de apropiación de espacios de representación urbana dinamizados las murgas, en tanto propuesta cultural con afluentes de protagonismo corporal y expresivo, en la ciudad de La Plata.

Por último, señalamos dos investigaciones en la ciudad de La Plata desde la antropología realizadas por María Pozzio (2002) y por Mariana Chavez (2004). Se trata de investigaciones etnográficas, que rescatan al movimiento murguero como modo de expresión de las nuevas formas de participación política.

Se ha dicho que las relaciones de sociabilidad juveniles están fuertemente marcadas por el renacer de la subjetividad y las emociones. Agrupamos aquí otra serie de trabajos donde algunos rituales como la música y el deporte, comienzan a ser entendidos desde una dimensión cultural y disputando un lugar en la construcción de identidades públicas. Algunas investigaciones argentinas, han revisado y estudiado la "cultura del rock" como un factor clave en la cuestión identitaria juvenil. Es así que Pablo Alabarces (1995) sostiene que el rock es portador de un sentido de inclusión más generacional que social, etario antes que geográfico y cronológico antes que económico. El fenómeno del rock, la cultura del rock, se asocia a las culturas juveniles, y marca una ruptura con las clasificaciones tradicionales que permitían agrupar a los sujetos -clases, etnias, naciones-, ya que es una hibridación de géneros musicales y también de públicos -estos públicos poseen diferencias pero comparten lo más importante para el caso, una misma marca epocal y generacional: son jóvenes.

Hablar de sectores juveniles suele disimular en la cuestión etaria la heterogeneidad social, justamente detrás de las disputas musicales, complejizadas con determinados usos de ropas, territorios, lecturas, consumos subsisten diferencias que insisten en reivindicarse como económico - sociales. 
La cultura juvenil de los noventa, dice Alabarces, prefiere formaciones que revelan una nueva visión del campo político, son los movimientos sociales: la dictadura había censurado las agrupaciones tradicionales, y desde ese entonces el rock se fortaleció como ordenador de grupos juveniles. En este sentido, el rock emerge como fenómeno organizador de las prácticas de los jóvenes.

Eva Giberti (1998) desde la teoría psicoanalítica conjuga tres paradigmas representativos de la modernidad: la adolescencia, el psicoanálisis y el rock. Parte de la idea de que el advenimiento del rock potencia algo no imaginado e inesperado protagonizado por jóvenes y adolescentes, y que carecía de representación para los adultos. El rock, dice la investigadora, puede interpretarse como operador político, vinculado con la idea de territorialidad, ya que para fundarse precisa espacios topológicos y geográficos y espacios psíquicos subjetivos que incluyen en su génesis y desarrollo la interacción con otro -los pares- en situación de tiempo, espacio y época.

Desde la sociología del deporte, Pablo Alabarces (2000) y su equipo de investigación, en el marco de una investigación acerca de las prácticas y representaciones sociales de los sectores populares, se preguntan por las prácticas y las significaciones de los hinchas de clubes de fútbol en Capital Federal y Gran Buenos Aires. El trabajo ha enfocando a la comúnmente llamada barra brava y las apropiaciones en términos dicotómicos de territorios propios y ajenos. Es así que José Garriga Zucal $(2000,2005)$ y María Verónica Moreira $(2000,2005)$ pretenden en su investigación desentrañar el vínculo entre la identidad deportiva, la pertenencia territorial y la violencia. La hipótesis de los investigadores consiste en que los sentidos de posesión territorial se combinan con el fuerte sentimiento de rivalidad que signa la relación entre 
las hinchadas, lo que conduce a feroces enfrentamientos callejeros por el resguardo de la propiedad.

Pujol, Sergio (2002) La década rebelde. Los años sesenta en la Argentina, Emecé, Buenos Aires. 


\section{Libro: La política en la escuela \\ Autor: Pedro Núñez \\ Año: 2013 \\ Editorial: La Crujía}

Las tres preguntas fundamentales que vertebran el libro, permiten pensar: las características que adquiere la relación entre la propuesta escolar y las actuales formas de ser joven; las cuestiones sobre la convivencia, la construcción del orden escolar y las demandas de "respeto"; y las acciones políticas de los y las jóvenes.

La primera parte muestra el proceso de dislocación entre la propuesta de la escuela media y las actuales formas de ser joven. Aquí presta atención a las diferentes formas de vivir la temporalidad que tienen jóvenes y adultos y a las disputas por las funciones de la escuela. En la segunda parte, desmenuza las causas y consecuencias de esa dislocación, haciendo hincapié en los diferentes sentidos que construyen los jóvenes y los adultos que forman parte de la institución en torno al ejercicio de la ciudadanía (la convivencia, el respeto, la justicia y la participación) y cómo esos sentidos se ponen en tensión en el espacio escolar. Es en esta segunda parte donde se analiza la letra de los acuerdos de convivencia y cómo estos se ponen en práctica según las características particulares de cada institución. En la tercera parte se hace hincapié en las formas de participación al interior de la escuela, tomando como hitos las tomas realizadas durante el 2010 y el 2012. Se analizan también las debilidades y fortalezas de los centros de estudiantes como espacios institucionales de participación.

Una de las particularidades que tiene este libro, es que piensa la escuela (en y sobre ella, como dice Dussel en el prólogo). Piensa cuáles son los sentidos en torno a la justicia, la autoridad, el respeto y la participación que construye y circulan en el espacio escolar, y cómo se ponen en tensión con los sentidos construidos por los jóvenes sobre esos conceptos. Además identifica, a través de un exhaustivo trabajo de campo, modos distintos de aprender y vivir la política y lo político de acuerdo con las características de cada institución, pero también de las historias y expectativas de quienes asisten a ellas. Importancia de los centros de estudiantes; sin embargo, no son los 
únicos ámbitos de participación en las escuelas. Crítica: muchas veces funcionan como lugares institucionales con lógicas difíciles de apropiar por parte de los jóvenes. Prácticas más y menos formalizadas de participación política en el ámbito escolar (pluralidad de espacios de participación). "Lejos de presuponer una 'forma juvenil' de la política, el autor nos ofrece una variedad de conductas y de sentidos políticos que tienen que ver con la clase social, el género, y también con la experiencia escolar y las historias de vida de los jóvenes" (Inés Dussel en el Prólogo).

\section{Más profundizado por capítulo}

\section{Primer capítulo}

En este primer capítulo, "Encuentro y desencuentros entre juventud (es) y escuela media", el autor comienza con una crítica a los discursos adultocráticos que tienden a analizar lo que ocurre actualmente en las escuelas según los parámetros que rigieron su propia escolaridad. Plantea que aunque existen matices dentro de este grupo (aquellos que rechazan la experiencia de la escuela media y esos otros que reivindican su paso por ella como el único modo posible de atravesarla), todos sitúan a la política como práctica vedada a los jóvenes, y sólo legitimada en los adultos. Esto produce que en las escuelas se parta de establecer a priori unos lugares que parecieran inamovibles (los adultos están en el lugar del saber y los jóvenes están perdidos y necesitan ser tutelados).

A partir de esta situación, y no siendo la única causa, se produce un proceso de dislocación entre la propuesta de la escuela media y las actuales formas de ser joven, en dos aspectos: las disputas por los significados sobre las "funciones de la escuela" y los distintos modos de vivir la temporalidad. Esto provoca, según el autor, al menos dos consecuencias: la aparición de tensiones inter e intra generacionales; y el hecho de que la escuela deja de ser garantía de futuro. La escuela ya no condensa la transmisión de la herencia cultural, como plantea Arendt, ya que entra en crisis la visión de la escuela como lugar de tránsito, encargada de preparar a los jóvenes para enfrentar los desafíos del mundo adulto. Ese descentramiento del conocimiento supone, según el autor, un descentramiento del lugar 
del adulto. La escuela propone unas lógicas ordenadoras de materias, tiempos y conocimientos a adquirir, mientras los jóvenes organizan sus vidas "como un proceso de edición, recortando, pegando, realizando múltiples actividades diferentes entre sí al mismo tiempo y eligiendo qué aspectos les resultan más interesantes" (Diferencias en el modo de vivir la temporalidad).

Así es que aparece una enorme dificultad para establecer las demandas aceptadas entre jóvenes y adultos. Esto en el marco de una ampliación de la cobertura de la escuela media (el $84,5 \%$ de la población en la franja etaria 13-17 años en 2010), sin desconocer que existen problemas de permanencia en la escuela media. El autor intenta problematizar esta cuestión, afirmando que no se puede analizar sólo por factores exógenos, ya que las tasas de desempleo y pobreza han disminuido en los últimos años, por lo cual propone mirar los factores endógenos, entre los que caracteriza la dificultad para modificar la matriz tradicional de la escuela media, que no permite la democratización de las prácticas internas de la escuela.

\section{Segundo capítulo}

En este segundo capítulo, el autor hace hincapié en la formación ciudadana al interior del espacio escolar. La formación del ciudadano adquirió distintas formas en los últimos años; principalmente, por el acceso masivo a la escuela secundaria de sectores que antes transitaban otros espacios. Por otro lado, se consolidaron legislaciones que abordan los derechos de los y las jóvenes que deben ser concretados en el espacio escolar. Las nuevas formas de enseñar y ejercer la ciudadanía, son analizadas por el autor a partir del recorrido por una serie de discusiones: la noción de convivencia (analizando los acuerdos de convivencia, explícitos o no, que aparecen en cada institución), el concepto de respeto y el concepto de justicia/injusticia.

\section{Convivencia.}

El autor utiliza el análisis de los acuerdos de convivencia vigentes en cada institución, para observar cómo son percibidos por los jóvenes esos acuerdos, cómo evalúan la participación en la confección de esos acuerdos, y qué tan respetados son por los adultos, poniéndolos en relación con las nociones de justicia/injustica construidas. 
En los últimos años, por ejemplo, se han promovido un conjunto de normativas que buscan favorecer la participación política de los alumnos en el ámbito escolar, incentivando la constitución de centros de estudiantes en todas las escuelas, por ejemplo.

Según las investigaciones presentadas por el autor, los reglamentos de convivencia varían según el contexto social en el que se encuentre la institución, ya que las necesidades para cada espacio son diferentes.

El autor los divide en tres tipos de reglamentos:

- Reglamentos tradicionales, donde se hace referencia a la apariencia, la puntualidad y la higiene (reproducen las formas apropiadas e inapropiadas de ser varón y de ser mujer).

- Reglamentos en contexto, que son aquellos que incluyeron las propuestas de entes provinciales, donde se incluyen las transgresiones ligadas al consumo de drogas en la escuela, falsificación de documentos, sustracción o robo. Estas cuestiones, según plantea el autor, están más ligadas a los miedos de quienes conforman la institución respecto de la población de jóvenes con las que trabajan.

- Modelo de derechos, que hacen hincapié en la convivencia democrática, la no discriminación, la defensa de los derechos, la libre expresión, entre otras. Lo interesante de este último tipo de reglamentos es que son parte de él todos los sujetos que conforman la institución, desde los directivos hasta los alumnos y alumnas.

\section{El respeto.}

La escuela es un espacio más donde se disputa la obtención de respeto entre los y las jóvenes. Sobre la base de una encuesta, el autor agrupó las formas de obtener respeto en tres grandes grupos: por la fuerza; por las capacidades personales (solidario, buen compañero); y por acciones estratégicas (siendo auténtico, acercándote a los grupos de más poder, estando a la moda).

Luego se realiza otro análisis que ya no tiene que ver con la búsqueda de respeto intra generacional, sino que establece cuáles son las características que los adultos tienen que tener para que los jóvenes los respeten (según los propios jóvenes).

- El respeto en base a la comprensión por parte de los docentes de las realidades de los jóvenes. Permiten generar una mayor perte- 
nencia con la institución, porque están abiertos los canales de diálogo y de construcción colectiva.

- El respeto por temor. En este caso los adultos ponen las responsabilidades por sobre los derechos, lo cual obtura la posibilidad de generar demandas.

- El respeto por argumentación. Este tipo de acuerdos, basados en el respeto hacia quien puede argumentar el por qué de su posición de autoridad, está asociado a los sectores medios-altos según la investigación, donde no se busca una relación horizontal, sino una relación jerárquica bien fundamentada.

\section{Las injusticias.}

Más allá de lo que prescriben las normas provinciales y nacionales, todos los actores que conforman cada institución construyen sus propios sentidos en torno a lo que es justo o injusto.

Entre los entrevistados, se reconocieron tres clases de injusticias:

- Vinculadas a las condiciones de la infraestructura escolar

- Las normas no son igualitarias

- Injusticias que se deben a la no intervención docente.

\section{Tercer capítulo}

En este tercer capítulo se hace hincapié en las tomas de escuelas que se produjeron en 2010 y 2012, donde emergieron formas políticas (que combinan elementos "nuevos" y "viejos"), a través de las cuales los jóvenes resignifican y practican la política y lo político. Son múltiples las maneras en las que la política se hace presente en la escuela, debido a la diversidad de modos de ser joven que conviven. El autor afirma que en la actualidad no son los centros de estudiantes los únicos espacios en los que se desarrollan prácticas políticas al interior de las escuelas, y que muchas veces, al ser espacios institucionalmente legitimados, los centros de estudiantes obturan la posibilidad de pensar la política y la participación desde lugares novedosos, por lo cual no resultan atractivos para los y las estudiantes. Sin embargo, muchas veces también es una puerta de entrada para un vínculo primero con la política, permitiéndoles los lazos con otras generaciones. Los centros de estudiantes son la forma en la cual los estudiantes "deben" participar en la escuela secundaria. Otro punto interesante en el análisis de los centros de estudiantes, 
es el retomarlos como espacios donde se despliega la sociabilidad juvenil y se articula la práctica política con otros aprendizajes y búsquedas identitarias (noviazgos, amigos, formas de vestir, lenguajes, estilos). Además, el autor aborda eso que los adultos llaman el perfil conflictivo de quienes forman parte de los centros de estudiantes, que se conforma como un discurso adultocrático que desvaloriza la política.

Particularidades de las "tomas" de escuelas: deslegitimación del uso de la violencia, desplazamiento de la figura del ciudadano cliente (noventa) hacia la demanda de derechos. "Poner el cuerpo" por sobre la búsqueda de alternativas institucionales.

\section{El libro es producto de las siguientes investigaciones:}

- Tesis doctoral "Política y poder en la escuela media. La socialización política juvenil en el espacio escolar".

- Trabajo de campo que formó parte de investigaciones realizadas en el área de Educación de FLACSO/Argentina (Proyecto PAV "Intersecciones entre desigualdad y escuela media: un análisis de las dinámicas de producción y reproducción de la desigualdad escolar y social", que se realizó entre 2006 y 2009 en Salta, Neuquén, Provincia de Buenos Aires y ciudad de Buenos Aires) y Proyecto PIP/CONICET "La reconfiguración de los vínculos entre jóvenes y adultos en la escuela media. Experiencias del orden de lo común y producción de desigualdades", en el cual se trabajó en cuatro escuelas de la provincia de Buenos Aires. (Se hicieron encuestas a los alumnos, entrevistas a alumnos y miembros de las instituciones escolares, grupos focales, observaciones de clases y actos escolares e interacciones en momentos de recreo o entrada y salida de los alumnos/as). 


\section{Libro: ¿Por qué los jóvenes están volviendo a la po- lítica?}

Autor: José Natanson

Año: 2012

Editorial: Debate

El libro de Natanson busca analizar el proceso de repolitización juvenil que se está viviendo en distintos países del mundo, considerando los rasgos comunes y diferenciales que los caracterizan, para abordar sus potencialidades y sus límites.

En el primer capítulo se analiza el concepto de juventud, donde el autor realiza una historización del término, situando su origen en los "años dorados" de la pos guerra, con el crecimiento de los sectores medios y la masificación de las universidades, corriéndose de las miradas que sitúan a la juventud como una categoría definida por la naturaleza, asociada a cuestiones etárea.

En un segundo capítulo el autor realiza una descripción más pormenorizada de cada uno de los procesos de participación juvenil que se fueron dando en distintos lugares del mundo, nombrándolos como la "segunda revolución de los jóvenes” (España, Egipto, Túnez, Chile, Nueva York, Londres, Argentina, Portugal), y analiza las causas de estos surgimientos, haciendo hincapié principalmente en lo que él llama una "brecha profunda", entre la existencia de jóvenes cada vez más capacitados e informados, y un mercado laboral cada vez más herméticamente cerrado para los jóvenes.

El tercer capítulo es ambicioso, busca generar un retrato de la juventud en Argentina, como lo presenta en su título, marcando las distintas juventudes que conviven bajo el paraguas de una misma generación, diferenciando principalmente a los sectores medios y altos de los sectores populares. Luego vuelve a los marcos generacionales más amplios, para hacer 
referencia a los momentos históricos compartidos por estos jóvenes, más allá de las diferencias previamente mencionadas (principalmente, el haber crecido en contextos de plena democracia, con recuerdos vagos o nulos de los procesos dictatoriales; y la relación de cercanía que tienen estos jóvenes con las nuevas tecnologías).

El cuarto capítulo aborda la militancia política de los jóvenes en Argentina, tomando como punto de referencia a $\mathrm{La}$ Cámpora, describiendo sus orígenes, analizando sus formas y vaticinando sus posibilidades y sus límites. Cuando en la conclusión busca encontrar las similitudes y diferencias que existen entre la juventud kirchnerista y el resto de los movimientos juveniles, plantea como principal diferencia el hecho de que la primera no se posiciona como un antipoder (como sí ocurre en el resto de los países analizados en este libro), sino que se incorpora a un dispositivo en funcionamiento. Cuando busca las razones para explicar esta diferenciación, elabora como tesis que en Medio Oriente, España o Inglaterra, el poder político y el poder económico se encuentran fusionados o, como mínimo, identificados, mientras que en Argentina, justamente lo que busca romper el kirchnerismo es esa identificación, lo cual conmueve a los jóvenes.

\section{Sobre la Juventud kirchnerista}

Natanson plantea que La Cámpora no es, como dicen muchos, una creación de Néstor y Cristina, sino que es un movimiento desde abajo que luego se sumó a un movimiento político ya consolidado. Y dice: "Ni siquiera con toda su voluntad y todos sus recursos el gobierno podría haber construido una adhesión de estas características si antes no hubiera adoptado una serie de medidas que conmovieron a los jóvenes, y si antes de eso no hubieran ocurrido los sucesos descriptos en las páginas anteriores: los núcleos de resistencia al neolibe- 
ralismo de los 90, el estallido de diciembre y la irrupción de las asambleas y los piquetes. Como suele suceder con los fenómenos políticos profundos, la repolitización juvenil no fue un estallido sino el resultado de un proceso largo y complejo".

Elige La Cámpora, entre todas las agrupaciones kirchneristas, por su visibilidad, su masividad y su posibilidad de servir como líder al resto. La Cámpora como síntesis, dice Natanson.

Luego se ocupa de diferenciar a La Cámpora de Montoneros, afirmando: "la politización en clave kirchnerista de un sector de la juventud actual sucede en un contexto, con unos actores y con unos objetivos que no tienen nada que ver con los de aquellos años". En consecuencia, afirma que el precedente más adecuado de La Cámpora es la Coordinadora alfonsinista, por varias cuestiones: ambos son movimientos progresistas, anticorporativos, que lograron el apoyo de núcleos intelectuales, ambos se plantearon como la posibilidad de renovación de los dos grandes partidos tradicionales de la Argentina. Plantea como similitud, además, la obtención de cargos públicos por parte de los jóvenes. Pero también están las diferencias: La Coordinadora se formó durante la Dictadura, mientras que La Cámpora se formó y fortaleció en plena democracia; y el autor muestra las diferencias entre los liderazgos de Alfonsín (más abierto y consensual) y de los Kirchner (más cerrados y verticalistas).

A partir de estas comparaciones extrae los posibles límites o problemas que puede llegar a tener la agrupación kirchnerista, entre ellos, la imposibilidad de formulación de una agenda propia y la supervivencia más allá del kirchnerismo. Y hace una advertencia también sobre los cargos en el Estados para los jóvenes: "entrañan un riesgo de amodorrar a quienes los ocupan en la comodidad del Estado, con efectos de ensimismamiento institucional, achatamiento de las pulsiones transformadoras y encasillamiento burocrático". Luego hace 
un recorrido histórico por la Coordinadora, buscando indicios para pensar otros posibles riesgos de La Cámpora, y concluye: "Ninguno de ellos (de La Coordinadora) logró construir un espacio o un liderazgo superador al del ex presidente, dejando sin proponérselo una enseñanza para los jóvenes de La Cámpora: para crecer hay que estar dispuesto a enterrar - simbólicamente - al padre, del mismo modo que para trascender al líder político hay que querer destronarlo".

Más adelante, desmantela tres prejuicios con respecto a La Cámpora que son recurrentes en los medios de comunicación: La juventud kirchnerista como creación de los Kirchner; la juventud kirchnerista como un todo homogéneo; y la juventud kirchnerista como un movimiento que se va a terminar cuando se termine el kirchnerismo.

Riesgos: sobreadaptación al gobierno y pérdida de la capacidad transformadora y creativa; y la necesidad de crear una agenda propia.

Posibilidades: es prácticamente el único sector (el kirchnerismo) que tiene un movimiento juvenil fuerte. La importancia, también, para el kirchnerismo, de contar con un núcleo fuerte de militancia que apoye genuinamente el proyecto. 


\section{Libro: Fuerza Propia. La Cámpora por dentro.}

\section{Autora: Sandra Russo \\ Año: 2014 \\ Editorial: Debate}

El libro recorre los últimos veinte años de la historia política del país a través de las biografías de ocho integrantes de la Mesa Nacional de La Cámpora, retratando las diversas formas de participación y acción de estos jóvenes, sus representaciones sobre lo político y sus mecanismos de inserción organizacional. En base a crónicas donde prevalece la voz de los protagonistas, la autora reconstruye cómo las trayectorias colectivas de éstos referentes se van conjugando con el objetivo de armar una orgánica nacional de la juventud kirchnerista. Asimismo, destaca los hechos políticos que fomentaron el crecimiento y la consolidación de la organización, las discusiones $\mathrm{y}$ decisiones en torno a normativas de funcionamiento, simbologías identificatorias y recursos comunicacionales y, por último, la proyección política del grupo para la futura década.

El aporte fundamental del material, frente a la supervivencia -incluso desde la academia- de miradas adultocéntricas (en sus versiones subalternizantes, micropolíticas o romántico-condescendientes), es emprender una abierta enunciación de los jóvenes como actores políticos que buscan construir poder, es decir, generar una fuerza propia que impacte en la transformación social. Con tal premisa, la narración no se subsume en una descripción de la "mística militante" movimientista, sino en las estrategias políticas para potenciar la organización, desde las más dogmáticas a las más pragmáticas. Lejos de una exaltación consensualista, se evidencia la productividad del conflicto para "encuadrar y amalgamar", a la vez que se explicita la particularidad de la posición sostenida 
por el grupo y sus antagonismos. Frente a visiones espontaneistas de la política, se revisan las múltiples dimensiones del "armado" como la coordinación de recursos, la gestión institucional y el trabajo territorial, resaltando los valores de la responsabilidad y la conducción para la perdurabilidad de la organización.

\section{La Cámpora por dentro}

La autora propone pensar la agrupación como la fuerza militante del proyecto kirchnerista que asegura su continuidad más allá del vaivén electoral, como una organización que acompañará tanto desde el oficialismo como desde la oposición. El libro tiene la virtud de realizar una composición entre hechos políticos, históricos y sociales, produciendo una imagen de la cotidianeidad pasada y presente de los miembros de la organización. La narración va desde una joven que se tatúa el Nestornauta, hasta una mujer que muere en villa 21-24 en Barracas y los militantes resuelven la comida y el alojamiento de sus hijos; de una cena en Río Gallegos de los integrantes de la Mesa de la Cámpora, hasta un joven haciendo un recorrido puerta por puerta en búsqueda de su propia identidad.

En La Cámpora confluyen tres tipos de militantes: los que provienen de organismos de derechos humanos, los que militaron en agrupaciones universitarias y los de militancia territorial. En declarada aversión a la videopolítica y el individualismo legados del neoliberalismo, promueven una política comunicacional hermética, evitando contestar los estigmas construidos por los medios hegemónicos en torno a la agrupación, que los definen como "vagos", "oportunistas", "hijos del poder", entre otros.

Las pertenencias biográficas plurales de los integrantes de la cúpula camporista dan cuenta cómo en el proceso de constitución identitaria de la organización kirchnerista se pudo 
articular una multiplicidad de demandas, teniendo como único rasgo unificador la identidad juvenil. Aun así, con la agrupación se referencian por lo menos tres generaciones: algunos dirigentes ya contaban con experiencias militantes en sus colegios secundarios a principios de los 90 .

El libro retoma una serie de discusiones ideológicas que la agrupación fue atravesando: la relación de los jóvenes con la política y el poder en el neoliberalismo y en la actualidad, las diferentes formas y contenidos del Estado y la incorporación de militantes en la gestión, el rol histórico de la generación de jóvenes, la formación de cuadros políticos, la definición de un modelo organizacional, las relaciones con otras agrupaciones, la cuestión de las jerarquías, las responsabilidades y el valor de una conducción frente a las lógicas asambleístas, la promoción de la participación ciudadana, entre otras.

Resulta necesario destacar dos capítulos que rompen el estilo biográfico del libro. El capítulo 11, recorre las estrategias comunicacionales de La Cámpora a través de entrevistas a los responsables de prensa. Se incluyen la realización de afiches y comunicados, la cobertura de las actividades territoriales y movilizaciones, la selección de consignas y símbolos diversos. El capítulo 14 narra cuatro historias de miembros de La Cámpora de Mendoza, Tucumán, San Luis y Corrientes de entre 20 y 24 años, que comenzaron a militar directamente en el kirchnerismo alrededor del 2008, y que se reconocen como la "generación del Bicentenario" o los "hijos de la democracia", los que se metieron en política por un proyecto y no "en contra". 
¿Cuánto dirias que te interesan las cuestiones politicas? " Nivel socio económico

\begin{tabular}{|c|c|c|c|c|c|}
\hline & & \multicolumn{3}{|c|}{ Nivel socio-económico } & \multirow[b]{2}{*}{ Total } \\
\hline & & вајо & Medio & Alto & \\
\hline \multirow{5}{*}{$\begin{array}{l}\text { ¿Cuánto } \\
\text { dirias que te } \\
\text { interesan las } \\
\text { cuestiones } \\
\text { politicas? }\end{array}$} & Me interesa mucho & $8,3 \%$ & $8,7 \%$ & $21,1 \%$ & $12,0 \%$ \\
\hline & Me interesan & $18,3 \%$ & $24,3 \%$ & $26,3 \%$ & $23,7 \%$ \\
\hline & Me interesan poco & $31,7 \%$ & $40,8 \%$ & $31,6 \%$ & $35,8 \%$ \\
\hline & No me interesan & $40,0 \%$ & $26,2 \%$ & $21.1 \%$ & $28.1 \%$ \\
\hline & $\mathrm{Ns} / \mathrm{NC}$ & $1.7 \%$ & & & $.4 \%$ \\
\hline Total & & $100,0 \%$ & $100,0 \%$ & $100,0 \%$ & $100,0 \%$ \\
\hline
\end{tabular}

¿Con cuánta frecuencla seguis (o te informas) de las noticlas/cuestiones politicas? * Nivel soclo-económico

\begin{tabular}{|c|c|c|c|c|c|}
\hline & & \multicolumn{3}{|c|}{ Nivel socio económico } & \multirow[b]{2}{*}{ Total } \\
\hline & & Bajo & Medio & Nito & \\
\hline \multirow{6}{*}{$\begin{array}{l}\text { ¿Con cuanta } \\
\text { frecuencia } \\
\text { seguis (o te } \\
\text { informas) de las } \\
\text { noticias/cuestio } \\
\text { nes politicas? }\end{array}$} & Nunca & 16,746 & 8,756 & $7,9 \%$ & 9,856 \\
\hline & Todos los dias & $23,3 \%$ & 40,48 & $36,8 \%$ & $32,7 \%$ \\
\hline & Casi todos los dias & $35.0 \%$ & $21.2 \%$ & $15,8 \%$ & 24,096 \\
\hline & Algunos dias & $10,09 \%$ & 18,396 & 26,396 & $18,9 \%$ \\
\hline & 1 a 2 veces por semana & $6,7 \%$ & $8.7 \%$ & $7,9 \%$ & $9.5 \%$ \\
\hline & Menos de 1 vez por semana & 8,396 & 2,996 & 5,396 & $5,1 \%$ \\
\hline Total & & $100,0 \%$ & $100,0 \%$ & $100,0 \%$ & $100,0 \%$ \\
\hline
\end{tabular}

JÓVENES Y POLÍTICA: UNA MIRADA DESDE LA COMUNICACIÓN 


\section{TABLASY CRUCES DE INDICADORES}

\begin{tabular}{|c|c|c|c|c|c|c|}
\hline \multicolumn{7}{|c|}{$\begin{array}{l}\text { ¿A través de que medio te informas más frecuentemente de las noticias/cuestiooes politicas?" } \\
\text { Nivel socio-económico }\end{array}$} \\
\hline & & \multicolumn{4}{|c|}{ Nivel socio econsómico } & \multirow[b]{2}{*}{ Total } \\
\hline & & \multicolumn{2}{|c|}{ Bajo } & Medio & \multirow{2}{*}{\begin{tabular}{|c|} 
Nute \\
$55,6 \mathrm{~S}$
\end{tabular}} & \\
\hline \multirow{8}{*}{$\begin{array}{l}\text { ¿A traves de } \\
\text { que medio te } \\
\text { intormiss mbs } \\
\text { frecuentement } \\
\text { e de los } \\
\text { noticiss/cuesti } \\
\text { ones politicas? }\end{array}$} & Televiskin & \multicolumn{2}{|c|}{$50,0 \%$} & 59,65 & & 54,95 \\
\hline & \multicolumn{2}{|c|}{ Portales de intormación o diarios digitailes } & 5,05 & $12,5 \leqslant$ & 16,75 & 12,85 \\
\hline & Dharios en papel / impresos & & $21,7 \%$ & $7,7 \%$ & $8,3 \%$ & $11.0 \%$ \\
\hline & Otras págines de Internet & & 1,75 & $7,7 \mathrm{~s}$ & $2,8 \%$ & $5.5 \mathrm{~N}$ \\
\hline & Rodio & & $13,3 \%$ & $4,8 \%$ & 8,35 & 6,26 \\
\hline & Redes sociales & & & $1,9 \%$ & $2,8 \%$ & $2.6 \mathrm{~S}$ \\
\hline & Otro & \multicolumn{2}{|c|}{$1,7 \mathrm{~S}$} & $4,8 \%$ & & 3,38 \\
\hline & Ninguno & \multicolumn{2}{|c|}{6,78} & $1,0 \mathrm{~S}$ & $5,6 \%$ & $3,7 \mathrm{~s}$ \\
\hline \multicolumn{2}{|l|}{ Total } & \multicolumn{2}{|c|}{$100,0 \%$} & 100,09 & $200,0 \%$ & $100,0 \%$ \\
\hline ¿Con qué & $\begin{array}{l}\text { lé frecuencia dirias que hab } \\
\text { socio } e x\end{array}$ & $\begin{array}{l}\text { bre cuesti } \\
\text { nico }\end{array}$ & nes & politica & $15 ? \cdot$ Nivel & \\
\hline & & Nivel & ocio- & econón & mico & \\
\hline & & Bajo & Me & dio & Alto & Total \\
\hline ¿Con qué & Muy Frecuentemente & 5,096 & 10 , & 696 & $7,9 \%$ & $8,4 \%$ \\
\hline frecuencia dirias & Frecuentemente & $20,0 \%$ & 31, & 796 & 31,696 & $26,2 \%$ \\
\hline $\begin{array}{l}\text { que hablass sobre } \\
\text { cuestiones }\end{array}$ & Poco frecuentemente & $50,0 \%$ & 39. & $4 \%$ & $47,4 \%$ & $46,2 \%$ \\
\hline politicas? & Nunca & $25,0 \%$ & 17 , & 396 & $13,2 \%$ & $18,9 \%$ \\
\hline & $\mathrm{Ns} / \mathrm{Nc}$ & & 1,0 & 696 & & 49 \\
\hline Total & & 100,096 & 100 & , O96 & 100,096 & 100,096 \\
\hline
\end{tabular}

\section{TABLASY CRUCES DE INDICADORES}

Participación en organización social, agrupación o partido politico, club o espacio de fomentos Sociales o agrupación religiosa * Nivel socio-económico

\begin{tabular}{|c|c|c|c|c|c|c|}
\hline & & \multicolumn{4}{|c|}{ Nivel socio-económico } & \multirow[b]{2}{*}{ Total } \\
\hline & & Bajo & Medio & Alto & $\mathrm{Ns} / \mathrm{Nc}$ & \\
\hline \multirow{2}{*}{$\begin{array}{l}\text { Participación en organización social, } \\
\text { agrupación o partido politico, dub o espacio } \\
\text { de Fomentos Sociales o agrupación religgiosa }\end{array}$} & Si & $20,0 \%$ & $20,2 \%$ & $21.1 \%$ & $16,2 \%$ & $19,2 \%$ \\
\hline & No & $80,0 \%$ & $79,8 \%$ & $78,9 \%$ & $83,8 \%$ & $80,8 \%$ \\
\hline Total & & $100,0 \%$ & $100,0 \%$ & $100,0 \%$ & $100,0 \%$ & $100,0 \%$ \\
\hline
\end{tabular}

¿Actualmente participás en alguna organización social, agrupación o partido politico? * Nivel socio-económico

\begin{tabular}{|c|c|c|c|c|c|}
\hline & \multicolumn{4}{|c|}{ Nivel socio-económico } & \multirow[b]{2}{*}{ Total } \\
\hline & & Bajo & Medio & Alto & \\
\hline \multirow{2}{*}{$\begin{array}{l}\text { ¿Actualmente participás en } \\
\text { alguna organización social, } \\
\text { agrupación o partido } \\
\text { político? }\end{array}$} & SI & $6,7 \%$ & $7,7 \%$ & $7,9 \%$ & $6,2 \%$ \\
\hline & No & $93,3 \%$ & $92,3 \%$ & $92,1 \%$ & $93,8 \%$ \\
\hline Total & & $100,0 \%$ & $100,0 \%$ & $100,0 \%$ & $100,0 \%$ \\
\hline
\end{tabular}

JÓVENES Y POLÍTICA: UNA MIRADA DESDE LA COMUNICACIÓN 


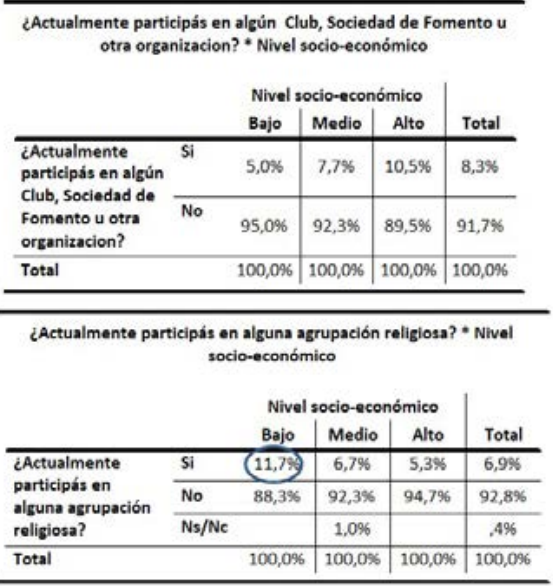

Participacion en Actividades en colegio / universidad * Nivel socio-económico

\begin{tabular}{ccc|c|c|c} 
& \multicolumn{4}{c}{ Nivel socio-económico } & \\
& Bajo & Medio & Alto & Total \\
\hline \multirow{3}{*}{ SI } & $45,3 \%$ & $46,5 \%$ & $60,5 \%$ & $47,9 \%$ \\
\cline { 2 - 6 } & No & $47,2 \%$ & $53,5 \%$ & $39,5 \%$ & $50,2 \%$ \\
\cline { 2 - 6 } & Ns/N c & $7,5 \%$ & & & $1,9 \%$ \\
\hline Total & & $100,0 \%$ & $100,0 \%$ & $100,0 \%$ & $100,0 \%$ \\
\hline
\end{tabular}

Asistir a una reunión o asamblea estudiantil * Nivel socio-económico

\begin{tabular}{|c|c|c|c|c|c|}
\hline & & \multicolumn{3}{|c|}{ Nivel socio-económico } & \multirow[b]{2}{*}{ Total } \\
\hline & & Bajo & Medio & Alto & \\
\hline \multirow{3}{*}{$\begin{array}{l}\text { Asistir a una } \\
\text { reunión o } \\
\text { asamblea } \\
\text { estudiantil }\end{array}$} & Si & $32,1 \%$ & $30,3 \%$ & $44,7 \%$ & $34,2 \%$ \\
\hline & No & $60,4 \%$ & $68,7 \%$ & $55,3 \%$ & $63,5 \%$ \\
\hline & $\mathrm{Ns} / \mathrm{Nc}$ & $7,5 \%$ & $1,0 \%$ & & $2,3 \%$ \\
\hline Total & & $100,0 \%$ & $100,0 \%$ & $100,0 \%$ & $100,0 \%$ \\
\hline
\end{tabular}

JÓVENES Y POLÍTICA: UNA MIRADA DESDE LA COMUNICACIÓN 
Participar en una protesta estudiantil * Nivel

socio-económico

\begin{tabular}{|c|c|c|c|c|c|}
\hline & & \multicolumn{3}{|c|}{ Nivel socio-económico } & \multirow[b]{2}{*}{ Total } \\
\hline & & Bajo & Medio & Alto & \\
\hline \multirow{3}{*}{$\begin{array}{l}\text { Participar en } \\
\text { una protesta } \\
\text { estudiantil }\end{array}$} & Si & $26,4 \%$ & $21,2 \%$ & $31,6 \%$ & $22,4 \%$ \\
\hline & No & $66,0 \%$ & $78,8 \%$ & $68,4 \%$ & $75,7 \%$ \\
\hline & $\mathrm{Ns} / \mathrm{Ne}$ & $7,5 \%$ & & & $1,9 \%$ \\
\hline Total & & $100,0 \%$ & $100,0 \%$ & $100,0 \%$ & $100,0 \%$ \\
\hline
\end{tabular}

Ser miembro del centro de estudiantes " Nivel

socio-económico

\begin{tabular}{|c|c|c|c|c|c|}
\hline & & \multicolumn{3}{|c|}{ Nivel socio-económico } & \multirow[b]{2}{*}{ Total } \\
\hline & & Bajo & Medio & Alto & \\
\hline \multirow{3}{*}{$\begin{array}{l}\text { Ser miembro } \\
\text { del centro de } \\
\text { estudiantes }\end{array}$} & Si & $13,2 \%$ & $11,1 \%$ & $13,2 \%$ & $10,3 \%$ \\
\hline & No & $79,2 \%$ & $88,9 \%$ & $86,8 \%$ & $87,8 \%$ \\
\hline & $\mathrm{Ns} / \mathrm{Nc}$ & $7,5 \%$ & & & $1,9 \%$ \\
\hline Total & & $100,0 \%$ & $100,0 \%$ & $100,0 \%$ & $100,0 \%$ \\
\hline
\end{tabular}

\section{TABLASY CRUCES DE INDICADORES}

\begin{tabular}{|c|c|c|c|c|c|}
\hline \multicolumn{6}{|c|}{$\begin{array}{l}\text { Presentarte como candidato en elecciones estudiantiles * Nivel } \\
\qquad \text { socio-económico }\end{array}$} \\
\hline & \multicolumn{5}{|c|}{ Nivel socio-económico } \\
\hline & & Bajo & Medio & Alto & Total \\
\hline \multirow{3}{*}{$\begin{array}{l}\text { Presentarte } \\
\text { como candidato } \\
\text { en elecciones } \\
\text { estudiantiles }\end{array}$} & $\mathrm{Si}$ & $13,2 \%$ & $6,1 \%$ & $7,9 \%$ & $6,5 \%$ \\
\hline & No & $79,2 \%$ & $93,9 \%$ & $92,1 \%$ & $91,6 \%$ \\
\hline & $\mathrm{Ns} / \mathrm{Nc}$ & $7,5 \%$ & & & $1,9 \%$ \\
\hline Total & & $100,0 \%$ & $100,0 \%$ & $100,0 \%$ & $100,0 \%$ \\
\hline
\end{tabular}

Ser representante del curso / año / facultad * Nivel socio-económico

\begin{tabular}{lll|l|l|l} 
& & \multicolumn{3}{c}{ Nivel socio-económico } & \\
& & Bajo & Medio & Alto & Total \\
\hline $\begin{array}{l}\text { Ser representante } \\
\text { del curso / año / } \\
\text { facultad }\end{array}$ & $\mathrm{Si}$ & $9,4 \%$ & $(24,2 \%)$ & $18,4 \%$ & $18,7 \%$ \\
\cline { 2 - 7 } & $\mathrm{No}$ & $83,0 \%$ & $75,8 \%$ & $81,6 \%$ & $79,4 \%$ \\
\cline { 2 - 6 } & $\mathrm{Ns} / \mathrm{Nc}$ & $7,5 \%$ & & & $1,9 \%$ \\
\hline Total & $100,0 \%$ & $100,0 \%$ & $100,0 \%$ & $100,0 \%$ \\
\hline
\end{tabular}

JÓVENES Y POLÍTICA: UNA MIRADA DESDE LA COMUNICACIÓN 


\begin{tabular}{|c|c|c|c|c|c|}
\hline \multicolumn{6}{|c|}{ Influencia politica* Nivel socio-económico } \\
\hline & & \multicolumn{3}{|c|}{ Nivel soeio.económieco } & \multirow[b]{2}{*}{ Total } \\
\hline & & Baje & Medio & Alto & \\
\hline & Tu familia directa (padres / hermanos) & $28,3 \%$ & $36,9 \%$ & (52.6) & 37,656 \\
\hline & Nodie & $26.7 \%$ & $29,1 \%$ & $21,1 \%$ & $27,4 \% 6$ \\
\hline & Amlgos / compañeros & $11,7 \%$ & $8,7 \%$ & $2.6 \%$ & $8,4 \%$ \\
\hline & Familla directa y otros & $3,3 \%$ & $6,8 \%$ & $18,4 \%$ & $7,3 \%$ \\
\hline & Los medios de comunicación & $8,3 \%$ & $6,8 \%$ & $2,6 \%$ & $6,2 \%$ \\
\hline & Lo presidente & $5,0 \%$ & $3,9 \%$ & & $2.9 \%$ \\
\hline & Aleún partido / aerupación politica & $3.3 \%$ & & $2.6 \%$ & $1,1 \%$ \\
\hline & Otros famillares (excluye padres $y$ hermanos) & $5,0 \mathrm{~s}$ & $1.9 \%$ & & $1.8 \%$ \\
\hline & Agrupación o movimiento social & & $1.0 \%$ & & $A \%$ \\
\hline & Otro ¿cubl? & $6,7 \%$ & $2.9 \%$ & & $5,5 \%$ \\
\hline & $\mathrm{Na} / \mathrm{Nc}$ & $1,7 \%$ & $1,9 \%$ & & $1,5 \%$ \\
\hline Total & & $100,0 \%$ & $100,0 \mathrm{~N}$ & $100,0 \%$ & 100,05 \\
\hline
\end{tabular}

\section{TABLASY CRUCES DEINDICADORES}

Tabla de contingencla ¿Usas actualmente Internet? * Nivel socio-económico

\begin{tabular}{lcc|c|c|c|c} 
& & \multicolumn{3}{c|}{ Nivel socio-económico } & \\
& & Bajo & Medio & Alto & Total \\
\hline \multirow{2}{*}{$\begin{array}{l}\text { ¿Usas actualmente } \\
\text { Internet? }\end{array}$} & $\mathrm{Si}$ & $79,7 \%$ & $93,1 \%$ & $97,4 \%$ & $92,3 \%$ \\
\cline { 2 - 6 } & No & $20,3 \%$ & $6,9 \%$ & $2,6 \%$ & $7,7 \%$ \\
\hline Total & & $100,0 \%$ & $100,0 \%$ & $100,0 \%$ & $100,0 \%$ \\
\hline
\end{tabular}

Tabla de contingencia ¿Cuánto usas actualmente Internet? * Nivel socio-económico

\begin{tabular}{|c|c|c|c|c|c|}
\hline & & \multicolumn{3}{|c|}{ Nivel socio-económico } & \multirow[b]{2}{*}{ Total } \\
\hline & & Bajo & Medio & Alto & \\
\hline \multirow{4}{*}{$\begin{array}{l}\text { ¿Cuánto usas } \\
\text { actualmente } \\
\text { Internet? }\end{array}$} & Todos los dias & $53,2 \%$ & $61,5 \%$ & $86,5 \%$ & $63,9 \%$ \\
\hline & Casi todos los dias & $12,8 \%$ & $19,8 \%$ & $5,4 \%$ & $17,5 \%$ \\
\hline & $\begin{array}{l}\text { Algunos dias a la } \\
\text { semana }\end{array}$ & $27,7 \%$ & $13,5 \%$ & $5,4 \%$ & $12,7 \%$ \\
\hline & De vez en cuando & $6,4 \%$ & $5,2 \%$ & $2,7 \%$ & $6,0 \%$ \\
\hline Total & & $100,0 \%$ & $100,0 \%$ & $100,0 \%$ & $100,0 \%$ \\
\hline
\end{tabular}

JÓVENES Y POLÍTICA: UNA MIRADA DESDE LA COMUNICACIÓN 


\begin{tabular}{|c|c|c|c|c|c|}
\hline \multicolumn{6}{|c|}{$\begin{array}{l}\text { Tabla de contingencia ¿Donde usas Internet? " Nivel } \\
\text { socio-económico }\end{array}$} \\
\hline & & \multicolumn{3}{|c|}{ Nivel socio-económico } & \multirow[b]{2}{*}{ Total } \\
\hline & & Bajo & Medio & Aito & \\
\hline \multirow{11}{*}{$\begin{array}{l}\text { ¿Dónde } \\
\text { usas } \\
\text { Internet? }\end{array}$} & Casa & $46,85 \%$ & 57,95 & 54,15 & 57,45 \\
\hline & Trabajo & $2,1 \%$ & $3,2 \%$ & $2,7 \mathrm{~K}$ & $2,4 \%$ \\
\hline & Cyber & 10,68 & $2,1 \%$ & & $4,4 \%$ \\
\hline & Celular & $10,6 \%$ & $4,2 \%$ & $8,1 \%$ & $6,4 \%$ \\
\hline & Otro & $6,4 \%$ & $1,1 \%$ & & $2,0 \%$ \\
\hline & Casa y Trabajo & $4,3 \%$ & $5,3 \%$ & $8,1 \%$ & $5,6 \%$ \\
\hline & Casa y cyber & $4,3 \%$ & $2,1 \%$ & $5,4 \%$ & $2,4 \%$ \\
\hline & Casa $y$ Celular & $6,4 \%$ & $14,7 \%$ & $16,2 \%$ & $11,6 \%$ \\
\hline & Casa y otro lugar & & $2,1 \%$ & & $1,6 \%$ \\
\hline & Trabajo y Celular & $4,3 \%$ & $1,1 \%$ & $2, \pi \%$ & $2,4 \%$ \\
\hline & $\begin{array}{l}\text { Casa, Trabajoy } \\
\text { Celular }\end{array}$ & $4,3 \%$ & $6,3 \%$ & $2,2 \%$ & $4,0 \%$ \\
\hline Total & & $100,0 \%$ & $100,0 \%$ & $100,0 \%$ & $100,0 \%$ \\
\hline
\end{tabular}

Tabla de contingencia ¿Usas actualmente Redes Sociales? * Nivel socio-económico

\begin{tabular}{|c|c|c|c|c|c|}
\hline & & \multicolumn{3}{|c|}{ Nivel socio-económico } & \multirow[b]{2}{*}{ Total } \\
\hline & & Bajo & Medio & Alto & \\
\hline \multirow{2}{*}{$\begin{array}{l}\text { ¿Usas actualmente } \\
\text { Redes Sociales? }\end{array}$} & Si & $91,5 \%$ & $86,3 \%$ & $86,5 \%$ & $88,8 \%$ \\
\hline & No & $8,5 \%$ & $13,7 \%$ & $13,5 \%$ & $11,2 \%$ \\
\hline Total & & $100,0 \%$ & $100,0 \%$ & $100,0 \%$ & $100,0 \%$ \\
\hline
\end{tabular}

JÓVENES Y POLÍTICA: UNA MIRADA DESDE LA COMUNICACIÓN 
¿Cuál es el principal problema más grave de La Plata? * Nivel socio-económico

\begin{tabular}{|c|c|c|c|c|c|}
\hline & & \multicolumn{3}{|c|}{ Nivel socio-económico } & \multirow[b]{2}{*}{ Total } \\
\hline & & Bajo & Medio & Alto & \\
\hline \multirow{14}{*}{$\begin{array}{l}\text { ¿Cuál es el } \\
\text { segundo } \\
\text { problema } \\
\text { más grave } \\
\text { de La } \\
\text { Plata? }\end{array}$} & Inseguridad & $50.8 \%$ & $62.1 \%$ & 71,19 & $59.0 \%$ \\
\hline & Pobreza / Miseria & $6,8 \%$ & $5.8 \%$ & $2.6 \%$ & $7,3 \%$ \\
\hline & Educación & $6,8 \%$ & $5,8 \%$ & $2,6 \%$ & $5,5 \%$ \\
\hline & Tránsito / Seguridad Vial & $5.1 \%$ & $2.9 \%$ & $5.3 \%$ & $4,4 \%$ \\
\hline & Desempleo & $6.8 \%$ & $1.0 \%$ & $2.6 \%$ & $3.3 \%$ \\
\hline & Drogadicción / Alcoholismo & $3.4 \%$ & $4,9 \%$ & & $2.9 \%$ \\
\hline & Transporte Público & $1,7 \%$ & $3,9 \%$ & $2,6 \%$ & $2,6 \%$ \\
\hline & Limpieza de calles & & $3,9 \%$ & & $1,5 \%$ \\
\hline & Falta de Viviendas & $1,7 \%$ & $1,0 \%$ & $2,6 \%$ & $1,1 \%$ \\
\hline & Falta de Asfalto & & & $2,6 \%$ & $.4 \%$ \\
\hline & Calles rotas & & $1,0 \%$ & &, $7 \%$ \\
\hline & Salud & $3,4 \%$ & $1,0 \%$ & $2,6 \%$ & $1,5 \%$ \\
\hline & Otro & $6,8 \%$ & $6,8 \%$ & $5,3 \%$ & $7,3 \%$ \\
\hline & $\mathrm{Ns} / \mathrm{Nc}$ & $6,8 \%$ & & & $2,6 \%$ \\
\hline Total & & $100,0 \%$ & $100,0 \%$ & $100,0 \%$ & $100,0 \%$ \\
\hline
\end{tabular}

Evaluación de la situación económica actual del pais * Nivel socio económico

\begin{tabular}{|c|c|c|c|c|c|}
\hline & & \multicolumn{3}{|c|}{ Nivel socio-económico } & \multirow[b]{2}{*}{ Total } \\
\hline & & Bajo & Medio & Alto & \\
\hline \multirow{6}{*}{$\begin{array}{l}\text { Evaluación de } \\
\text { la situación } \\
\text { económica } \\
\text { actual del pais }\end{array}$} & Muy Mala & $12,0 \%$ & $8,7 \%$ & $10,5 \%$ & $12,5 \%$ \\
\hline & Mala & $23,7 \%$ & $32,0 \%$ & $26,3 \%$ & $28,3 \%$ \\
\hline & Regular & $40,7 \%$ & $43,7 \%$ & $39,5 \%$ & $42,6 \%$ \\
\hline & Buena & $13,6 \%$ & $14,6 \%$ & $23,7 \%$ & $15,8 \%$ \\
\hline & Muy Buena & $10,0 \%$ & & & $.4 \%$ \\
\hline & $\mathrm{Ns} / \mathrm{Nc}$ & & $1,0 \%$ & & $.4 \%$ \\
\hline Total & & $100,0 \%$ & $100,0 \%$ & $100,0 \%$ & $100,0 \%$ \\
\hline
\end{tabular}

Evaluación de la situación económica del pais a un año * Nivel socio-económico

\begin{tabular}{|c|c|c|c|c|c|}
\hline & \multicolumn{4}{|c|}{ Nivel socio-económico } & \multirow[b]{2}{*}{ Total } \\
\hline & & Bajo & Medio & Alto & \\
\hline \multirow{4}{*}{$\begin{array}{l}\text { Evaluación de } \\
\text { la situación } \\
\text { económica del } \\
\text { país a un año }\end{array}$} & Mejor & $(18,69$ & $18,6 \%$ & $7,9 \%$ & $18,4 \%$ \\
\hline & Igual & $33,9 \%$ & $33,3 \%$ & (47,49 & $37,9 \%$ \\
\hline & Peor & $44,1 \%$ & $45,1 \%$ & $39,5 \%$ & $40,1 \%$ \\
\hline & $\mathrm{Ns} / \mathrm{Nc}$ & $3,4 \%$ & $2,9 \%$ & $5,3 \%$ & $3,7 \%$ \\
\hline Total & & $100,0 \%$ & $100,0 \%$ & $100,0 \%$ & $100,0 \%$ \\
\hline
\end{tabular}

JÓVENES Y POLÍTICA: UNA MIRADA DESDE LA COMUNICACIÓN 
Evaluación de la situación económica personal a un año * Nivel socio-económico

\begin{tabular}{|c|c|c|c|c|c|c|}
\hline & \multicolumn{5}{|c|}{ Nivel socio-económico } & \multirow[b]{2}{*}{ Total } \\
\hline & & Bajo & Medio & Alto & $\mathrm{Ns} / \mathrm{Nc}$ & \\
\hline \multirow{4}{*}{$\begin{array}{l}\text { Evaluación de la } \\
\text { situación } \\
\text { económica } \\
\text { personal a un añ́c }\end{array}$} & Mejor & $41,4 \%$ & $38,8 \%$ & $35,1 \%$ & $39,7 \%$ & $39,1 \%$ \\
\hline & Igual & $36,2 \%$ & $46,6 \%$ & 62,28 & $39,7 \%$ & $44,6 \%$ \\
\hline & Peor & $22,4 \%$ & $12,6 \%$ & $2,7 \%$ & $13,7 \%$ & $13,7 \%$ \\
\hline & Ns/Ne & & $1,9 \%$ & & $6,8 \%$ & $2,6 \%$ \\
\hline Total & & $100,0 \%$ & $100,0 \%$ & $100,0 \%$ & $100,0 \%$ & $100,0 \%$ \\
\hline
\end{tabular}

\begin{tabular}{|c|c|c|c|c|c|}
\hline \multicolumn{6}{|c|}{$\begin{array}{l}\text { ¿Cuánto diria ud. que le afecta la medida del gobierno nacional de regular y/o limitar la } \\
\text { compra de dollares para el ahorro personal y las transacciones inmobiliarlas? * Nivel } \\
\text { socio-económico }\end{array}$} \\
\hline & & \multicolumn{3}{|c|}{ Nivel socio económico } & \multirow[b]{2}{*}{ Total } \\
\hline & & Bajo & Medio & Alto & \\
\hline \multirow{5}{*}{$\begin{array}{l}\text { ¿Cudinto diria Ud. } \\
\text { que le afecta la } \\
\text { medida del } \\
\text { goblerno nacional } \\
\text { de regular y/o } \\
\text { limitar la compra } \\
\text { de dólares para el } \\
\text { ahorro personal y } \\
\text { las trancacciones } \\
\text { inmobiliarias? }\end{array}$} & Me ha alectado mucho & $10,3 \%$ & 4,996 & $18,4 \%$ & $9,2 \%$ \\
\hline & Me ha afectado & & $10,7 \%$ & 13,266 & $8,8 \%$ \\
\hline & Me ha afectado poco & $3,4 \%$ & $14,6 \%$ & $15,8 \%$ & $12,9 \%$ \\
\hline & No me ha afectado & 82,89 & $69.9 \%$ & $52.6 \%$ & $68,4 \%$ \\
\hline & $\mathrm{Ns} / \mathrm{Nc}$ & $3,4 \%$ & & &, $7 \%$ \\
\hline Total & & $100,0 \mathrm{~s}$ & $100,0 \%$ & $100,0 \mathrm{~N}$ & 100,08 \\
\hline
\end{tabular}

JÓVENES Y POLÍTICA: UNA MIRADA DESDE LA COMUNICACIÓN 


\section{TABLASY CRUCES DE INDICADORES}

¿Cuín de acuerdo se encuentra con la Asignación Universal por hijo? " Nivel socio-económico

\begin{tabular}{|c|c|c|c|c|c|}
\hline & & \multicolumn{3}{|c|}{ Nivel soclo-económico } & \multirow[b]{2}{*}{ Total } \\
\hline & & Bajo & Medio & Alto & \\
\hline \multirow{5}{*}{$\begin{array}{l}\text { LCujn de acuerdo } \\
\text { se encuentra con } \\
\text { la Asignación } \\
\text { Universal por hijo? }\end{array}$} & Muy de acuerdo & $16,9 \%$ & $16,5 \%$ & 26,350 & $17,9 \%$ \\
\hline & De acuerdo & $55,9 \%$ & $40,8 \%$ & $42,1 \%$ & $45,1 \%$ \\
\hline & Poco de acuerdo & $11.9 \%$ & $17,5 \%$ & $13,2 \%$ & $16,5 \%$ \\
\hline & Nada de acuendo & $15,3 \%$ & $22,3 \%$ & $15,8 \%$ & $17,9 \%$ \\
\hline & $\mathrm{Ns} / \mathrm{Nc}$ & & $2.9 \%$ & $2,6 \%$ & $2.6 \%$ \\
\hline Total & & $100,0 \%$ & $100,0 \%$ & $100,0 \%$ & $100,0 \%$ \\
\hline
\end{tabular}

¿Cuán de acuerdo se encuentra con la Nacionalización de Aerolineas Argentinas? * Nivel socio-económico

\begin{tabular}{|c|c|c|c|c|c|}
\hline & & \multicolumn{3}{|c|}{ Nivel socio-económico } & \multirow[b]{2}{*}{ Total } \\
\hline & & Bajo & Medio & Alto & \\
\hline \multirow{5}{*}{$\begin{array}{l}\text { ¿Cuán de acuerdo } \\
\text { se encuentra con } \\
\text { la Nacionalización } \\
\text { de Aerolineas } \\
\text { Argentinas? }\end{array}$} & Muy de acuerdo & $5.1 \%$ & $14,6 \%$ & $23.7 \%$ & $12.5 \%$ \\
\hline & De acuerdo & $45,8 \%$ & $43,7 \%$ & $39,5 \%$ & $45,1 \%$ \\
\hline & Poco de acuerdo & $10,2 \%$ & $10,7 \%$ & $21.1 \%$ & $11,4 \%$ \\
\hline & Nada de acuerdo & $6,8 \%$ & $13,6 \%$ & $10,5 \%$ & $11,4 \%$ \\
\hline & $\mathrm{Ns} / \mathrm{Ne}$ & $32,2 \%$ & $17.5 \%$ & $5,3 \%$ & $19,8 \%$ \\
\hline Total & & $100,0 \%$ & $100,0 \%$ & $100,0 \%$ & $100,0 \%$ \\
\hline
\end{tabular}

\section{TABLASY CRUCES DE INDICADORES}

\begin{tabular}{|c|c|c|c|c|c|}
\hline \multicolumn{6}{|c|}{$\begin{array}{l}\text { ¿Cuin de acuerdo se encuentra con Renegociación y pago de la Deuda } \\
\qquad \text { Externa? * Nivel socio-económico }\end{array}$} \\
\hline & & \multicolumn{3}{|c|}{ Nivel socio-económico } & \multirow[b]{2}{*}{ Total } \\
\hline & & Bajo & Medio & Alto & \\
\hline \multirow{5}{*}{$\begin{array}{l}\text { LCujn de acuerdo } \\
\text { se encuentra con } \\
\text { Renegociación y } \\
\text { pago de la Deuda } \\
\text { Externa? }\end{array}$} & Muy de acuerdo & $5,2 \%$ & $9.7 \%$ & $15,8 \%$ & $9.2 \%$ \\
\hline & De acuerdo & $43,1 \%$ & $38,8 \%$ & $47,4 \%$ & $42,3 \%$ \\
\hline & Poco de acuerdo & $12.1 \%$ & $14,6 \%$ & $15,8 \%$ & $13.2 \%$ \\
\hline & Nadla de acaerdo & $12.1 \%$ & $14,6 \%$ & $5,3 \%$ & $11,8 \%$ \\
\hline & $\mathrm{Ns} / \mathrm{Nc}$ & $27,6 \%$ & $21.4 \%$ & $15,8 \%$ & $23,5 \%$ \\
\hline \multicolumn{2}{|l|}{ Total } & $100,0 \%$ & $100,0 \%$ & $100,0 \%$ & $100,0 \%$ \\
\hline \multicolumn{6}{|c|}{$\begin{array}{l}\text { ¿Cuán de acuerdo se encuentra con Ley de medios y servicios } \\
\text { Audiovisuales? * Nivel socio-económico }\end{array}$} \\
\hline & & \multicolumn{3}{|c|}{ Nivel socio-económico } & \\
\hline & & Bajo & Medio & Alto & Total \\
\hline \multirow{5}{*}{$\begin{array}{l}\text { ¿Cuán de acuerdo } \\
\text { se encuentra con } \\
\text { Ley de medios y } \\
\text { servicios } \\
\text { Audiovisuales? }\end{array}$} & Muy de acuerdo & $11,9 \%$ & $13,6 \%$ & $18,9 \%$ & $12,6 \%$ \\
\hline & De acuerdo & $30,5 \%$ & $25.2 \%$ & $32,4 \%$ & $30.0 \%$ \\
\hline & Poco de acuerdo & $13,6 \%$ & $11.7 \%$ & $18,9 \%$ & $13.7 \%$ \\
\hline & Nada de acuerdo & $16,9 \%$ & 31,19 & $18,9 \%$ & $23,3 \%$ \\
\hline & $\mathrm{Ns} / \mathrm{Nc}$ & $27,1 \%$ & 18,496 & $10,8 \%$ & $20,4 \%$ \\
\hline Total & & $100,0 \%$ & $100,0 \%$ & $100,0 \%$ & $100,0 \%$ \\
\hline
\end{tabular}




\section{TABLASY CRUCES DE INDICADORES}

¿Cuán de acuerdo se encuentra con Nacionalización de Ypr? "Nivel

$$
\text { socio cconómico }
$$

\begin{tabular}{llc|c|c|c|c} 
& \multicolumn{4}{c}{ Nivel socio-económico } & \\
& & Bajo & Medio & Alto & Total \\
\hline \multirow{2}{*}{$\begin{array}{l}\text { ¿Cuán de acuerdo } \\
\text { se encuentra con }\end{array}$} & $\begin{array}{l}\text { Muy de acuerdo } \\
\text { Nacionalización } \\
\text { de YpF? }\end{array}$ & $11,9 \%$ & $21,4 \%$ & $26,3 \%$ & $17,3 \%$ \\
\cline { 2 - 7 } & De acuerdo & $50,8 \%$ & $43,7 \%$ & $50,0 \%$ & $47,1 \%$ \\
\cline { 2 - 7 } & Poco de acuerdo & $8,5 \%$ & $7,8 \%$ & $5,3 \%$ & $9,6 \%$ \\
\cline { 2 - 7 } & Nada de acuerdo & $8,5 \%$ & $14,6 \%$ & $10,5 \%$ & $11,4 \%$ \\
\cline { 2 - 7 } & Ns/Nc & $20,3 \%$ & $12,6 \%$ & $7,9 \%$ & $14,7 \%$ \\
\hline Total & $100,0 \%$ & $100,0 \%$ & $100,0 \%$ & $100,0 \%$ \\
\hline
\end{tabular}

¿Cuán de acuerdo se encuentra con Plan de Créditos para Viviendas (ProCrear)? * Nivel socio-económico

\begin{tabular}{llc|c|c|c} 
& & \multicolumn{3}{c|}{ Nivel socio-económico } & \\
& & Bajo & Medio & Alto & Total \\
\hline \multirow{2}{*}{$\begin{array}{l}\text { ¿Cuán de acuerdo } \\
\text { se encuentra con }\end{array}$} & Muy de acuerdo & $15,3 \%$ & $15,5 \%$ & $28,9 \%$ & $16,9 \%$ \\
\cline { 2 - 7 } $\begin{array}{l}\text { Plan de Créditos } \\
\text { para Viviendas } \\
\text { (Procrear)? }\end{array}$ & De acuerdo & $49,2 \%$ & $51,5 \%$ & $44,7 \%$ & $47,8 \%$ \\
\cline { 2 - 7 } & Poco de acuerdo & $8,5 \%$ & $13,6 \%$ & $7,9 \%$ & $11,0 \%$ \\
\cline { 2 - 7 } & Nada de acuerdo & $13,6 \%$ & $12,6 \%$ & $13,2 \%$ & $12,9 \%$ \\
\cline { 2 - 6 } & Ns/Nc & $13,6 \%$ & $6,8 \%$ & $5,3 \%$ & $11,4 \%$ \\
\hline Total & $100,0 \%$ & $100,0 \%$ & $100,0 \%$ & $100,0 \%$ \\
\hline
\end{tabular}

¿Estaría Ud. de acuerdo que la Presidenta Cristina Kirchner pueda ser reelegida para un nuevo mandato en el 2015? * Nivel socio-económico

\begin{tabular}{|c|c|c|c|c|c|}
\hline & & \multicolumn{3}{|c|}{ Nivel socio-económico } & \multirow[b]{2}{*}{ Total } \\
\hline & & Bajo & Medio & Alto & \\
\hline \multirow{3}{*}{$\begin{array}{l}\text { ¿Estaria Ud. de } \\
\text { acuerdo que la } \\
\text { Presidenta Cristina } \\
\text { Kirchner pueda ser } \\
\text { reelegida para un } \\
\text { nuevo mandato en } \\
\text { el 2015? }\end{array}$} & Si & 28,82 & $20,4 \%$ & $15,8 \%$ & $20,6 \%$ \\
\hline & No & $66,1 \%$ & $77,7 \%$ & $73,7 \%$ & $74,6 \%$ \\
\hline & $\mathrm{Ns} / \mathrm{Nc}$ & $5,1 \%$ & $1,9 \%$ & $10,5 \%$ & $4,8 \%$ \\
\hline Total & & $100,0 \%$ & $100,0 \%$ & $100,0 \%$ & $100,0 \%$ \\
\hline
\end{tabular}

JÓVENES Y POLÍTICA: UNA MIRADA DESDE LA COMUNICACIÓN 


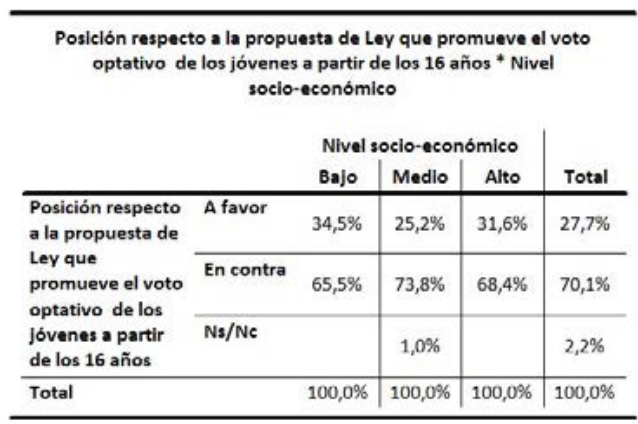

\begin{tabular}{|c|c|c|c|c|c|}
\hline \multicolumn{6}{|c|}{$\begin{array}{l}\text { La edad del voto es un asunto serio que de beria debatirse con mayor } \\
\text { protundidad, antes de tomar una decision " Nivel socio cconomico }\end{array}$} \\
\hline & & \multicolumn{3}{|c|}{ Nivel socio-económico } & \multirow[b]{2}{*}{ Total } \\
\hline & & Bajo & Mredis & Alto & \\
\hline \multirow{5}{*}{$\begin{array}{l}\text { a edad del voto } \\
\text { es un asunto } \\
\text { serio que deberia } \\
\text { debatirse con } \\
\text { mayor } \\
\text { profundidad, } \\
\text { antes de tomar } \\
\text { una declsibn }\end{array}$} & Muy de acuerdo & 29,38 & 45,546 & 47,496 & 42,28 \\
\hline & De acuerdo & $51,7 \%$ & $43,6 \%$ & $39,5 \%$ & $43,7 \%$ \\
\hline & Poco de acuerdo & $6,9 \%$ & $6.9 \%$ & $7,9 \%$ & $7,5 \%$ \\
\hline & Nada de acuerdo & $10,3 \%$ & $3,0 \%$ & $5,3 \%$ & $5,6 \%$ \\
\hline & $\mathrm{Ns} / \mathrm{Nc}$ & $1,7 \%$ & 1,06 & & $1,1 \%$ \\
\hline \multicolumn{2}{|l|}{ Total } & $100,0 \%$ & $100,0 \%$ & $100,0 \%$ & 100,09 \\
\hline \multicolumn{6}{|c|}{$\begin{array}{l}\text { Los menores de } 18 \text { años no están maduros, ni preparados para votar, son } \\
\text { manipulables * Nivel socio-económico }\end{array}$} \\
\hline & & \multicolumn{3}{|c|}{ Nivel socio-económico } & \\
\hline & & Bajo & Medio & Alto & Total \\
\hline \multirow{5}{*}{$\begin{array}{l}\text { Los menores de } \\
18 \text { años no } \\
\text { están maduros, } \\
\text { ni preparados } \\
\text { para votar, son } \\
\text { manipulables }\end{array}$} & Muy de acuerdo & $24,1 \%$ & $37,6 \%$ & $31,6 \%$ & $32,2 \%$ \\
\hline & De acuerdo & $31,0 \%$ & $39,6 \%$ & $36,8 \%$ & $36,3 \%$ \\
\hline & Poco de acuerdo & $8.6 \%$ & $5.9 \%$ & $13,2 \%$ & $9,4 \%$ \\
\hline & Nada de acuerdo & $32,8 \%$ & $16,8 \%$ & $18,4 \%$ & $21,3 \%$ \\
\hline & $\mathrm{Ns} / \mathrm{Ne}$ & $3,4 \%$ & & & $.7 \%$ \\
\hline Total & & $100,0 \%$ & $100,0 \%$ & $100,0 \%$ & $100,0 \%$ \\
\hline
\end{tabular}

JÓVENES Y POLÍTICA: UNA MIRADA DESDE LA COMUNICACIÓN 


\begin{tabular}{|c|c|c|c|c|c|}
\hline \multicolumn{6}{|c|}{$\begin{array}{l}\text { La propuesta del voto a los } 16 \text { años es una maniobra electoral y llevaria la } \\
\text { militancia política a contextos educativos * Nivel socio-económico }\end{array}$} \\
\hline & & \multicolumn{3}{|c|}{ Nivel socio-económico } & \multirow[b]{2}{*}{ Total } \\
\hline & & Bajo & Medio & Alto & \\
\hline \multirow{5}{*}{$\begin{array}{l}\text { La propuesta del } \\
\text { voto a los } 16 \text { años } \\
\text { es una maniobra } \\
\text { electoral y llevaría } \\
\text { la militancia } \\
\text { política a } \\
\text { contextos } \\
\text { educativos }\end{array}$} & Muy de acuerdo & $12,1 \%$ & $28,0 \%$ & (36,8\% & $24,6 \%$ \\
\hline & De acuerdo & $34,5 \%$ & $36.0 \%$ & $36,8 \%$ & $37.1 \%$ \\
\hline & Poco de acuerdo & $19.0 \%$ & $17.0 \%$ & $13.2 \%$ & $17.4 \%$ \\
\hline & Nada de acuerdo & 24,19 & 17,096 & $13,2 \%$ & 17,096 \\
\hline & $\mathrm{Ns} / \mathrm{Ne}$ & $10,3 \%$ & $2.0 \%$ & & $3.8 \%$ \\
\hline Total & & $100,0 \%$ & $100,0 \%$ & $100,0 \%$ & $100,0 \%$ \\
\hline
\end{tabular}

La propuesta de habilitar optativamente el voto a partir de los 16 años implica la ampliación de derechos de los más jóvenes y promueve la participación ciudadana * Nivel socio-económico

\begin{tabular}{|c|c|c|c|c|c|}
\hline & & \multicolumn{3}{|c|}{ Nivel socio-económico } & \multirow[b]{2}{*}{ Total } \\
\hline & & Bajo & Medio & Alto & \\
\hline $\begin{array}{l}\text { La propuesta de } \\
\text { habilitar }\end{array}$ & Muy de acuerdo & $10,3 \%$ & $17,8 \%$ & $18,4 \%$ & $14,6 \%$ \\
\hline $\begin{array}{l}\text { optativamente el } \\
\text { voto a partir de los }\end{array}$ & De acuerdo & $39,7 \%$ & $36,6 \%$ & $31,6 \%$ & $35,8 \%$ \\
\hline $\begin{array}{l}16 \text { años implica la } \\
\text { ampliación de }\end{array}$ & Poco de acuerdo & $19,0 \%$ & $18,8 \%$ & $23,7 \%$ & $20,5 \%$ \\
\hline $\begin{array}{l}\text { derechos de los } \\
\text { más jóvenes y }\end{array}$ & Nada de acuerdo & $24,1 \%$ & $24,8 \%$ & $26,3 \%$ & $24,6 \%$ \\
\hline $\begin{array}{l}\text { promueve la } \\
\text { participación } \\
\text { cludadana }\end{array}$ & $\mathrm{Ns} / \mathrm{Nc}$ & $6,9 \%$ & $2,0 \%$ & & $4,5 \%$ \\
\hline Total & & $100,0 \%$ & $100,0 \%$ & $100,0 \%$ & $100,0 \%$ \\
\hline
\end{tabular}


Si un joven de 16 años es penalmente responsable, no se le debería negar el derecho al voto ${ }^{*}$ Nivel socio-económico

\begin{tabular}{|c|c|c|c|c|c|}
\hline & & \multicolumn{3}{|c|}{ Nivel socio-económico } & \multirow[b]{2}{*}{ Total } \\
\hline & & Bajo & Medio & Alto & \\
\hline \multirow{5}{*}{$\begin{array}{l}\text { SI un joven de } 16 \\
\text { años es } \\
\text { penalmente } \\
\text { responsable, no se } \\
\text { le deberia negar el } \\
\text { derecho al voto }\end{array}$} & Muy de acuerdo & $22,4 \%$ & $20,8 \%$ & $10,5 \%$ & $16,8 \%$ \\
\hline & De acuerdo & $39,7 \%$ & $32,7 \%$ & $28,9 \%$ & $37,7 \%$ \\
\hline & Poco de acuerdo & $12,1 \%$ & $12,9 \%$ & $21,1 \%$ & $13,1 \%$ \\
\hline & Nada de acuerdo & $17,2 \%$ & $32,7 \%$ & $36,8 \%$ & $29,1 \%$ \\
\hline & $\mathrm{Ns} / \mathrm{Ne}$ & $8,6 \%$ & $1,0 \%$ & $2,6 \%$ & $3,4 \%$ \\
\hline Total & & $100,0 \%$ & $100,0 \%$ & $100,0 \%$ & $100,0 \%$ \\
\hline
\end{tabular}

JÓVENES Y POLÍTICA: UNA MIRADA DESDE LA COMUNICACIÓN 